ASDRUBAL DO NASCIMENTO QUEIROZ FILHO

ESTUDO DA INFLUÊNCIA DOS EFEITOS DE INTERAÇÃO HIDRODINÂMICOS EM OPERAÇÕES DE ALÍVIO AUXILIADAS POR SISTEMAS DP 
ASDRUBAL DO NASCIMENTO QUEIROZ FILHO

\section{ESTUDO DA INFLUÊNCIA DOS EFEITOS DE INTERAÇÃO HIDRODINÂMICOS EM OPERAÇÕES DE ALÍVIO AUXILIADAS POR SISTEMAS DP}

Dissertação apresentada à Escola

Politécnica da Universidade de São

Paulo para obtenção do título de

Mestre em Engenharia Elétrica

Área de Concentração:

Engenharia de Sistemas

Orientador:

Prof. Dr. Eduardo Aoun Tannuri 
Este exemplar foi revisado e alterado em relação à versão original, sob responsabilidade única do autor e com a anuência de seu orientador.

São Paulo, de janeiro de 2010.

Assinatura do autor

Assinatura do orientador

\section{FICHA CATALOGRÁFICA}

Queiroz Filho, Asdrúbal do Nascimento

Estudo da influência dos efeitos de interação hidrodinâmicos

em operações de alívio auxiliadas por sistemas DP I A.N.

Queiroz Filho. -- São Paulo, 2010.

$100 \mathrm{p}$.

Dissertação (Mestrado) - Escola Politécnica da Universidade de São Paulo. Departamento de Engenharia de Telecomunicações e Controle.

1. Sistemas de controle (Embarcações) 2. Desenvolvimento de tecnologia I. Universidade de São Paulo. Escola Politécnica. Departamento de Engenharia de Telecomunicações e Controle II. t. 
Dedico este trabalho a Deus em primeiro lugar, ao meu pai (em memória), à minha mãe e à minha noiva. 


\section{AGRADECIMENTOS}

Agradeço a Deus por ter me iluminado, dado forças e saúde para concluir este trabalho.

Ao meu pai pelos ensinamentos e por ter me incentivado a nunca parar de estudar, à minha mãe pelo apoio e compreensão.

À minha namorada pela compreensão, apoio nas horas mais difíceis e por sempre estar ao meu lado.

Á minha e irmã e meu cunhado pela constante ajuda, incentivo e apoio.

Ao meu orientador Eduardo, que muito me incentivou e principalmente muito me ajudou na execução deste trabalho, sem o qual este não seria possível de ser realizado.

Ao professor Jaime por ter me orientado em muitos aspectos na primeira fase do programa de mestrado.

A todos os meus amigos que direta e indiretamente me ajudaram durante a execução deste trabalho.

Ao TPN (Tanque de Provas Numérico) e toda a sua equipe pela compreensão e por ter me proporcionado os meios para realizar os experimentos em suas instalações e utilizar seus recursos.

Á Petrobras pela motivação do trabalho e fornecimento de dados relevantes para as simulações.

Ao CNPq pela bolsa de estudos concedida. 


\section{RESUMO}

Hoje em dia, a maioria das operações de alívio é feita utilizando um sistema de posicionamento dinâmico (DP). O sistema DP permite controlar a posição relativa entre o navio aliviador e o FPSO (Floating Production Storage and Offloading), trazendo desta forma muitas vantagens à operação. Neste tipo de operação os dois corpos flutuantes precisam ficar muito próximos um do outro em alto-mar, aumentando de forma significativa a interação hidrodinâmica entre eles.

Quando um corpo está no mar ele se torna uma barreira à propagação das ondas, distorcendo o campo de ondas ao redor. Este efeito é chamado de efeito de sombra de onda ou simplesmente efeito de sombra. $O$ efeito de sombra depende do comprimento de onda, do tamanho do corpo que o está criando e da direção de propagação da onda.

O efeito de sombra altera de forma significativa a distribuição de energia das ondas do mar na região do fenômeno, alterando desta forma, o comportamento do corpo que está sob a influência do mesmo. Com o comportamento do corpo alterado é esperado que o sistema DP se comporte de forma diferente quando sob influência do efeito de sombra. Este trabalho se propõe a estudar a influência que o efeito de sombra causa no sistema DP, visando obter dados para melhorar os projetos de sistema DP.

Palavras chave: Sistema de Posicionamento Dinâmico, FPSO, Navio Aliviador, Efeito de sombra. 


\begin{abstract}
Nowadays, a great number of offloading operations is carried out using a dynamic positioning (DP) system. The DP system allows the position between the shuttle tanker (ST) and the FPSO platform (Floating Production Storage and Offloading) to be controlled, bringing several advantages to the operation. In this kind of operation the two vessels must be kept very close in the sea, increasing significantly the hydrodynamic interaction effects between them.

When a body is floating at the sea, it turns into a barrier to the wave propagation, disturbing the wave field around it. This effect is called shielding effect or shielding area. The shielding area depends on the wave length, the size of the body and the wave direction.

The shielding area significantly disturbs the energy of the wave field nearby the FPSO. Because of that, it is expected that the shuttle tanker presents a different hydrodynamic behavior. The purpose of this work is to study the influence of the shielding area on the DP system, trying to obtain data to improve DP systems' design.
\end{abstract}

Keywords: Dynamic Position system, FPSO, Shuttle Tanker, shielding effect. 
LISTA DE TABELAS

Tabela 1 - Características do navio aliviador e do FPSO 44

Tabela 2 - Alturas significativas mais prováveis (PETROBRAS, 2005)

Tabela 3 - Força média e desvio padrão em cada propulsor.................................................50

Tabela 4 - Porcentagem relativa à potencia instalada. ........................................................... 70 


\section{LISTA DE ILUSTRAÇÕES}

Figura 1 - Aliviador Stavanger durante operação de alívio na plataforma (a) vista da ponte de

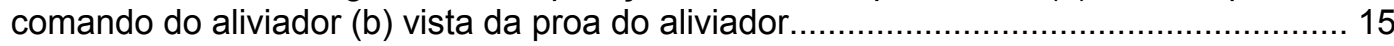

Figura 2 - Vista aérea de uma operação de alívio ................................................................... 15

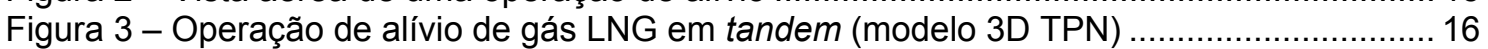

Figura 4 - Operação de alívio de gás LNG side-by-side ..................................................... 16

Figura 5 - Barcaça BGL1 em operação de içamento em plataforma tipo jaqueta (modelo 3D

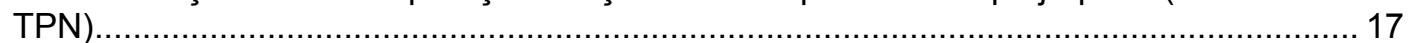

Figura 6 - Navio de suporte ao lado de uma barcaça ................................................................ 18

Figura 7 - Coeficiente de deriva lateral no aliviador calculados sem considerar efeito de interação ("unshielded"), com o método exato ("Exac") e com o método do campo de ondas perturbado ("appro") (adaptado de Orozco e Chen 2003) .................................... 23

Figura 8 - Campo de ondas na presença do FPSO ( $\mathrm{H}=1 \mathrm{~m} ; \mathrm{T}=8 \mathrm{~s}$, incidência de través) extraída de Tannuri et. al. 2004.

Figura 9 - (a) simulação considerando o efeito de interação de ondas; (b) simulação não considerando tal efeito (extraída de Tannuri et. al. 2004) ............................................ 24

Figura 10 - Espectro de Mar do tipo JONSWAP com Hs=9,5m, freqüência de pico de 0,55 e $a_{0}=0,01234$.

Figura 11 - (a) Definição dos movimentos; (b) Sistema DP; (c) Console de comando (adaptado

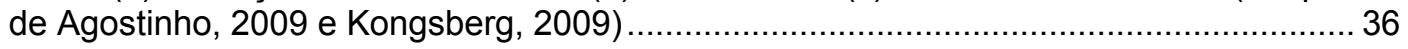

Figura 12 - Diagrama de Blocos de um Sistema de Posicionamento Dinâmico........................... 37

Figura 13 - Diagrama Elementos de um Sistema DP (extraído de Tannuri, 2002) ................... 39

Figura 14 - (a) Propulsor azimutal (b) Propulsor em túnel (c) propulsor principal e leme

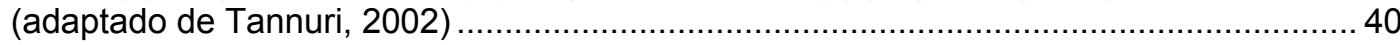

Figura 15 - Setores operacionais de operações de alívio tipo tandem para FPSO em com sistema de amarração espalhado. (Tannuri ET. al. 2009) ……….................................. 45

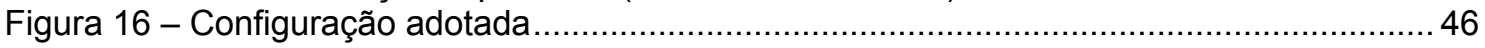

Figura 17 - Posição dos propulsores em metros (com relação ao CG do navio), potência em cada propulsor $(\mathrm{P})$ e máximo e mínimo empuxo estimado(T). ...................................... 47

Figura 18 - Movimentação do sistema (a); utilização média dos propulsores (b); distância relativa entre o navio aliviador e o FPSO (c) ............................................................... 49

Figura 19 - Séries temporais da posição do navio aliviador ..................................................... 49

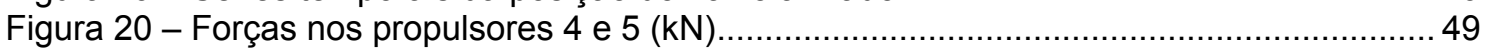

Figura 21 - Força resultante do sistema DP............................................................... 50

Figura 22 - Potência total do sistema DP para Hs=3.0m e incidência de $270^{\circ}$......................... 51

Figura 23 - Mapa de elevação de onda não considerando a influência do navio aliviador para incidência de $270^{\circ}$ e 5 s de período (regular).................................................................. 52

Figura 24 - Mapa de elevação de onda considerando a influência do navio aliviador para incidência de $270^{\circ}$, 5 s de período (regular) e d=160m. .................................................. 52

Figura 25 - Mapa de elevação de onda não considerando a influência do navio aliviador para

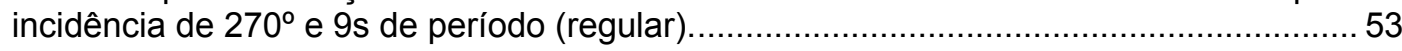

Figura 26 - Potência total do sistema DP para Hs=3,0m e incidência de $240^{\circ} \ldots \ldots \ldots \ldots \ldots \ldots \ldots \ldots . . . . . . . . . .54$

Figura 27 - Coeficientes de deriva de surge do navio aliviador para incidencia de $180^{\circ}$.......... 55

Figura 28 - Mapa de elevação de onda não considerando a influência do navio aliviador para incidência de $240^{\circ}$ e 9 s de período (regular).................................................................5 56

Figura 29 - Mapa de elevação de onda considerando a influência do navio aliviador para incidência de $240^{\circ}$, 9s de período (regular) e d=160m. .................................................5 56

Figura 30 - Potência total do sistema DP para Hs=3.0m e incidência de $210^{\circ}$. ........................ 58

Figura 31 - Mapa de elevação de onda não considerando a influência do navio aliviador para incidência de $210^{\circ}$ e 9 s de período (regular)

Figura 32 - Mapa de elevação de onda considerando a influência do navio aliviador para incidência de $210^{\circ}, 9$ s de período (regular) e d=160m..................................................5 59

Figura 33 - Potência total do sistema DP para Hs variável e incidência de $270^{\circ}$...........................60

Figura 34 - Potência total do sistema DP para Hs variável e incidência de $240^{\circ}$.......................61 61

Figura 35 - Potência total do sistema DP para Hs variável e incidência de $210^{\circ}$.........................62 62

Figura 36 - Potência total do sistema DP para Hs variável e incidência de $210^{\circ}$........................ 63 
Figura 37 - Mapa de elevação de onda considerando a influência do navio aliviador para incidência de $270^{\circ}, 7 \mathrm{~s}$ de período (regular) e $\mathrm{d}=160 \mathrm{~m}$.

Figura 38 - Mapa de elevação de onda considerando a influência do navio aliviador para incidência de $270^{\circ}, 13 \mathrm{~s}$ de período (regular) e $d=160 \mathrm{~m}$.

Figura 39 - Potência total do sistema DP para Hs variável e incidência de $240^{\circ}$.......................6 65

Figura 40 - Mapa de elevação de onda não considerando a influência do navio aliviador para incidência de $240^{\circ}$, 9s de período (regular) e $d=160 \mathrm{~m}$.

Figura 41 - Mapa de elevação de onda considerando a influência do navio aliviador para incidência de $240^{\circ}, 13 \mathrm{~s}$ de período (regular) e $\mathrm{d}=160 \mathrm{~m}$. .................................................6 67

Figura 42 - Potência total do sistema DP para Hs variável e incidência de $240^{\circ}$......................67 67

Figura 43 - Mapa de elevação de onda não considerando a influência do navio aliviador para incidência de $210^{\circ}$, 9s de período (regular) e $d=160 \mathrm{~m}$.

Figura 44 - Mapa de elevação de onda considerando a influência do navio aliviador para incidência de $210^{\circ}$, 9s de período (regular) e $d=160 \mathrm{~m}$.

Figura 45 - Mapa de elevação de onda não considerando o navio aliviador para incidência de $270^{\circ}$ e 5 s de período.

Figura 46 - Mapa de elevação de onda não considerando o navio aliviador para incidência de $270^{\circ}$ e 7 s de período.

Figura 47 - Mapa de elevação de onda não considerando o navio aliviador para incidência de $270^{\circ}$ e 9 s de período.

Figura 48 - Mapa de elevação de onda não considerando o navio aliviador para incidência de

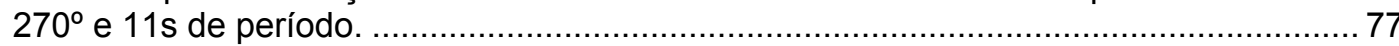

Figura 49 - Mapa de elevação de onda não considerando o navio aliviador para incidência de

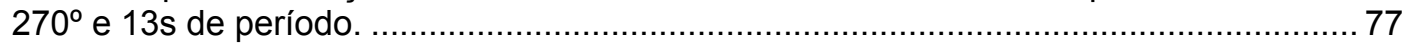

Figura 50 - Mapa de elevação de onda não considerando o navio aliviador para incidência de

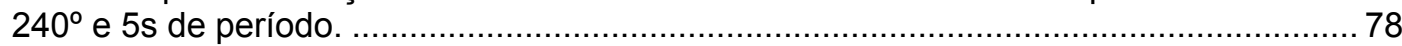

Figura 51 - Mapa de elevação de onda não considerando o navio aliviador para incidência de $240^{\circ}$ e $7 \mathrm{~s}$ de período.

Figura 52 - Mapa de elevação de onda não considerando o navio aliviador para incidência de

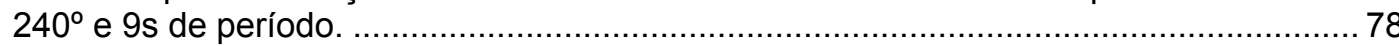

Figura 53 - Mapa de elevação de onda não considerando o navio aliviador para incidência de

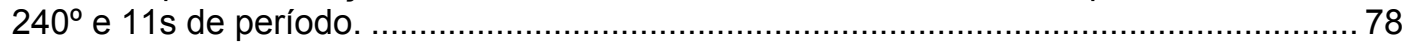

Figura 54 - Mapa de elevação de onda não considerando o navio aliviador para incidência de

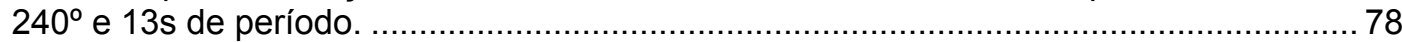

Figura 55 - Mapa de elevação de onda não considerando o navio aliviador para incidência de $210^{\circ}$ e 5 s de período.

Figura 56 - Mapa de elevação de onda não considerando o navio aliviador para incidência de

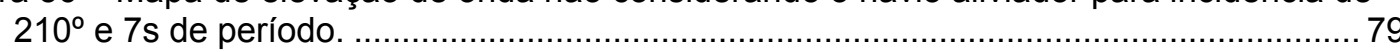

Figura 57 - Mapa de elevação de onda não considerando o navio aliviador para incidência de $210^{\circ}$ e 9 s de período.

Figura 58 - Mapa de elevação de onda não considerando o navio aliviador para incidência de

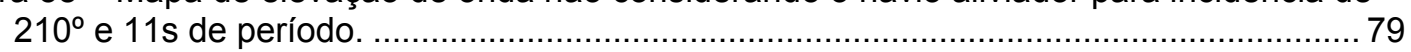

Figura 59 - Mapa de elevação de onda não considerando o navio aliviador para incidência de $210^{\circ}$ e 13 s de período. ........................................................................................ 79

Figura 60 - Mapa de elevação de onda considerando o navio aliviador para incidência de $270^{\circ}$,

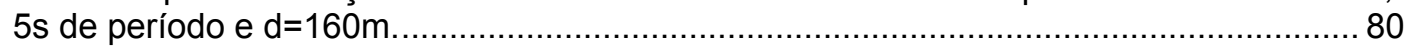

Figura 61 - Mapa de elevação de onda considerando o navio aliviador para incidência de $270^{\circ}$,

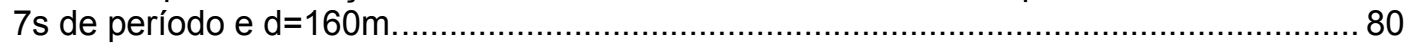

Figura 62 - Mapa de elevação de onda considerando o navio aliviador para incidência de $270^{\circ}$,

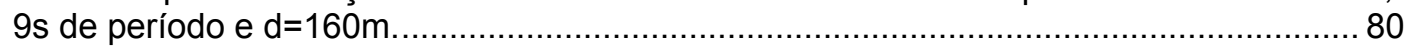

Figura 63 - Mapa de elevação de onda considerando o navio aliviador para incidência de $270^{\circ}$,

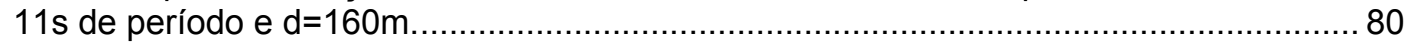

Figura 64 - Mapa de elevação de onda considerando o navio aliviador para incidência de $270^{\circ}$,

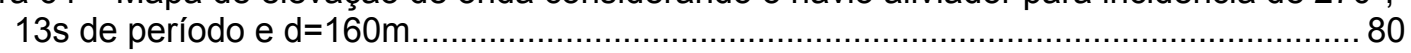

Figura 65 - Mapa de elevação de onda considerando o navio aliviador para incidência de $240^{\circ}$,

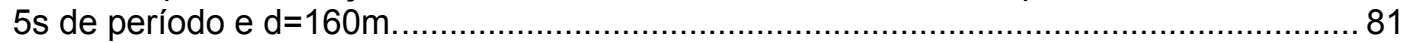

Figura 66 - Mapa de elevação de onda considerando o navio aliviador para incidência de $240^{\circ}$,

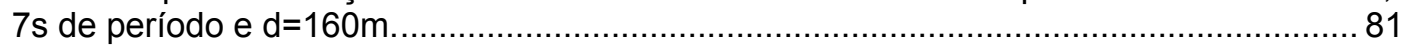

Figura 67 - Mapa de elevação de onda considerando o navio aliviador para incidência de $240^{\circ}$,

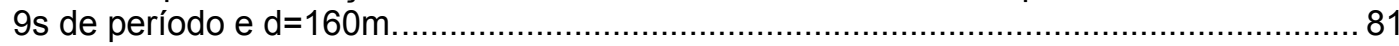


Figura 68 - Mapa de elevação de onda considerando o navio aliviador para incidência de $240^{\circ}$,

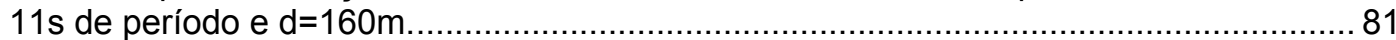

Figura 69 - Mapa de elevação de onda considerando o navio aliviador para incidência de $240^{\circ}$,

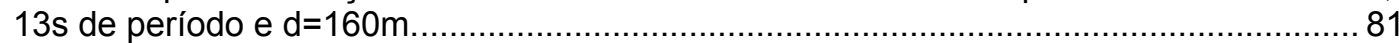

Figura 70 - Mapa de elevação de onda considerando o navio aliviador para incidência de $210^{\circ}$,

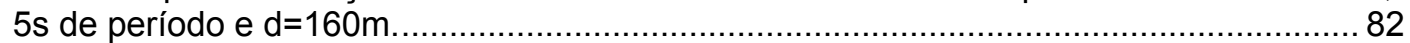

Figura 71 - Mapa de elevação de onda considerando o navio aliviador para incidência de $210^{\circ}$,

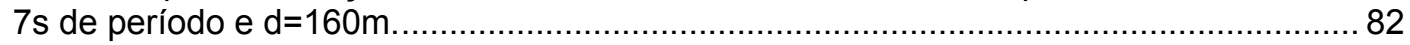

Figura 72 - Mapa de elevação de onda considerando o navio aliviador para incidência de $210^{\circ}$,

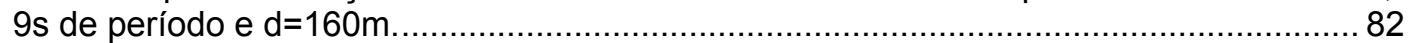

Figura 73 - Mapa de elevação de onda considerando o navio aliviador para incidência de $210^{\circ}$,

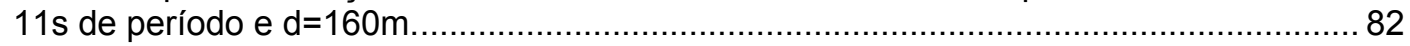

Figura 74 - Mapa de elevação de onda considerando o navio aliviador para incidência de $210^{\circ}$,

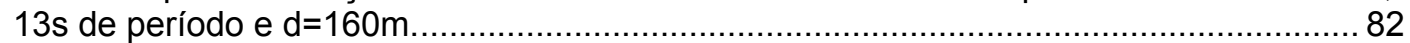

Figura 75 - Mapa de elevação de onda considerando o navio aliviador para incidência de $270^{\circ}$,

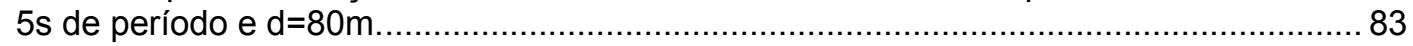

Figura 76 - Mapa de elevação de onda considerando o navio aliviador para incidência de $270^{\circ}$,

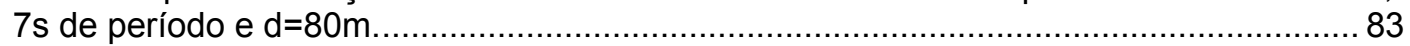

Figura 77 - Mapa de elevação de onda considerando o navio aliviador para incidência de $270^{\circ}$,

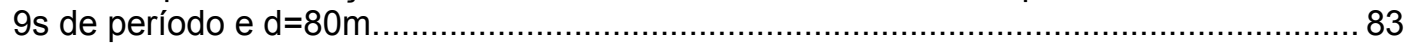

Figura 78 - Mapa de elevação de onda considerando o navio aliviador para incidência de $270^{\circ}$,

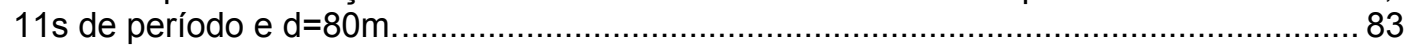

Figura 79 - Mapa de elevação de onda considerando o navio aliviador para incidência de $270^{\circ}$,

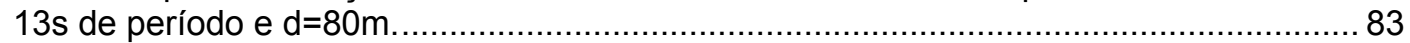

Figura 80 - Mapa de elevação de onda considerando o navio aliviador para incidência de $240^{\circ}$,

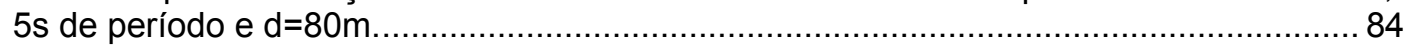

Figura 81 - Mapa de elevação de onda considerando o navio aliviador para incidência de $240^{\circ}$,

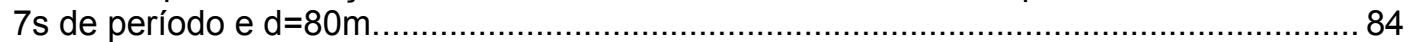

Figura 82 - Mapa de elevação de onda considerando o navio aliviador para incidência de $240^{\circ}$,

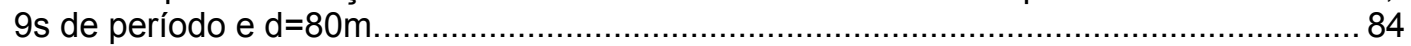

Figura 83 - Mapa de elevação de onda considerando o navio aliviador para incidência de $240^{\circ}$,

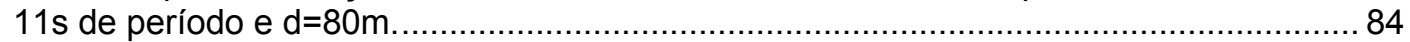

Figura 84 - Mapa de elevação de onda considerando o navio aliviador para incidência de $240^{\circ}$,

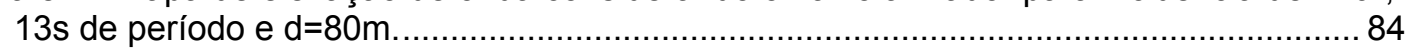

Figura 85 - Mapa de elevação de onda considerando o navio aliviador para incidência de $210^{\circ}$,

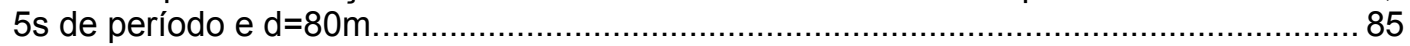

Figura 86 - Mapa de elevação de onda considerando o navio aliviador para incidência de $210^{\circ}$,

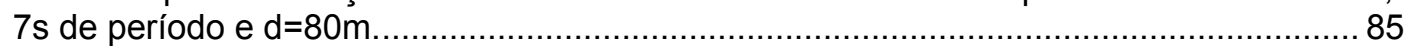

Figura 87 - Mapa de elevação de onda considerando o navio aliviador para incidência de $210^{\circ}$,

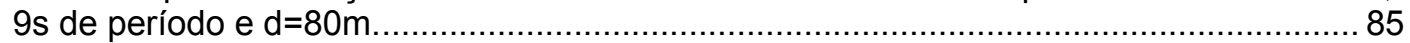

Figura 88 - Mapa de elevação de onda considerando o navio aliviador para incidência de $210^{\circ}$,

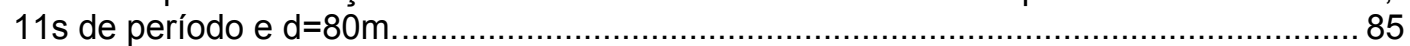

Figura 89 - Mapa de elevação de onda considerando o navio aliviador para incidência de $210^{\circ}$,

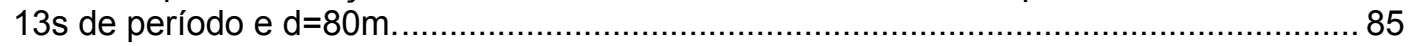

Figura 90 - Mapa de elevação de onda não considerando o navio aliviador para incidência de

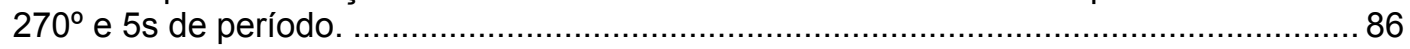

Figura 91 - Mapa de elevação de onda não considerando o navio aliviador para incidência de

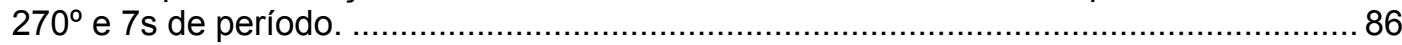

Figura 92 - Mapa de elevação de onda não considerando o navio aliviador para incidência de

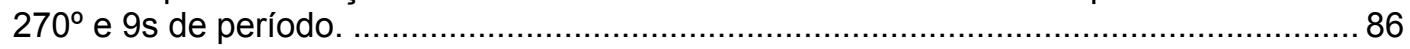

Figura 93 - Mapa de elevação de onda não considerando o navio aliviador para incidência de

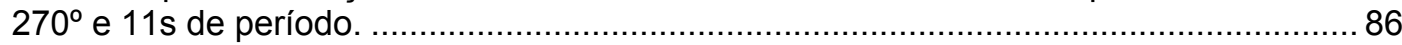

Figura 94 - Mapa de elevação de onda não considerando o navio aliviador para incidência de

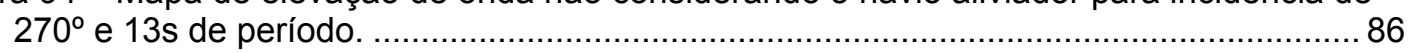

Figura 95 - Mapa de elevação de onda não considerando o navio aliviador para incidência de

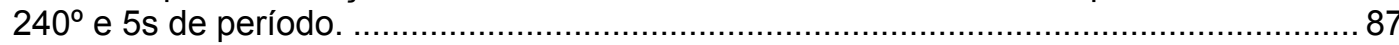

Figura 96 - Mapa de elevação de onda não considerando o navio aliviador para incidência de

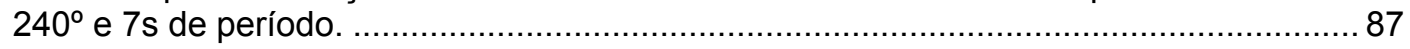

Figura 97 - Mapa de elevação de onda não considerando o navio aliviador para incidência de $240^{\circ}$ e 9 s de período. 
Figura 98 - Mapa de elevação de onda não considerando o navio aliviador para incidência de $240^{\circ}$ e 11 s de período.

Figura 99 - Mapa de elevação de onda não considerando o navio aliviador para incidência de $240^{\circ}$ e 13 s de período.

Figura 100 - Mapa de elevação de onda não considerando o navio aliviador para incidência de

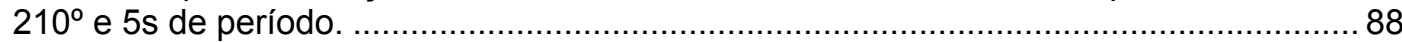

Figura 101 - Mapa de elevação de onda não considerando o navio aliviador para incidência de $210^{\circ}$ e $7 \mathrm{~s}$ de período.

Figura 102 - Mapa de elevação de onda não considerando o navio aliviador para incidência de

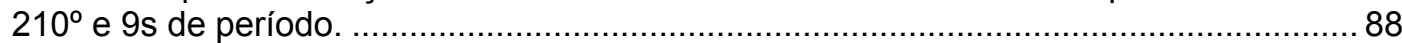

Figura 103 - Mapa de elevação de onda não considerando o navio aliviador para incidência de $210^{\circ}$ e $11 \mathrm{~s}$ de período.

Figura 104 - Mapa de elevação de onda não considerando o navio aliviador para incidência de

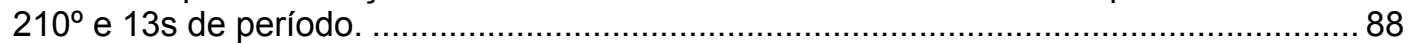

Figura 105 - Mapa de elevação de onda considerando o navio aliviador para incidência de $270^{\circ}$ e 5 s de período

Figura 106 - Mapa de elevação de onda considerando o navio aliviador para incidência de $270^{\circ}$

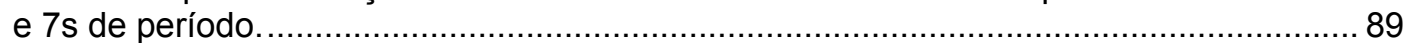

Figura 107 - Mapa de elevação de onda considerando o navio aliviador para incidência de $270^{\circ}$ e 9 s de período.

Figura 108 - Mapa de elevação de onda considerando o navio aliviador para incidência de $270^{\circ}$

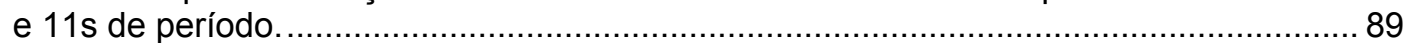

Figura 109 - Mapa de elevação de onda considerando o navio aliviador para incidência de $270^{\circ}$ e 13 s de período.

Figura 110 - Mapa de elevação de onda considerando o navio aliviador para incidência de $240^{\circ}$

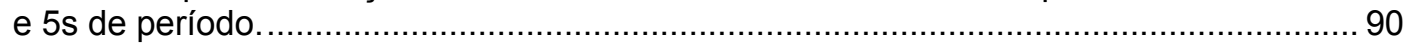

Figura 111 - Mapa de elevação de onda considerando o navio aliviador para incidência de $240^{\circ}$ e $7 \mathrm{~s}$ de período.

Figura 112 - Mapa de elevação de onda considerando o navio aliviador para incidência de $240^{\circ}$

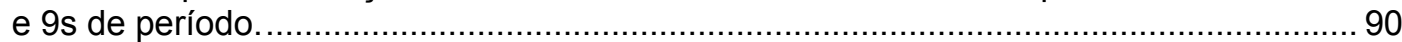

Figura 113 - Mapa de elevação de onda considerando o navio aliviador para incidência de $240^{\circ}$ e 11 s de período...

Figura 114 - Mapa de elevação de onda considerando o navio aliviador para incidência de $240^{\circ}$

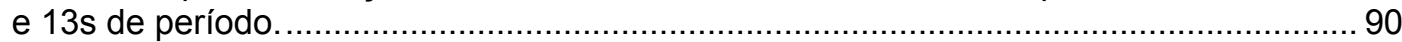

Figura 115 - Mapa de elevação de onda considerando o navio aliviador para incidência de $210^{\circ}$ e 5 s de período.

Figura 116 - Mapa de elevação de onda considerando o navio aliviador para incidência de $210^{\circ}$

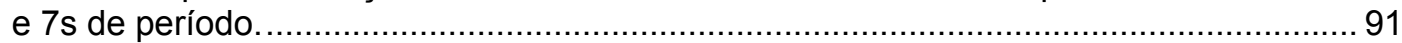

Figura 117 - Mapa de elevação de onda considerando o navio aliviador para incidência de $210^{\circ}$ e 9s de período.

Figura 118 - Mapa de elevação de onda considerando o navio aliviador para incidência de $210^{\circ}$

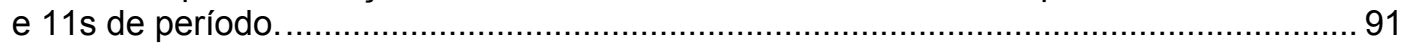

Figura 119 - Mapa de elevação de onda considerando o navio aliviador para incidência de $210^{\circ}$

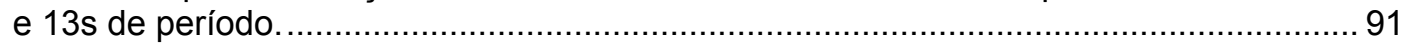

Figura 120 - Direção de propagação de onda em ralação ao FPSO e ao Navio Aliviador........ 92 Figura 121 - Coeficientes de deriva de surge do navio aliviador para incidências de $150^{\circ}, 180^{\circ}$

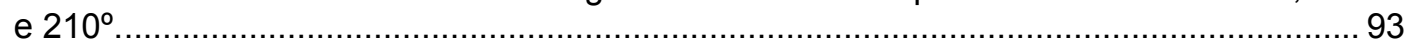

Figura 122 - Coeficientes de deriva de sway do navio aliviador para incidências de $150^{\circ}, 180^{\circ} \mathrm{e}$

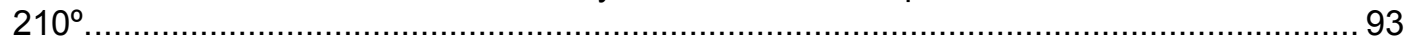

Figura 123 - Coeficientes de deriva de yaw do navio aliviador para incidências de $150^{\circ}, 180^{\circ} \mathrm{e}$

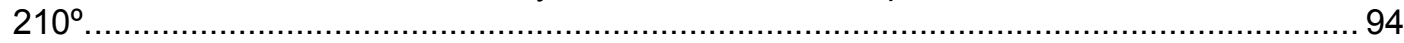

Figura 124 - Coeficientes de deriva de surge do navio aliviador para incidências de $150^{\circ}, 180^{\circ}$ e $210^{\circ}$, considerando a influência do FPSO para $\mathrm{d}=160 \mathrm{~m}$. ........................................... 94

Figura 125 - Coeficientes de deriva de sway do navio aliviador para incidências de $150^{\circ}, 180^{\circ} \mathrm{e}$ $210^{\circ}$, considerando a influência do FPSO para $d=160 \mathrm{~m}$. ............................................ 95

Figura 126 - Coeficientes de deriva de yaw do navio aliviador para incidências de $150^{\circ}, 180^{\circ} \mathrm{e}$

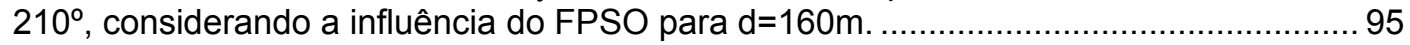

Figura 127 - Coeficientes de deriva de surge do navio aliviador para incidências de $150^{\circ}, 180^{\circ}$ e $210^{\circ}$, considerando a influência do FPSO para d=80m. ............................................ 96 
Figura 128 - Coeficientes de deriva de sway do navio aliviador para incidências de $150^{\circ}, 180^{\circ} \mathrm{e}$

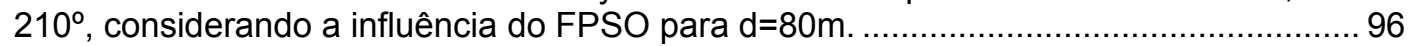

Figura 129 - Coeficientes de deriva de yaw do navio aliviador para incidências de $150^{\circ}, 180^{\circ} \mathrm{e}$ $210^{\circ}$, considerando a influência do FPSO para $\mathrm{d}=80 \mathrm{~m}$. .97

Figura 130 - Coeficientes de deriva de surge do navio aliviador para incidências de $150^{\circ}, 180^{\circ}$ e $210^{\circ}$, considerando a influência do FPSO para $\mathrm{d}=80 \mathrm{~m}$. ................................... 97

Figura 131 - Coeficientes de deriva de sway do navio aliviador para incidências de $150^{\circ}, 180^{\circ} \mathrm{e}$

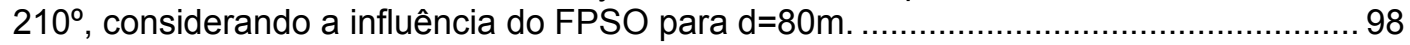

Figura 132 - Coeficientes de deriva de yaw do navio aliviador para incidências de $150^{\circ}, 180^{\circ} \mathrm{e}$ $210^{\circ}$, considerando a influência do FPSO para $d=80 \mathrm{~m}$. 98

Figura 133 - Coeficientes de deriva de surge do navio aliviador para incidências de $150^{\circ}, 180^{\circ}$ e $210^{\circ}$, considerando a influência do FPSO para $d=80 \mathrm{~m}$. 99

Figura 134 - Coeficientes de deriva de sway do navio aliviador para incidências de $150^{\circ}, 180^{\circ} \mathrm{e}$

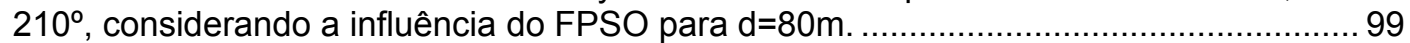

Figura 135 - Coeficientes de deriva de yaw do navio aliviador para incidências de $150^{\circ}, 180^{\circ} \mathrm{e}$ $210^{\circ}$, considerando a influência do FPSO para $d=80 \mathrm{~m}$. 


\section{SUMÁRIO}

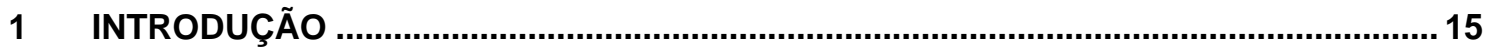

1.1 MOTIVAÇÃO

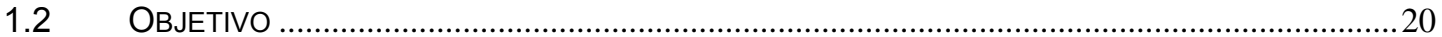

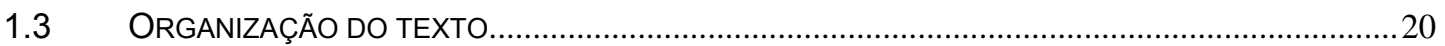

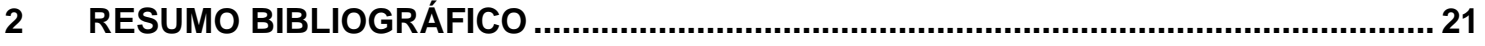

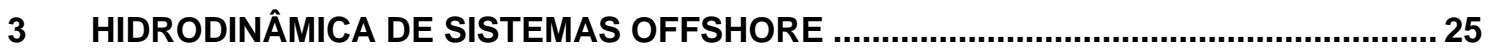

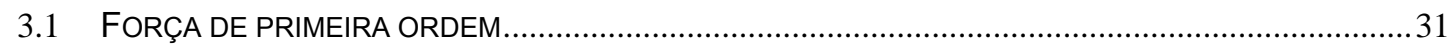

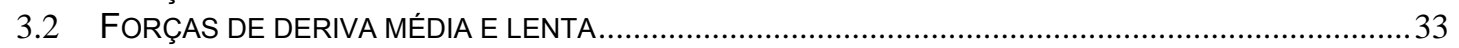

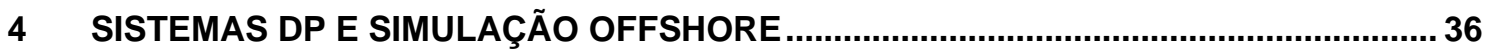

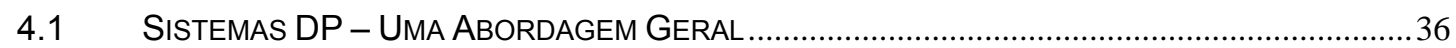

4.2 SISTEMAS DP E EFEITO DE SOMBRA DE ONDA EM SIMULADORES COMERCIAIS ......................40

4.3 O SIMULADOR TPN...................................................................................................42

5 ESTUDO DE CASO - OPERAÇÃO DE ALÍVIO …....................................................... 44

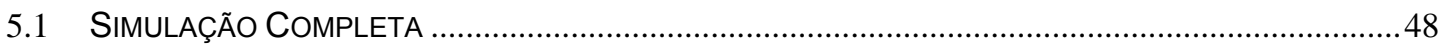

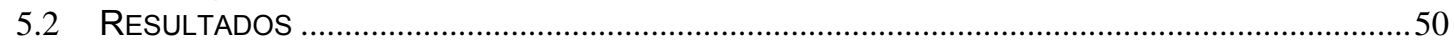

5.2.1 FPSO carregado e navio aliviador em condição de lastro com altura significativa

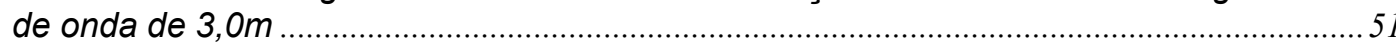
5.2.2 FPSO carregado e navio aliviador em condição de lastro com altura significativa

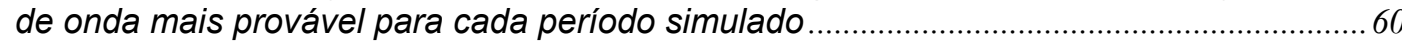
5.2.3 FPSO em condição de lastro e navio aliviador carregado com altura significativa

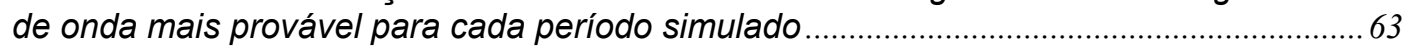

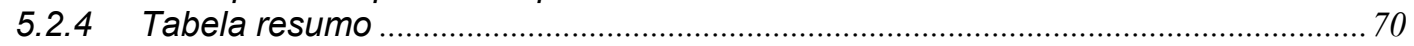

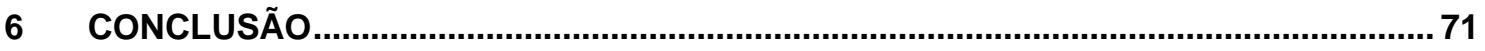

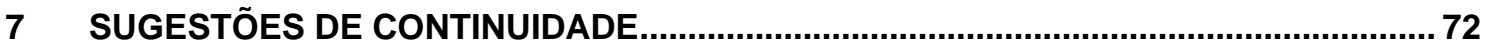

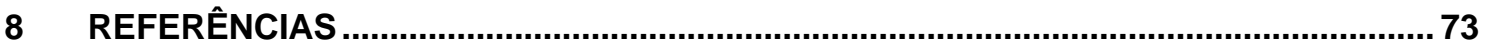

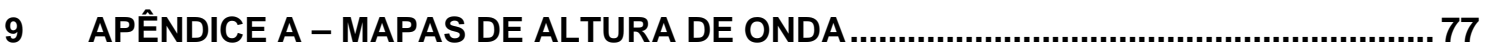

9.1 FPSO CARREGADO E NAVIO ALIVIADOR EM CONDIÇÃO DE LASTRO ………………......................77

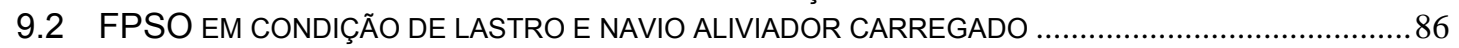

10 APÊNDICE B - COEFICIENTES DE DERIVA DO NAVIO ALIVIADOR ..........................92

10.1 FPSO CARREGADO E NAVIO ALIVIADOR EM CONDIÇÃO DE LASTRO NÃO CONSIDERANDO A

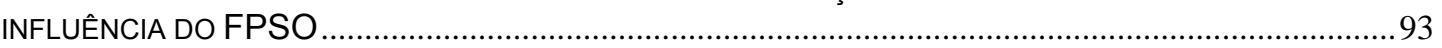
10.2 FPSO CARREGADO E NAVIO ALIVIADOR EM CONDIÇÃO DE LASTRO CONSIDERANDO A

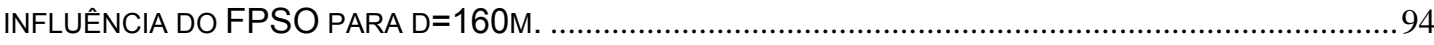
10.3 FPSO CARREGADO E NAVIO ALIVIADOR EM CONDIÇÃO DE LASTRO CONSIDERANDO A

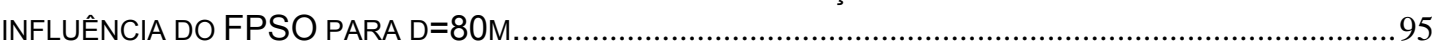
10.4 FPSO EM CONDIÇÃO DE LASTRO E NAVIO ALIVIADOR CHEIO NÃO CONSIDERANDO A

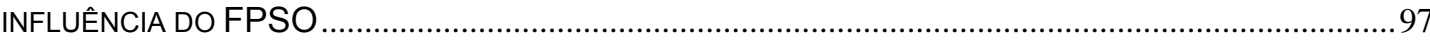
10.5 FPSO EM CONDIÇÃO DE LASTRO E NAVIO ALIVIADOR CHEIO CONSIDERANDO A INFLUÊNCIA DO FPSO 


\section{INTRODUÇÃO}

Operações offshore envolvendo múltiplos corpos flutuantes são freqüentes, seja para o escoamento de petróleo ou de gás produzido em altomar, ou para a realização de instalações ou reparos em plataformas ou instalações de estruturas submersas (sub-sea). Um exemplo bastante importante de operações envolvendo múltiplos corpos flutuantes é o alívio (offloading) de petróleo. Estas são realizadas com o navio aliviador (shuttle) conectado em tandem com o FPSO/cisterna, a uma distância não maior que 160m (exemplos na Figura 1 e Figura 2).

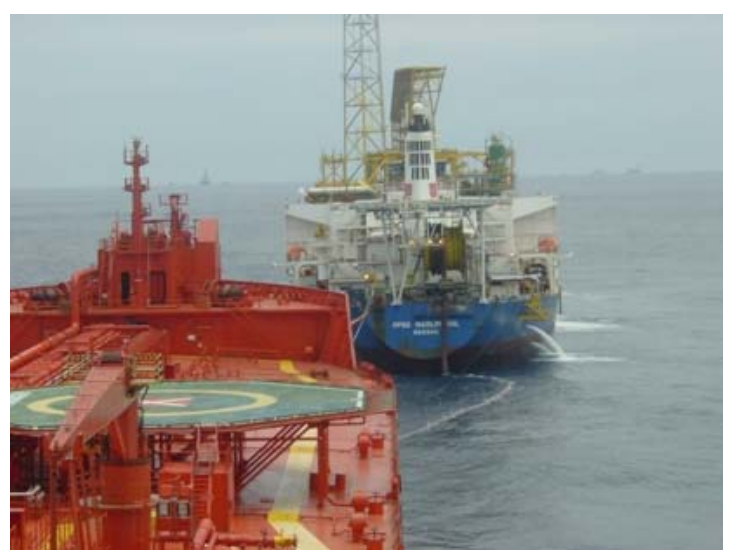

(a)

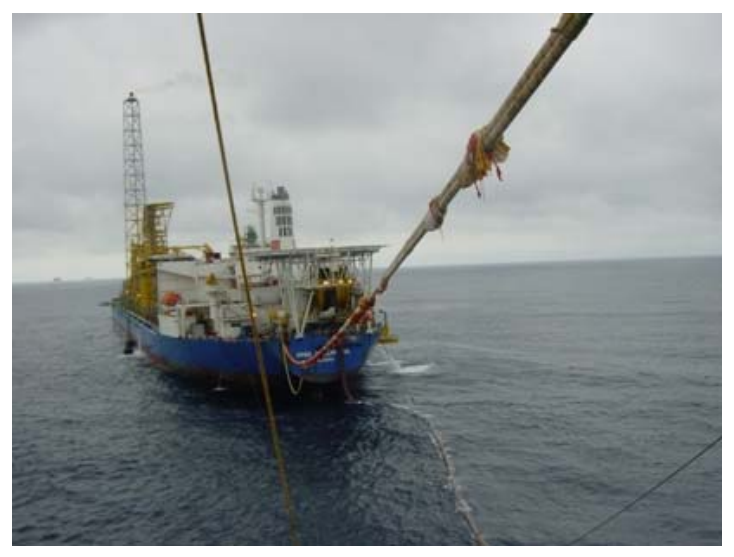

(b)

Figura 1 - Aliviador Stavanger durante operação de alívio na plataforma (a) vista da ponte de comando do aliviador (b) vista da proa do aliviador

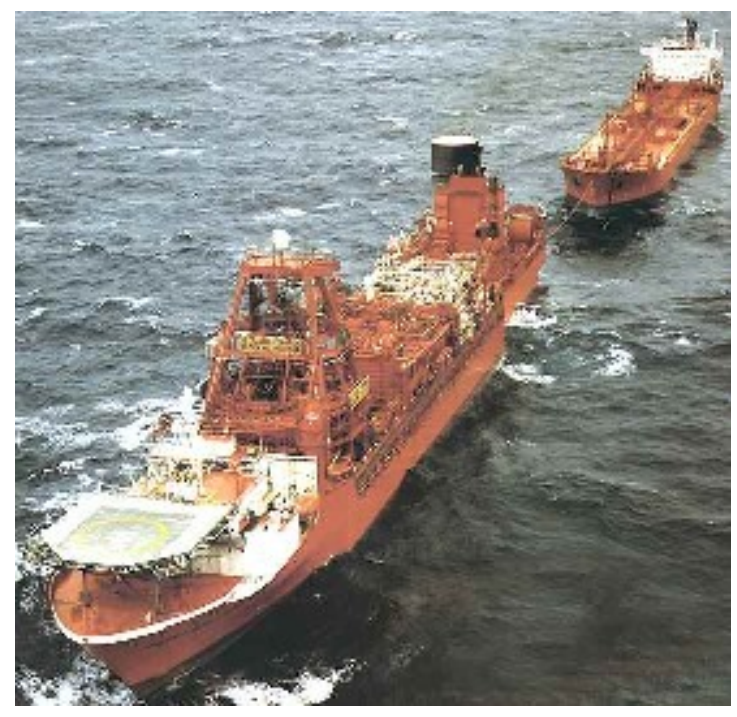

Figura 2 - Vista aérea de uma operação de alívio 
Outra operação de alívio que está sendo avaliada atualmente é a transferência de gás natural liquefeito, que exige a utilização de mangotes criogênicos. Estes, devido ao problema de isolamento térmico, não podem entrar em contato com o mar, ficando suspensos através de uma lança, o que exige uma maior proximidade entre a plataforma (possivelmente do tipo FPSO) e o navio de transporte. A Figura 3 apresenta um modelo 3D feito no TPN (Tanque de Provas Numérico) de uma operação deste tipo, considerando-se a opção de alívio em tandem e uma estrutura para apoio do mangote criogênico. Outra solução utilizada é o alívio side-by-side, onde o navio é amarrado ao lado da plataforma (Figura 4).

Como neste tipo de operação os dois corpos têm que ficar muito próximos um do outro no mar, os efeitos de interação hidrodinâmicos entre os corpos são muito significativos.
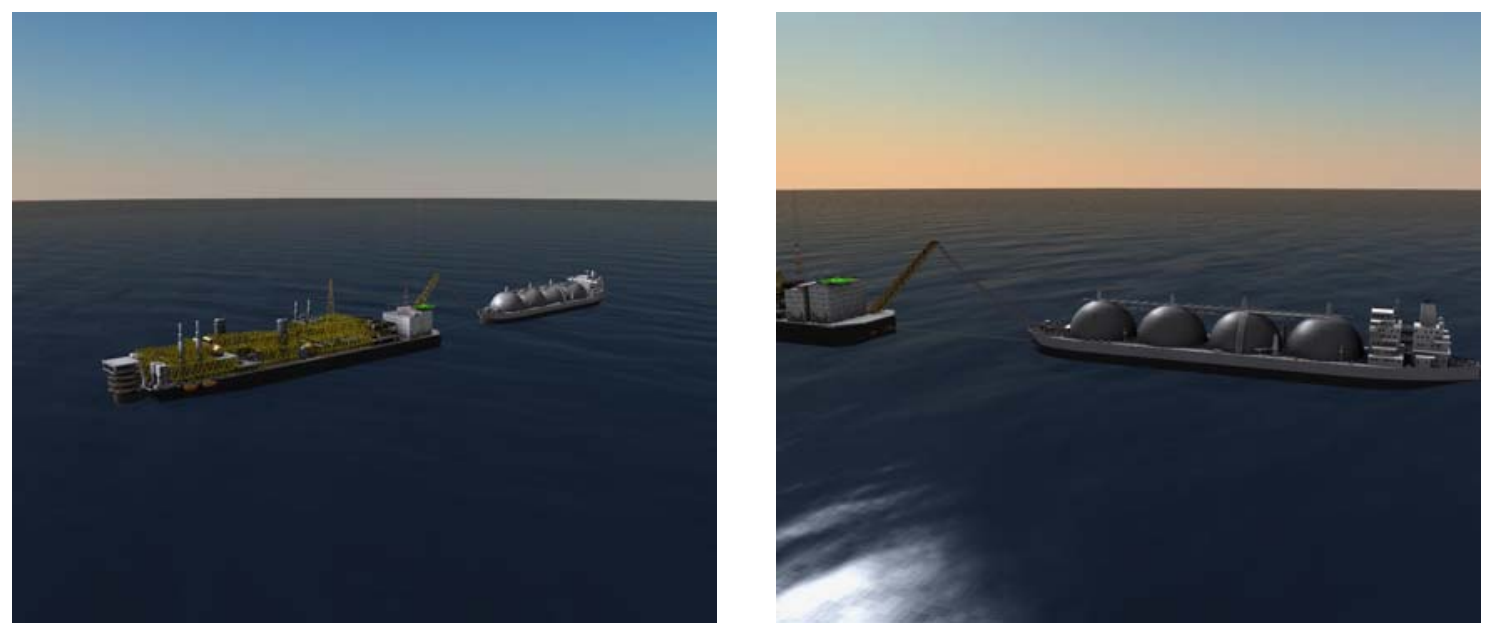

Figura 3 - Operação de alívio de gás LNG em tandem (modelo 3D TPN)
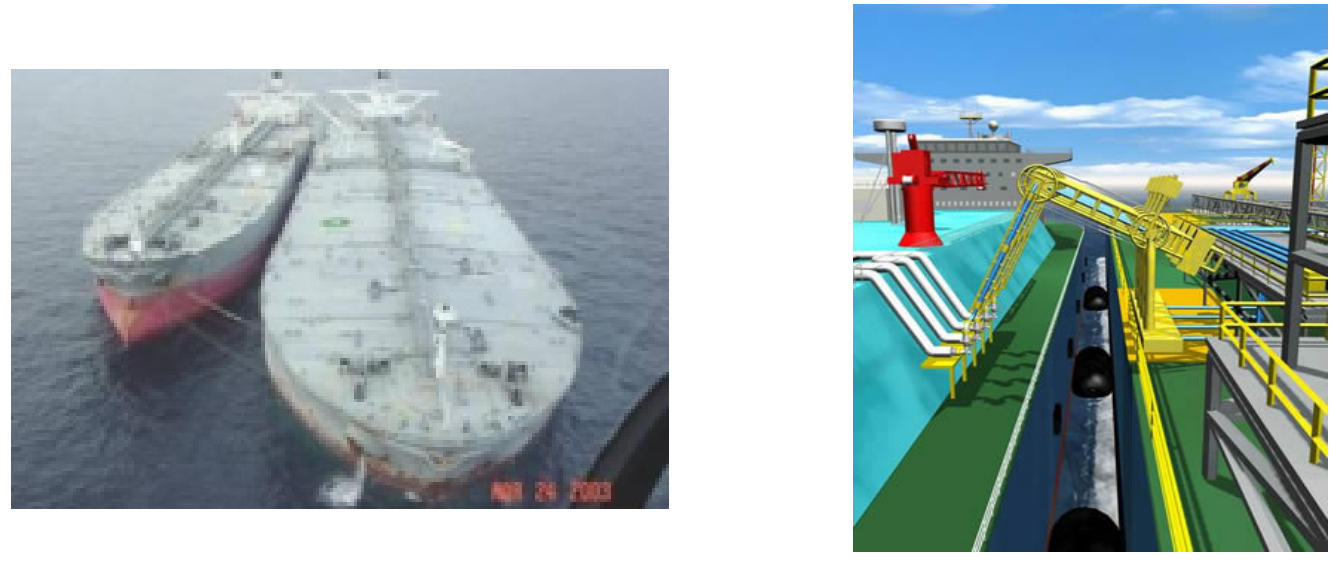

Figura 4 - Operação de alívio de gás LNG side-by-side 
Além das operações de alívio, existem outras operações, aonde os efeitos de interação hidrodinâmicos são relevantes. Uma delas é o içamento de cargas no convés de plataformas fixas ou amarradas, que exige que a barcaça de apoio fique ainda mais próxima da plataforma. Na Figura 5 apresenta-se o modelo TPN de uma operação de instalação de módulo gerador em uma plataforma fixa do tipo jaqueta, realizada pela barcaça BGL1. Pode-se notar que a interferência aerodinâmica entre os corpos deverá ser significativa. Por outro lado, devido à estrutura composta por treliças da plataforma, a interferência hidrodinâmica deve ser reduzida neste caso.

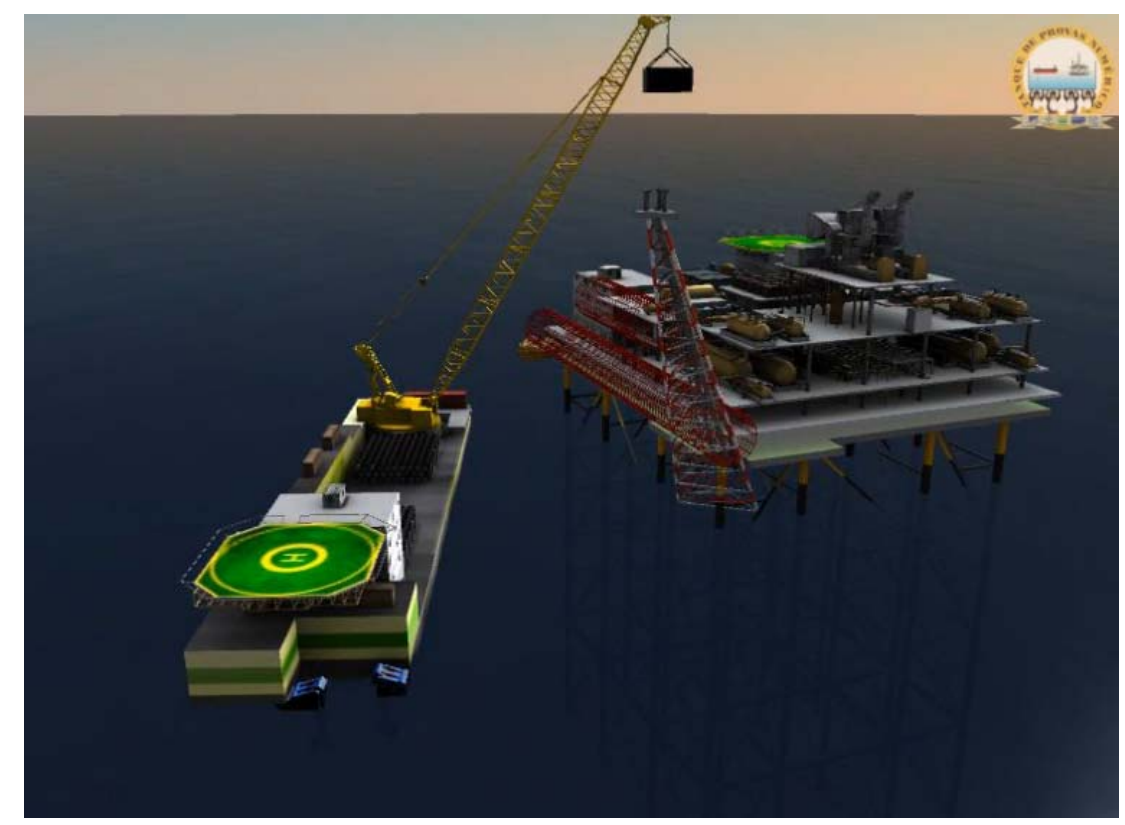

Figura 5 - Barcaça BGL1 em operação de içamento em plataforma tipo jaqueta (modelo 3D TPN)

Operações com Flotel, AHTS, sondas de perfuração, também são bastante influenciadas pelos efeitos de interação entre corpos, tal como é exemplificado na Figura 6. 


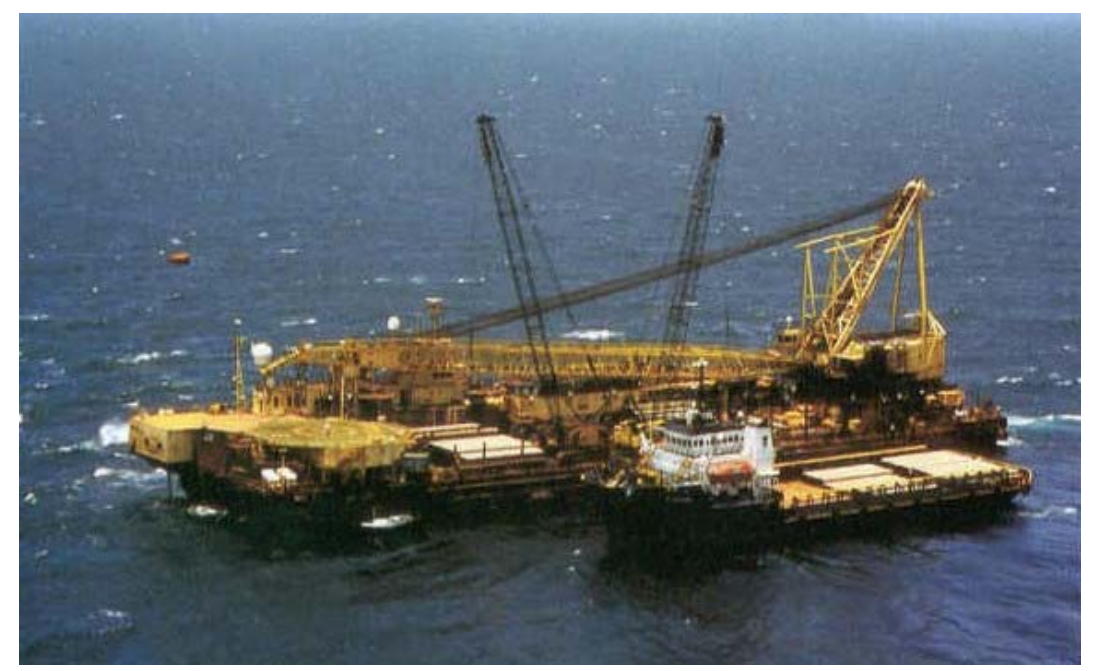

Figura 6 - Navio de suporte ao lado de uma barcaça

Hoje em dia, uma grande porção das operações de alívio é realizada utilizando um sistema de posicionamento dinâmico. O sistema de posicionamento dinâmico (DP) é utilizado para fazer manobras de aproximação ou para manter constante a posição relativa entre dois corpos no mar. No caso de operações de alívio de petróleo, na fase de conexão com a plataforma, o navio aliviador faz uma manobra de aproximação e fica a uma distância mínima de 80m. Depois faz uma manobra de recuo e fica a uma distância de aproximadamente $160 \mathrm{~m}$, durante a fase de transferência de óleo. Com o DP é possível realizar tais operações de uma maneira muito mais precisa, segura e eficiente.

Dentre os muitos efeitos de interação hidrodinâmicos que surgem quando os corpos estão próximos em alto-mar como, por exemplo, a onda irradiada por um corpo, um se torna relevante quando operações de alívio são realizadas. Quando um corpo está em alto-mar, este se torna uma barreira à propagação de ondas, distorcendo o campo de ondas ao redor, podendo gerar uma área onde há pouca onda. Este efeito é chamado de efeito de sombra de onda ou simplesmente efeito de sombra. O efeito de sombra depende da relação entre o comprimento de onda e o comprimento da barreira. Assim o efeito de sombra de onda gerado por um corpo de grandes dimensões como o de um FPSO possui grande influência no comportamento dinâmico do navio aliviador, mesmo quando o navio aliviador é dotado de sistema DP. 


\subsection{Motivação}

Por serem operações de risco, estas têm sido freqüentemente estudadas e simuladas numericamente. Devido à proximidade dos corpos supõe-se que os efeitos de interação hidrodinâmicos para este tipo de operação sejam relevantes e, por isso, a modelagem numérica de tais efeitos tem sido alvo de pesquisas, que objetivam o desenvolvimento de modelos onde tais efeitos sejam considerados.

Quando o navio aliviador é dotado de sistema DP, é esperado que o efeito de sombra cause uma variação na energia gasta pelo sistema DP, caso estes sejam relevantes. Sendo assim, surge como motivação a este trabalho verificar a relevância destes efeitos em operações de alívio envolvendo sistemas DP. Isso, para que ao se desenvolverem simuladores comerciais, estes forneçam resultados de simulação mais apurados com relação à energia e força nos propulsores do sistema DP. Desta forma será possível fazer projetos de sistema DP de forma mais confiável, reduzindo os riscos associados a estas operações.

O tema abordado é bastante atual, constituindo-se de um dos principais tópicos de pesquisa na área de hidrodinâmica aplicada, com o crescente interesse em se considerar tais efeitos nas fases de análise e projeto de estruturas e corpos flutuantes. Comprovando esta tendência, há dois projetos de cooperação entre institutos de pesquisa, universidades e empresas de petróleo (JIP - Joint Industry Projects) coordenado pelo Instituto de Pesquisa Marítima Holandês (Marin - Maritime Research Institute Netherlands) enfocando tal tema. No primeiro, denominado Offloading Operability I, finalizado no ano de 2006, realizaram-se diversos estudos por meio de experimentos em tanque de provas para se avaliar modelos de interferência entre corpos, relacionadas a ondas, vento e correnteza. Neste caso, o foco era a operação de alívio do tipo tandem. O mesmo estudo segue em continuidade (JIP Offloading Operation II), no qual objetiva-se avaliar operações de navios muito próximos, operando em configuração side-by-side. A Escola Politécnica da Universidade de São Paulo realizou alguns desenvolvimentos neste tema, focando problemas de correnteza (Fucatu 2003 e Simos 2008), onda (Tannuri et. al. 2004) e vento (Tannuri et al., 2009). 
Na seção 2 será feita uma breve revisão sobre os desenvolvimentos atuais na área em questão.

\subsection{Objetivo}

Este estudo tem como objetivo principal estudar a influência dos efeitos de interação hidrodinâmicos de onda entre corpos em operações de alívio envolvendo sistema DP. Para isso o simulador TPN (Tanque de Provas Numérico) (Nishimoto 2003) será utilizado. O simulador TPN vem sendo desenvolvido na Escola Politécnica em parceria com a indústria brasileira de petróleo (PETROBRAS S.A.) e outras importantes instituições de pesquisa do país. O TPN é freqüentemente utilizado pela Petrobras para simular operações offshore, incluindo operações de alívio.

Para que se tenham resultados de simulação mais apurados, é necessário que o efeito de sombra seja corretamente calculado. No próximo capítulo serão discutidos os métodos existentes para o cálculo dos efeitos de interação hidrodinâmicos.

Para estudar a influência do efeito de sombra nos resultados de simulação um caso real de operação de alívio DP na bacia de Campos é considerado. Uma comparação detalhada entre os resultados com e sem o efeito de sombra é apresentada, enfatizando a relevância do efeito de sombra.

\subsection{Organização do texto}

No capítulo 2 será feito um estudo sobre efeito de sombra e os trabalhos desenvolvidos na área.

No capítulo 3 será resumida a teoria linear e de segunda ordem de ondas.

No capítulo 4 será apresentado o sistema DP e como o sistema DP tem sido abordado juntamente com o efeito de sombra nos simuladores comerciais. Apresenta-se uma descrição funcional do simulador TPN.

No capítulo 5 os resultados de simulação serão apresentados e discutidos e no capítulo 6 serão apresentadas as conclusões deste trabalho. 


\section{RESUMO BIBLIOGRÁFICO}

Neste capítulo será feito um estudo sobre os trabalhos de efeito de sombra de onda e como o efeito de sombra pode ser calculado.

O problema de interação hidrodinâmica entre corpos próximos, decorrente da ação de ondas, é normalmente resolvido através da solução do problema potencial de difração-radiação utilizando programas tais como o Wamit (Wave Analisys MIT) (Wamit, 2000), considerando a malha dos dois ou mais corpos simultaneamente. No modo tradicional de simulação, o WAMIT é executado apenas uma vez, antes da simulação no domínio do tempo começar, para calcular todos os coeficientes hidrodinâmicos usados pelo simulador. Para isso uma posição relativa entre os dois corpos deve ser escolhida, o que é normalmente feito como sendo a condição inicial do simulador ou uma estimada posição média. Entretanto, durante a simulação, a posição relativa dos corpos pode variar devido à ação de vento, correnteza e onda, fazendo com que os coeficientes hidrodinâmicos calculados deixem de ser validos. Por isso, às vezes, o Wamit é executado considerando cada corpo em separado, desprezando, neste caso, qualquer efeito de interação hidrodinâmico entre os corpos. Este método é chamado método sem efeito de sombra (zero-shielding method), como exposto por Orozco e Chen 2003.

Orozco e Chen (2003) avaliaram duas formas de se considerar o efeito de sombra (wave shielding effect). No método denominado "exato", os coeficientes hidrodinâmico dos corpos foram calculados considerando-se várias posições relativas entre os mesmos. Os resultados destas análises foram armazenados em um banco de dados. Conforme a posição relativa dos corpos variava durante a simulação os coeficientes hidrodinâmicos eram atualizados. No método denominado "campo de ondas perturbado", avalia-se apenas o campo de ondas na presença do FPSO, e estima-se a altura e direção da onda incidente sobre o aliviador em cada posição que o mesmo se encontrar dentro daquele campo de ondas. Calculado este espectro, as forças de deriva são obtidas utilizando-se os coeficientes de deriva do aliviador isolado. A vantagem clara deste método é não requer a solução do problema potencial multi-corpos, 
tornando a simulação mais simples. Entretanto, não é considerado o possível efeito de interação do aliviador sobre o campo de ondas e sobre o FPSO. Assim, em problemas onde supostamente a influência do navio aliviador sobre o campo de ondas seja semelhante a do FPSO tal abordagem não é indicada.

Os autores concluíram que o método "campo de ondas perturbado" não é adequado, considerando-se o método "exato" como mais próximo da realidade física do problema. De acordo com os autores, o método do "campo de ondas perturbado", fornece resultados muito similares a não se considerar o efeito de interação.

Os autores não apresentaram resultados de simulação tampouco uma análise experimental, e apenas realizaram comparações nas forças de deriva. A Figura 7 apresenta um resultado ilustrativo, considerando-se a incidência de onda de $157,5^{\circ}$ em relação ao FPSO. Pode-se ver a grande diferença entre os coeficientes de deriva obtidos pelo método "exato" e pelo método do "campo de ondas perturbado", que se aproxima em grande faixa de períodos do calculado a não se considerar os efeitos de interação. Pode-se verificar que para freqüências menores (até $0,6 \mathrm{rad} / \mathrm{s}$ ), os efeitos de interação são pequenos, e não há diferenças significativas entre qualquer método. Entretanto, para freqüências maiores, os efeitos de interação são mais significativos, aumentando a discrepância entre o método "exato" e o método em que não se considera o efeito de interação (unshielded). Neste caso, o método do "campo de ondas perturbado" fica muito próximo ao unshielded, indicando a inadequação deste método.

Dado o grande recurso computacional disponível no TPN e os resultados anteriormente descritos, o método "exato" foi adotado atualmente para o desenvolvimento do TPN em suas novas versões.

Um primeiro estudo realizado neste assunto no grupo de pesquisa foi apresentado em Tannuri et. al. (2004). Neste, avaliou-se o efeito de sombra de onda do FPSO no comportamento dinâmico do navio aliviador não considerando Sistema DP. Neste estudo o método "exato" foi adotado e foi mostrando que o FPSO atua como se fosse um quebra ondas (Figura 8). Nesta figura a escala de cores representa a altura da onda em determinada posição em relação à altura da onda ao longe. 


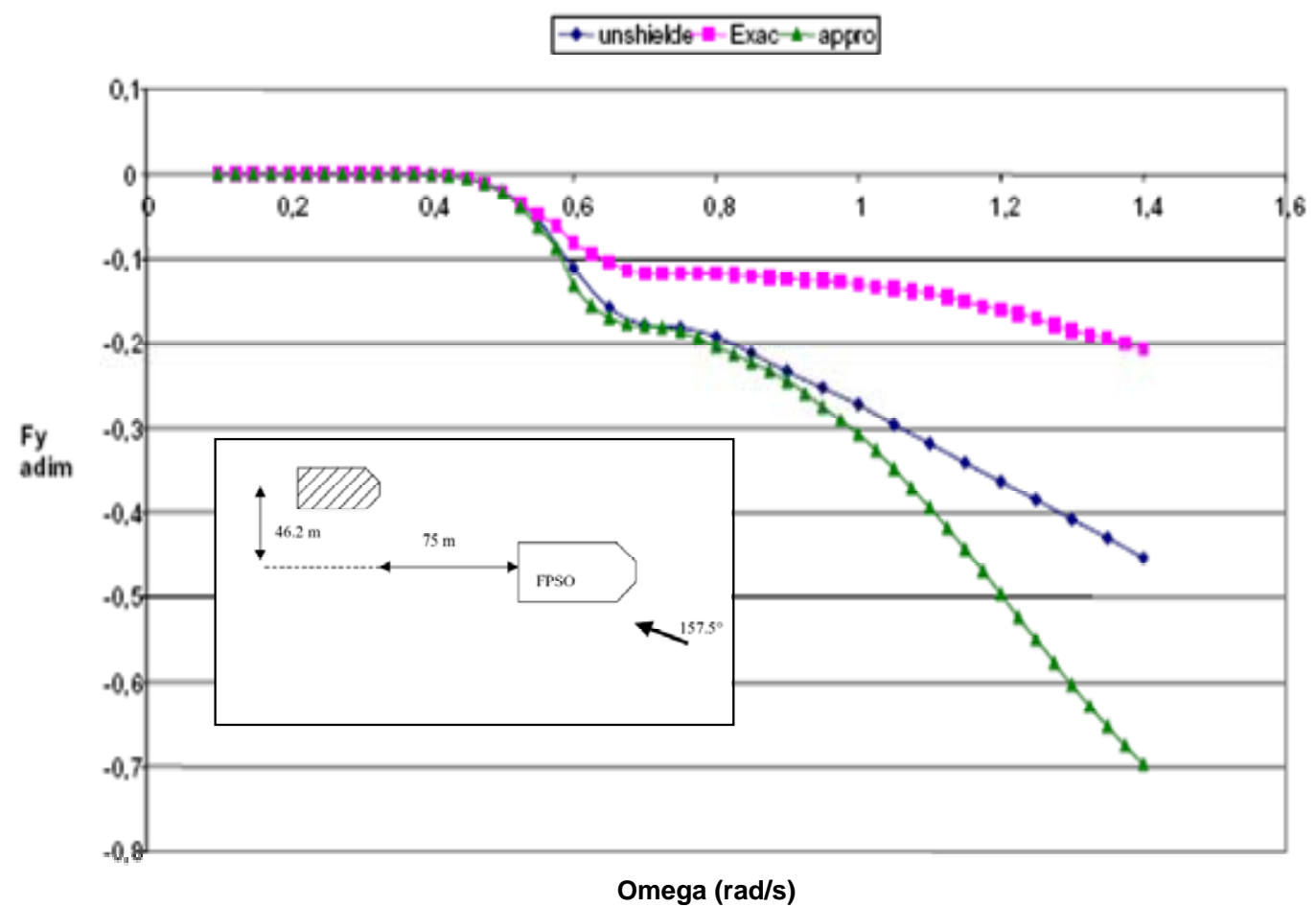

Figura 7 - Coeficiente de deriva lateral no aliviador calculados sem considerar efeito de interação (“unshielded"), com o método exato ("Exac") e com o método do campo de ondas perturbado (“appro”) (adaptado de Orozco e Chen 2003)

O método exato para o cálculo dos efeitos de interação hodrodinâmicos consiste em se recalcular todos os coeficientes hidrodinâmicos dos corpos para configurações onde a posição relativa dos corpos varie durante a simulação, considerando a malha dos dois ou mais corpos simultaneamente. O TPN utiliza o Wamit para o cálculo destes coeficientes. Portanto, durante a simulação a posição relativa entre os corpos é monitorada e, quando, uma alteração significativa é detectada a simulação é interrompida e o Wamit é executado, considerando-se a nova posição. Após o termino da execução do Wamit os dados de entrada do TPN são atualizados e a simulação é retomada. Para isso, realizou-se a adaptação preliminar do simulador TPN para a execução do programa Wamit ao longo da simulação.

A Figura 9 mostra uma comparação entre uma simulação considerando ou não o efeito de sombra de onda, na qual se pode ver uma diferença significativa no comportamento dinâmico do aliviador. No caso da ausência da interação, previa-se a ocorrência de uma oscilação, o que não ocorre quando se considera a interação. 


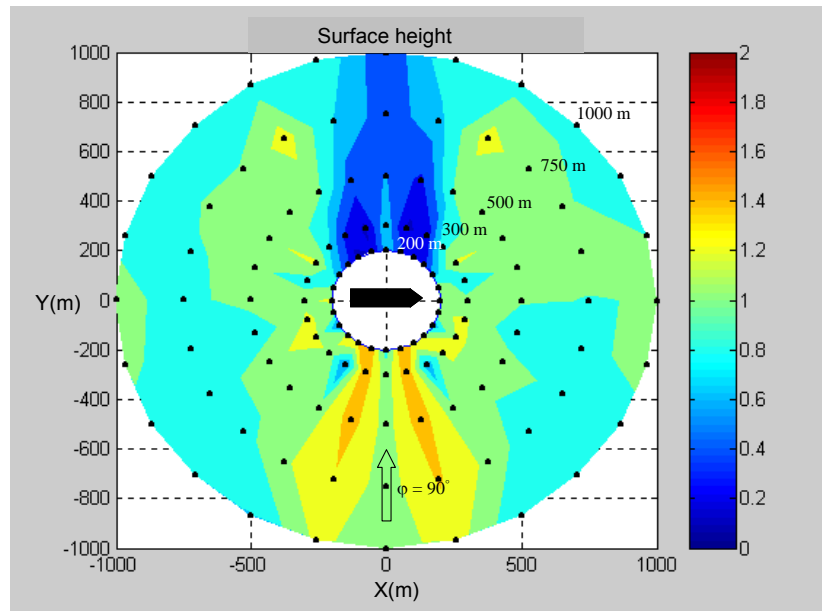

Figura 8 - Campo de ondas na presença do FPSO (H=1m; T=8s, incidência de través) - extraída de Tannuri et. al. 2004.

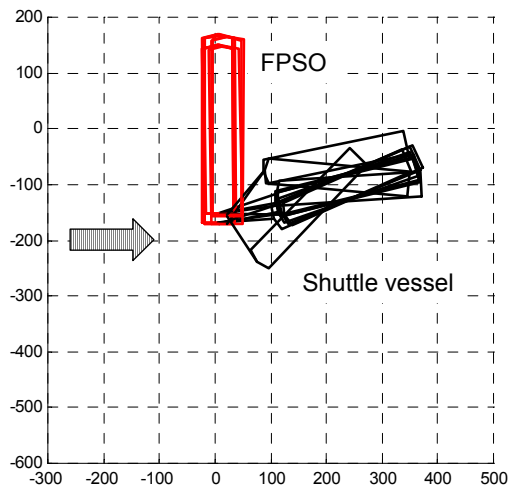

(a)

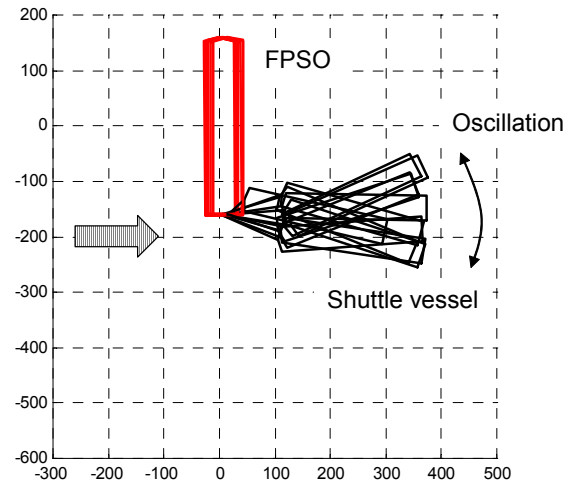

(b)

Figura 9 - (a) simulação considerando o efeito de interação de ondas; (b) simulação não considerando tal efeito (extraída de Tannuri et. al. 2004)

Como parâmetro para se recalcular os coeficientes hidrodinâmicos, os autores realizaram uma análise de sensibilidade quanto aos valores de variação da posição relativa entre os corpos para os quais se deve resolver novamente o problema potencial. Para um navio FPSO do tipo VLCC e um aliviador do tipo Suezmax, chegaram a $\left(\Delta \mathrm{X}_{\max }, \Delta \mathrm{Y}_{\max }, \Delta \psi_{\max }\right)=\left(10 \mathrm{~m}, 10 \mathrm{~m}, 5^{\circ}\right)$. 


\section{HIDRODINÂMICA DE SISTEMAS OFFSHORE}

O estudo do comportamento dinâmico de estruturas flutuantes em ondas requer, como ponto de partida, a modelagem da excitação causada por uma determinada situação de mar.

É importante mencionar que no ambiente oceânico são encontrados diversos fenômenos ondulatórios de natureza distinta. No entanto apenas as chamadas ondas de vento ou "wind waves" são de interesse no estudo da dinâmica de sistemas offshore, pois estas ondas se encontram em uma faixa de freqüência capaz de excitar a dinâmica dos corpos de dimensões usuais em engenharia naval.

As ondas de vento, como o nome sugere, são geradas pela ação do vento. $O$ vento interage com a superfície do mar, transmitindo parte de sua energia à água, a qual se propaga na forma de ondas. Três parâmetros são de especial importância na geração das ondas de gravidade: a velocidade do vento, à distância sob a qual o vento pode atuar na superfície do mar (também chamado de pista) e o tempo total de ação do vento. Se o vento possuir uma pista muito longa para atuar sobre a superfície do mar, chegará um momento em que o aumento da quantidade de energia transmitida ao mar dependerá apenas da velocidade do vento. Neste momento, diz-se que o mar está plenamente desenvolvido. Conseqüentemente enquanto o mar não atingiu esta situação, diz-se que o mesmo encontra-se em desenvolvimento.

As ondas de vento são resultantes da composição de várias componentes causadas pela ação do vento em diferentes locais da superfície do mar. A ação do vento em regiões diferentes ocorre de maneira independente e aleatória, assim, as ondas podem ser vistas como uma soma de inúmeras ondas regulares de amplitudes, freqüências e até direções diferentes o que às caracterizam como um fenômeno irregular e aleatório. Por isso ao se observar o mar próximo ou na sua região de formação não se conseguirá observar uma única direção de propagação. Este estado de mar é denominado de mar local ou de cristas-curtas (short-crested sea). Por outro lado, caso seja possível distinguir uma direção de propagação das ondas de 
forma que toda a aleatoriedade da onda se manifeste nesta direção, o mar é chamado de swell ou de cristas-longas (long-crested sea). Isto é característico de um mar longe de sua região de geração. Este fenômeno pode ser explicado através da relação de dispersão(1). A relação de dispersão impõe uma relação entre a freqüência e o número de onda.

$$
\begin{aligned}
& k=\frac{\omega^{2}}{g \tanh (k h)} \\
& \mathrm{k}-\text { Número de onda }(1 / \mathrm{m}) \\
& \omega-\text { Freqüência angular }(\mathrm{rad} / \mathrm{s}) \\
& \mathrm{g}-\text { Aceleração da gravidade }\left(9,81 \mathrm{~m} / \mathrm{s}^{2}\right) \\
& \mathrm{h}-\text { Profundidade da água do } \mathrm{mar}(\mathrm{m})
\end{aligned}
$$

Em termos da velocidade de propagação da onda, já substituindo(1) obtém-se:

$$
\begin{aligned}
& c=\frac{\lambda}{\mathrm{T}}=\frac{\omega}{k}=\sqrt{\frac{g}{k} \cdot \tanh (k h)} \\
& \mathrm{c}-\text { Velocidade de propagação }(\mathrm{m} / \mathrm{s}) \\
& \mathrm{T}-\text { Período }(\mathrm{s}) \\
& \lambda \text { - comprimento de onda }(\mathrm{m})
\end{aligned}
$$

Portanto, por (2) obtém-se que a velocidade de propagação da onda cresce com o seu comprimento. Assim, se em um dado momento for identificado um mar no qual há uma superposição de ondas de diferentes freqüências, o que é característico de um mar próximo à sua região de geração, com o passar do tempo, à medida que estas ondas se afastam da região de geração, as diferentes componentes do mar tendem a se dispersar, formando zonas mais homogêneas, com períodos e comprimentos bem definidos, formando o swell.

Por simplificação, este trabalho discutirá a definição de espectro considerando o caso mais simples, de mar unidirecional, sendo este o modelo 
adotado nas simulações decorrentes. Porém, é importante mencionar, que um mar real é muitas vezes formado pela composição de um swell e um mar local, geralmente se propagando em direções distintas. Nesse caso, o espectro de energia do mar será caracterizado por mais de um pico de energia.

O caráter aleatório das ondas de vento traz como conseqüência a necessidade de um tratamento estatístico do problema. Devido à aleatoriedade das ondas do mar é impossível reproduzir exatamente um dado estado de mar. Porém, é possível calcular a energia total contida em um dado estado de mar e como esta energia se distribui em freqüência. A densidade de energia em torno de uma freqüência $\omega_{c}$ é dada por:

$$
S\left(\omega_{c}\right)=\frac{1}{2 . \Delta \omega} \sum_{\omega_{c}}^{\omega_{c}+\Delta \omega} A_{c}{ }^{2}
$$

$\mathrm{S}$ - Densidade espectral de energia $\left(\mathrm{m}^{2} . \mathrm{s}\right)$

$\Delta \omega-$ Intervalo de freqüência $(\mathrm{rad} / \mathrm{s})$

$\omega_{c}-$ Freqüência de referência $(\mathrm{rad} / \mathrm{s})$

$A_{c}$ - Amplitude da componente de onda (m)

Como um mar irregular pode ser visto como sendo uma soma de inúmeras componentes regulares, pode-se obter a densidade espectral de energia (Energy Spectral Density) $S(\omega)$ do mar. Para tal, assume-se que a elevação do mar em um dado ponto é um processo estacionário. Na prática esta afirmação é verdadeira dentro de intervalos que podem variar de $1 / 2$ a até 10h (Faltinsen 1990).

O gráfico da densidade espectral de energia (Figura 10), muitas vezes chamado de espectro de energia, ilustra a distribuição de energia pela freqüência, sendo que a energia total por unidade de área contida neste estado de mar é dada por:

$$
E=\rho \cdot g \int_{0}^{\infty} S(\omega) \cdot d \omega
$$


E - Energia total $\left(\mathrm{kg} / \mathrm{s}^{2}\right.$ ou $\left.\mathrm{J} / \mathrm{m}^{2}\right)$

$\rho$ - Densidade da água $\left(\mathrm{kg} / \mathrm{m}^{3}\right)$

$\mathrm{g}$ - Aceleração da gravidade $\left(\mathrm{m} / \mathrm{s}^{2}\right)$

Assim, pode-se dizer que o mar fica caracterizado pelo seu espectro de energia.

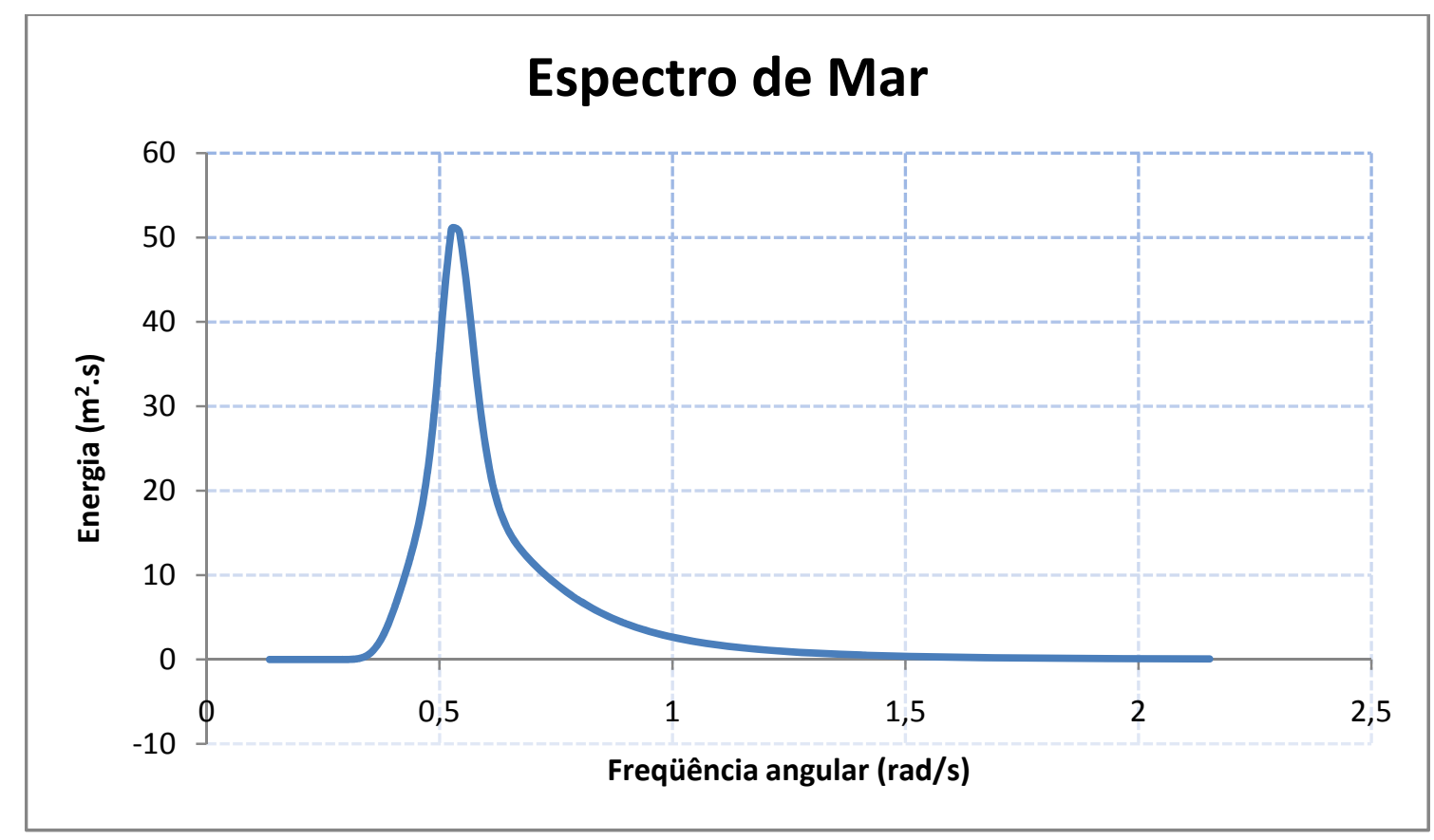

Figura 10 - Espectro de Mar do tipo JONSWAP com Hs=9,5m, freqüência de pico de 0,55 e $a_{0}=0,01234$.

Alternativamente, os espectros podem ser representados por modelos teóricos em função de sua altura significativa (significant wave height $-H_{s}$ ). A altura significativa de ondas $H_{s}$ é definida como a média das $1 / 3$ maiores ondas. Existe mais de um modelo teórico para se representar um espectro de mar. O modelo de Pierson-Moskowitz (5) (Pierson \& Moskowitz, 1964), por exemplo, foi obtido de forma semi-empírica com base na análise de dados de ondas do Atlântico Norte. Pelo fato destes dados serem provindos de uma região onde o vento possui uma grande pista para atuar, este modelo de espectro representa melhor mares desenvolvidos.

$$
S(\omega)=\frac{a_{0} \cdot g^{2}}{\omega^{5}} \exp \left(-\frac{5}{4}\left(\frac{\omega_{0}}{\omega}\right)^{4}\right)
$$


Sendo:

$$
\begin{aligned}
& \omega-\text { freqüência angular (rad/s) } \\
& \omega_{0}-\text { freqüência angular de pico do espectro (rad/s) } \\
& a_{0}=\frac{5}{16 g^{2}} H_{s}^{2} \omega_{0}^{4} \\
& \mathrm{H}_{\mathrm{s}}-\text { altura significativa }(\mathrm{m})
\end{aligned}
$$

Para representar mares em desenvolvimento a formulação de espectro mais utilizada é o JONSWAP. JONSWAP que significa Joint North Sea Wave Project foi um projeto conduzido entre 1968 e 1969 no Mar do Norte ao longo de uma linha de 100 milhas com origem na ilha Sylt (costa noroeste da Alemanha). A análise dos dados resultou na proposta de um formato de espectro para mares gerados em pistas limitadas (fetch-limited) ou costeiros. Esta formulação foi primeiramente introduzida na conferência 17th International Towing Tank Conference (ITTC, 1984). É uma generalização do espectro de Pierson-Moskowitz, pois adiciona em sua formulação um parâmetro de forma $\gamma$ que permite alterar a forma do espectro em relação ao de Pierson-Moskowitz. Pode ser escrito como:

$$
S(\omega)=\frac{a_{0} \cdot g^{2}}{\omega^{5}} \exp \left[-\frac{5}{4}\left(\frac{\omega_{0}}{\omega}\right)^{4}\right] \gamma^{\exp \left[\frac{-\left(\omega-\omega_{0}\right)^{2}}{2 \sigma^{2} \omega_{0}^{2}}\right]}
$$

com $\sigma$ dado por:

$$
\sigma=\left\{\begin{array}{l}
0,07 \rightarrow \omega \leq \omega_{0} \\
0,09 \rightarrow \omega>\omega_{0}
\end{array}\right.
$$

Pode-se observar que se $\gamma=1$ o espectro de JONSWAP se iguala ao de Pierson-Moskowitz quando $a_{0}$ é dado por (6). Quanto maior este fator, mais 
estreito se torna o espectro de JONSWAP, tornando-se mais apropriado para representar mares do tipo swell, uma vez que este tipo de mar possui sua energia concentrada numa faixa de freqüência menor.

Este trabalho supõe que as operações de alívio estudadas são realizadas na Bacia de Campos, região costeira do Rio de Janeiro. Tipicamente o modelo de espectro adotado na Bacia de Campos é o JONSWAP, com o parâmetro $a_{0}$, segundo PETROBRAS 2005, dado por:

$$
a_{0}=\frac{5}{16 g^{2}} H s^{2} \omega_{0}^{4}[1-0,287 \cdot \ln (\gamma)]
$$

Quando um corpo está no mar sob ação de ondas dois efeitos distintos podem ser observados: o efeito de radiação de onda e os efeitos de transmissão e reflexão da onda incidente. O primeiro efeito pode ser entendido como a composição das ondas geradas por um corpo flutuante que oscila. Como um corpo flutuante pode oscilar em seis graus de liberdade, tem-se uma onda distinta gerada para cada grau de liberdade. O nome se refere ao fato de que o corpo, ao se movimentar, irradia ondas que se propagam, afastando-se do mesmo. O segundo efeito é devido à onda incidente no corpo. Este efeito pode ser decomposto também em duas componentes distintas: A primeira referente à onda transmitida, ou seja, a onda que continua se propagando na mesma direção (como se o corpo fosse ausente); e a segunda referente à espalhamento desta onda uma vez que a mesma incide sobre o corpo fixo. Da solução do primeiro resultam as forças inerciais (massas adicionais) e 0 chamado "amortecimento de radiação" (radiation damping), enquanto do segundo resultam as chamadas "forças de excitação" (wave-exciting forces) que são aquelas efetivamente responsáveis por induzir os movimentos de primeira ordem do corpo (movimentos que possuem freqüência igual a da onda incidente).

Além das forças de excitação ou de primeira ordem também aparecem no corpo outras duas forças de interesse devido a efeitos de segunda ordem. Desta forma as forças decorrentes da presença de onda podem ser divididas em três componentes: 
a) Força de excitação de onda, também chamada de componente linear, dentro da faixa de freqüência das ondas, é linearmente proporcional à altura das ondas (Faltinsen 1990).

b) Componente constante, ou Força de Deriva Média, causada pela parcela de onda refletida no corpo flutuante (Faltinsen 1990).

c) Componente de baixa freqüência, ou Força de Deriva Lenta, de intensidade menor que as duas primeiras, causada pelo fenômeno de modulação que ocorre com ondas de freqüência próximas. (Faltinsen 1990).

Para a determinação total dos efeitos de onda sobre a dinâmica do navio amarrado, a hipótese de independência dos movimentos de alta e baixa freqüência é adotada, ou seja, a resultante total sobre o corpo é a composição linear de todas as componentes.

No caso onde há dois corpos próximos os efeitos de difração e irradiação de um corpo podem afetar o comportamento dinâmico do outro. O efeito de irradiação, por provocar uma onda irradiada, pode acabar excitando a dinâmica do outro. Já o efeito de difração é o responsável pela formação da região de sombra. Quanto maior a parcela de onda refletida, maior será a região de sombra formada.

\subsection{Força de primeira ordem}

As forças de primeira ordem podem ser calculadas através da integração do campo de pressão sobre a superfície molhada do corpo, campo este obtido através do potencial de velocidades advindo da solução da equação de Laplace (pois assume-se escoamento potencial). Para calcular o campo de pressão e integrar o mesmo sobre a superfície molhada do corpo o Wamit pode ser utilizado. O Wamit é um software comercial desenvolvido pelo MIT (Massachusetts Institute of Technology) que calcula o campo de pressão a partir do potencial de velocidades, o integra na superfície molhada de um corpo sob a ação de ondas sem velocidade de avanço, fazendo uso do método de 
elementos de contorno (Boundary elements method) (Wamit Reference Manual). Como saída o Wamit calcula, entre outras coisas, as chamadas funções de transferência de um corpo flutuante. Três tipos de função de transferência são calculadas pelo Wamit: As $R A O_{i}(\omega, \beta)$ (Response Amplitude Operator) onde $\omega$ é a freqüência da onda, $\beta$ é o ângulo de incidência da onda em relação ao corpo e $i$ é o grau de liberdade do movimento no corpo (de 1 a 6) que calculam diretamente o movimento do corpo, as $E W F_{i}(\omega, \beta)$ (Exciting Wave Forces) que calculam a força de primeira ordem e as SDF (Second Drift Forces) que serão vistas mais detalhadamente na secção 3.2. Como entrada o Wamit recebe um arquivo descrevendo a geometria do casco e as freqüências e ângulos de incidência de onda relativos ao mesmo nos quais as funções de transferência devem ser calculadas. O Wamit então calcula uma função de transferência para cada grau de liberdade.

As $E W F_{i}$ podem ser definidas como sendo:

$E W F_{i}(\omega, \beta)=\frac{F_{i}(\omega, \beta)}{A(\omega)}$

$F_{i}(\omega, \beta)$ - Força provocada pela onda de freqüência $\omega$ e direção de incidência $\beta$ (para $\mathrm{i}=1,2,3,4,5,6)(\mathrm{N})$;

$A(\omega)$ - Amplitude de onda de freqüência $\omega$ e direção de propagação $\beta$ $(\mathrm{m})$;

De posse das funções de transferência $\operatorname{EWF}_{i}(\omega, \beta)$ e do espectro do mar é possível obter os espectros de força ou momento, que podem ser calculados por:

$$
S_{f_{i}}(\omega, \beta)=S(\omega) \cdot\left|E W F_{i}(\omega, \beta)\right|^{2}
$$

onde:

$S_{f_{i}}$ - espectro de força $\left(\mathrm{N}^{2} . \mathrm{s}\right)$ ou momento $\left(\mathrm{N}^{2} . \mathrm{m}^{2} . \mathrm{s}\right)$

$\beta$ - ângulo de incidência 
Então as forças e momentos de primeira ordem, em função do tempo, são calculados via transformação inversa de Fourier como segue:

$$
F_{i}(t, \beta)=\sum_{j=0}^{n} \sqrt{S_{f_{i}}\left(\omega_{j}, \beta\right) \cdot \Delta \omega} \cos \left(-\omega_{j} . t+\varphi_{j}\right)
$$

onde:

$$
t-\text { tempo (s) }
$$

$n$ - número total de freqüências

$\varphi$ - fase inicial da componente harmônica

$$
\Delta \omega=\omega_{j}-\omega_{j-1}
$$

\subsection{Forças de deriva média e lenta}

As forças de segunda ordem exercem uma grande influência sobre os movimentos horizontais (surge, sway e yaw) de sistemas de grande porte amarrados, pois apresentam componentes de baixa freqüência, excitando mais intensamente estes movimentos, que apresentam baixas freqüências naturais (em geral, menores que $0,06 \mathrm{rad} / \mathrm{s}$ ). Devido a este fato as forças de segunda ordem são calculadas normalmente apenas para estes graus de liberdade. Os esforços de segunda ordem médios (freqüência nula) são chamados de forças de deriva média, e as outras componentes (que são lentamente variáveis no tempo) são denominadas forças de deriva lenta (slow drift forces).

Quando a onda incide sobre um corpo, parte da energia continua se propagando no mesmo sentido, passando pelo corpo (onda transmitida). Outra parte é refletida, passando a se propagar em sentido oposto (efeito de difração). À grande variação da quantidade de movimento associada à parcela que tem seu sentido de propagação invertido pela presença do corpo, associase a força de deriva média. Quando as dimensões do corpo são muito menores que o comprimento de onda, a parcela refletida é bem pequena (o corpo "acompanha" a onda) e esta força é reduzida. Para ondas com comprimento pequeno em relação às dimensões características do corpo, esta parcela é considerável e a força de deriva média torna-se significativa. 
As forças de deriva podem ser obtidas a partir das $S D F_{i}(\omega, \beta)$ (para $i=1,2,6)$. As SDFs são funções de transferência quadráticas, (Quadratic Transfer Function - QTFs), definidas como sendo (Faltinsen 1990):

$$
S D F_{i}(\omega, \beta)=\frac{\bar{F}_{i}(\beta)}{A(\omega)^{2}}
$$

$\bar{F}$ - Força média provocada pela onda de freqüência $\omega$ na direção de incidência $\beta$ (para $i=1,2,6)(\mathrm{N})$

As SDFs também são calculadas pelo Wamit para as mesmas freqüências e ângulos das funções de transferência lineares.

A força de deriva média pode ser calculada como segue (Faltinsen 1990):

$$
F_{d m i}(\beta)=2 \cdot \int_{0}^{\infty} S(\omega) \cdot S D F(\omega, \beta) \cdot d \omega
$$

A interação quadrática entre duas ondas harmônicas de freqüências quaisquer, $\omega_{j}$ e $\omega_{k}$, tem como resultado o aparecimento da força de deriva lenta, que tem uma natureza oscilatória com freqüência igual à "freqüência diferença" $\left(\mu=\omega_{k}-\omega_{j}\right)$.

Normalmente, a força de deriva lenta tem intensidade menor que as outras duas forças, porém dependendo do sistema de amarração utilizado, esta força pode ter um efeito significativo, causando movimentos oscilatórios lentos de grande amplitude, devido à ressonância do sistema. O espectro de deriva lenta pode ser calculado como segue:

$$
S_{d l_{i}}(\mu, \beta)=8 \cdot \int_{0}^{\infty} S(\omega) \cdot S(\omega+\mu) \cdot S L D F(\omega, \omega+\mu, \beta)^{2} \cdot d \omega
$$

onde:

$$
\operatorname{SLDF}\left(\omega_{1}, \omega_{2}, \beta\right)=\frac{F_{i}\left(\omega_{1}, \omega_{2}, \beta\right)}{A\left(\omega_{1}\right) \cdot A\left(\omega_{2}\right)}
$$


$F_{i}\left(\omega_{1}, \omega_{2}, \beta\right)$ - Força ou momento de segunda ordem devido a interação entre $\omega_{1}$ e $\omega_{2}$ (N ou N.m)

Newman (1974) propôs uma simplificação ao espectro de deriva lenta conhecida como aproximação de Newman, deixando-a em função das SDFs como segue (é interessante mencionar que as SDFs são um caso particular das SLDFs onde $\left.\omega_{1}=\omega_{2}\right)$ :

$$
S_{d l i}(\mu, \beta)=8 \cdot \int_{0}^{\infty} S(\omega) \cdot S(\omega+\mu) \cdot S D F\left(\omega+\frac{\mu}{2}, \beta\right)^{2} \cdot d \omega
$$

Aranha e Fernandes (1995) mostram que para as "freqüências diferenças" $\mu$ menores que 0,1 , o espectro de deriva lenta pode ser considerado como ruído branco, ou seja, independe do valor de $\mu$. Assim, a fórmula para o cálculo do espectro de deriva lenta para $\mu$ muito menor que um pode ser escrita como segue:

$$
S_{d l i}(\mu, \beta)=8 \cdot \int_{0}^{\infty} S(\omega)^{2} \cdot S D F(\omega, \beta)^{2} \cdot d \omega
$$

Com os espectros de força de deriva lenta, as forças no domínio do tempo $\left(F_{d l}\right)$ podem ser calculadas aplicando-se a transformada inversa de Fourier.

$$
F_{d l i}(t, \beta)=\sum_{j=0}^{m-1} \sqrt{2 \cdot S_{d l i}\left(\mu_{j}, \beta\right) \Delta \mu} \cdot \cos \left(-\mu_{j} t+\varphi_{j}\right)
$$

onde:

$$
\begin{aligned}
& m-\text { total de freqüências diferença } \\
& \Delta \mu=\Delta \omega
\end{aligned}
$$




\section{SISTEMAS DP E SIMULAÇÃO OFFSHORE}

\subsection{Sistemas DP - Uma Abordagem Geral}

Define-se posicionamento dinâmico como um sistema que controla automaticamente a posição horizontal e aproamento de uma embarcação por meio de propulsão ativa (Bray, 1998; Fossen 1994). Em linhas gerais, corresponde a um complexo sistema de controle, composto por sensores (DGPS, sonar, anemômetros, giroscópios, etc.), atuadores (propulsores e leme) e um processador central responsável pela execução do algoritmo de controle e pela interface com o operador (Figura 11b; c).

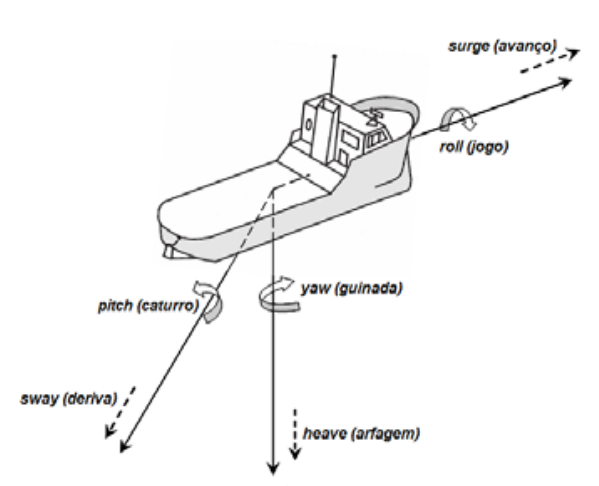

(a)

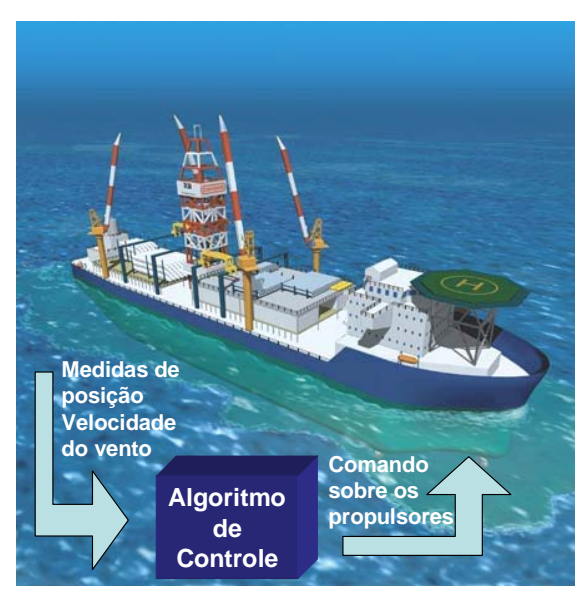

(b)

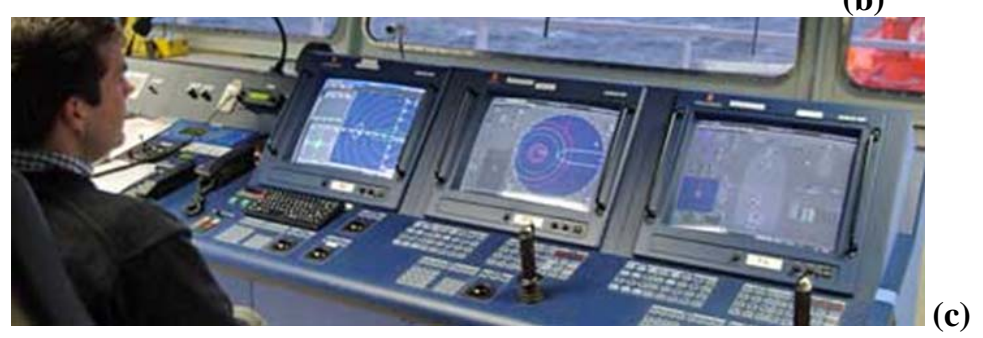

Figura 11 - (a) Definição dos movimentos; (b) Sistema DP; (c) Console de comando (adaptado de Agostinho, 2009 e Kongsberg, 2009)

A motivação inicial para o desenvolvimento deste sistema remonta ao início da década de 60. Foi quando surgiu a necessidade de se explorar petróleo em águas mais profundas. Até então a exploração de petróleo era quase que exclusivamente feita a profundidades de até $500 \mathrm{~m}$, pois a tecnologia dominante era a de plataformas do tipo jaqueta, porque são economicamente viáveis até esta profundidade. 
Para profundidades superiores começou-se a desenvolver os sistemas de amarração, tecnologia utilizada até os dias de hoje. Estes sistemas são empregados, por exemplo, em navios de perfuração, barcaças de lançamento de dutos e plataformas semi-submersíveis de produção. Visando diminuir o custo destas operações, em 1961 nos Estados Unidos foram instalados quatro propulsores azimutais com controle manual no navio de perfuração "Cuss 1" na tentativa de substituir o sistema de amarração de quatro linhas, utilizado até então neste navio. Mais tarde no mesmo ano, desenvolveu-se o primeiro Sistema DP no navio "Eureka". Este possuía um controlador analógico que recebia a informação de posição de um sensor do tipo fio tensionado (taut-wire) e comandava os propulsores.

A Figura 12 ilustra o diagrama de blocos de um Sistema DP e todos os componentes envolvidos em sua malha de controle. A seguir, cada componente será detalhado.

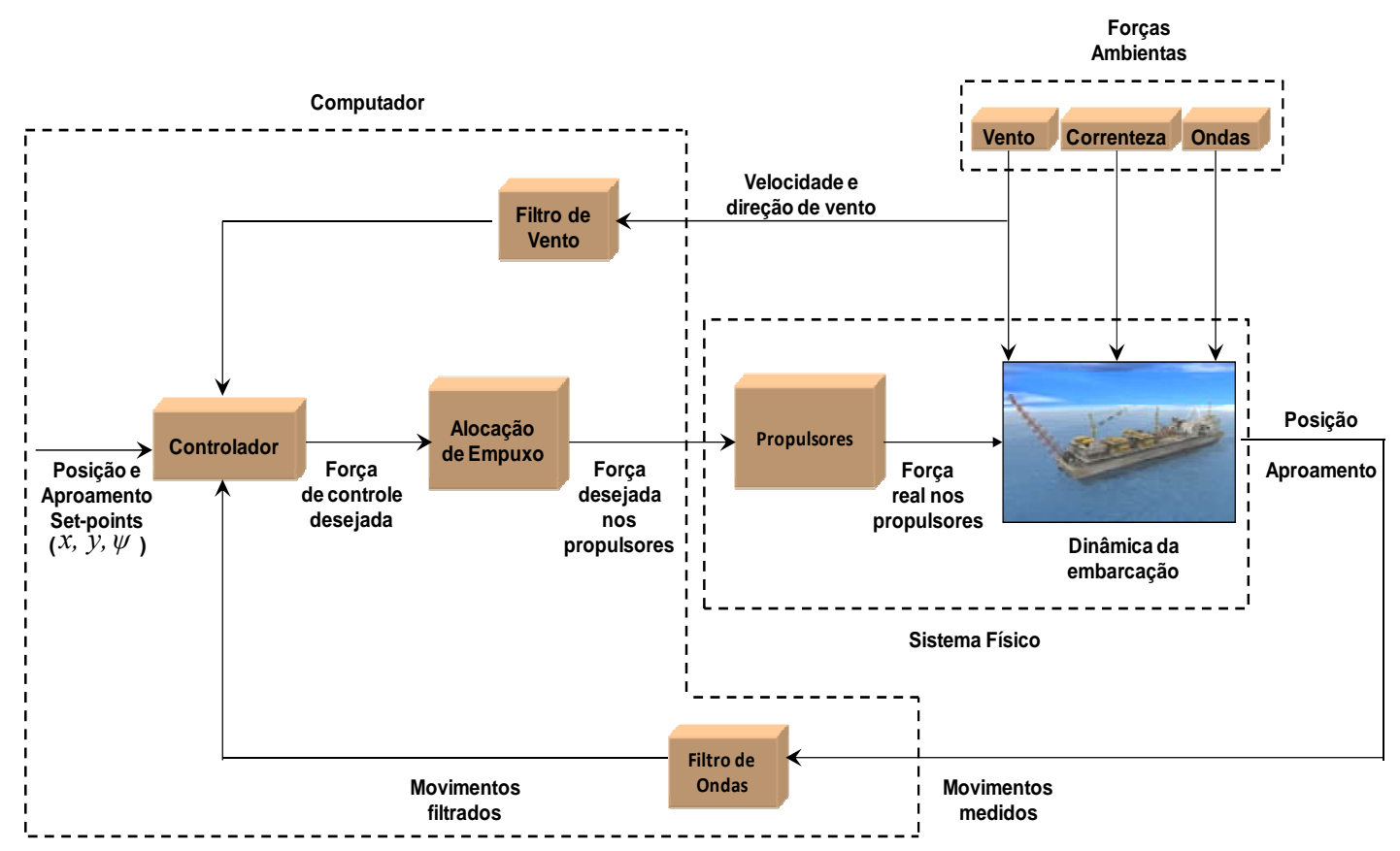

Figura 12 - Diagrama de Blocos de um Sistema de Posicionamento Dinâmico

As medidas da posição e aproamento provenientes de sensores são filtradas pelo Filtro de Ondas. Nos sistemas comercialmente disponíveis, utilizase um Filtro de Kalman Estendido (EKF) para realizar esta função. Em altomar, a embarcação sofre a ação de forças provocadas pela correnteza, onda e vento, que induzem movimentos da ordem da freqüência das ondas incidentes, e movimentos de baixa freqüência. O objetivo do Sistema DP é controlar 
exclusivamente os movimentos de baixa freqüência horizontais. O controle dos movimentos de primeira ordem exigiria uma potência muito elevada e poderia causar o desgaste dos propulsores. Além da função de filtragem, o EKF realiza a fusão de sensores, que corresponde em obter a estimativa ótima da posição e aproamento baseado em informações de múltiplos sensores. Por ser um filtro baseado em modelo dinâmico da embarcação, permite também obter estimativas razoáveis de posição durante alguns instantes em que há perda de sinal do DGPS (função esta conhecida como dead-reckoning) e da força ambiental resultante sobre o navio.

Um algoritmo de controle calcula as forças resultantes e momento de yaw necessários para o posicionamento da embarcação, baseado na posição atual calculada pelo Filtro de Ondas e na posição requerida (set-point). Utilizam-se, em sistemas comerciais, controladores do tipo ProporcionalDerivativo (PD) para cada um dos três movimentos. Estas forças são, então, distribuídas pelos propulsores (geralmente, embarcações com Sistema DP possuem de 3 a 9 propulsores) por meio de um algoritmo de alocação de empuxo (TAL - Thruster Allocation Logic). Este algoritmo corresponde a um método de otimização não-linear com restrições. O objetivo é obter um sistema de forças de atuação com resultante igual à calculada pelo controlador, com mínimo de consumo de potência e levando em conta as restrições de funcionamento e saturação de cada propulsor. $O$ vento, medido pelos anemômetros, são em parte compensados por uma malha de pré-alimentação (feedforward).

Além dos complexos algoritmos de controle, filtragem, e alocação descritos, o Sistema DP é composto por um grande conjunto de componentes que garantem o seu funcionamento. A Figura 13 apresenta o diagrama destes componentes, agrupados na forma de subsistemas. Além do subsistema de controle já descrito anteriormente, apresentam-se a seguir as funcionalidades dos demais subsistemas de forma resumida. 


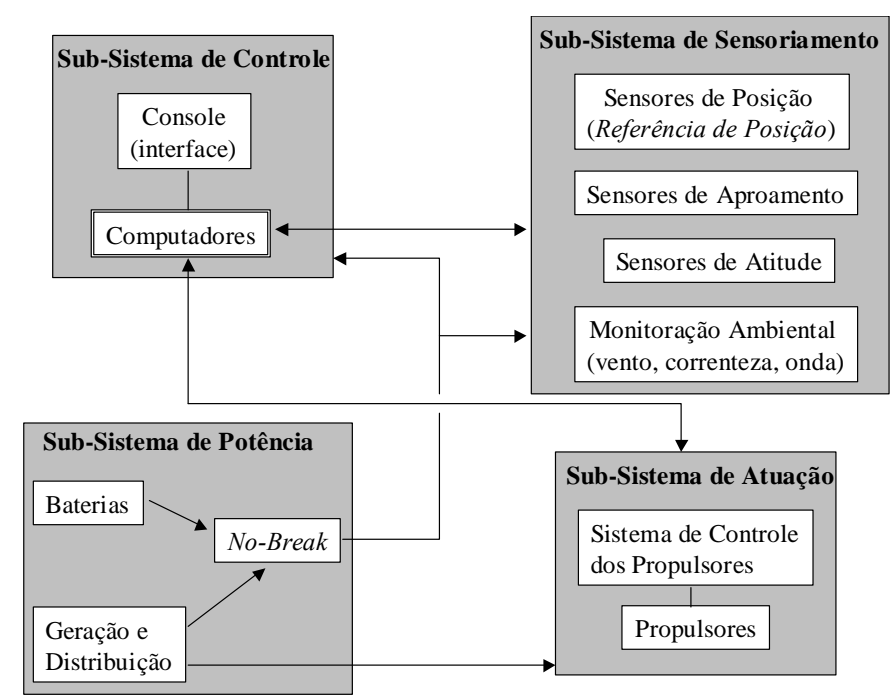

Figura 13 - Diagrama Elementos de um Sistema DP (extraído de Tannuri, 2002)

O subsistema de potência é responsável por fornecer energia ao Sistema DP, que consome uma grande parte da energia produzida na embarcação, com variações abruptas de carga devidas a súbitas mudanças das condições ambientais, como por exemplo, rajadas de vento. Uma das arquiteturas mais utilizadas é diesel-elétrica, com todos os consumidores alimentados eletricamente e a potência gerada por alternadores diesel. Um nobreak (conhecido como UPS - Uninterruptible Power Supply) associado a um banco de baterias é utilizado para estabilizar a energia fornecida aos componentes eletrônicos do SPD.

O subsistema de atuação é composto pelos diversos tipos de propulsores e pelos sistemas de controle associados a cada um deles. Os mais comuns são os propulsores principais e leme posicionados na popa da embarcação (Figura 14c); os propulsores em túnel (Figura 14b), montados em túneis instalados transversalmente ao casco e os azimutais (Figura 14a), que podem direcionar o empuxo gerado, através de um grau de liberdade adicional de rotação. A variação do empuxo nos propulsores pode ser obtida pela variação do ângulo das pás ou por variação da rotação. 


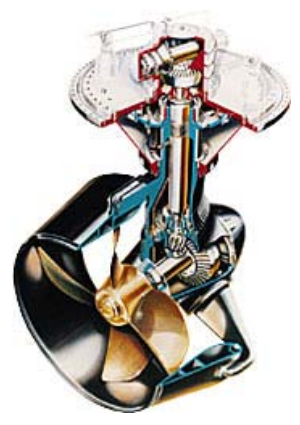

(a)

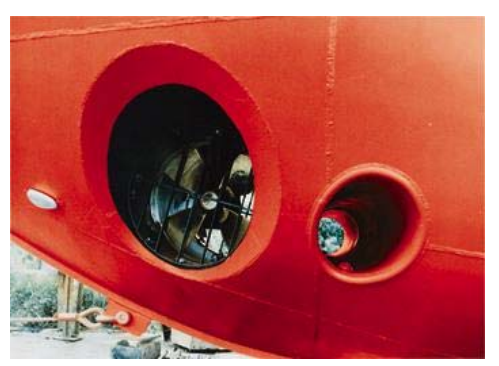

(b)

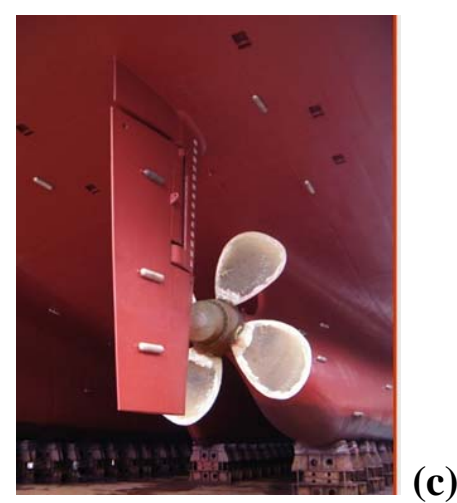

(c)

Figura 14 - (a) Propulsor azimutal (b) Propulsor em túnel (c) propulsor principal e leme (adaptado de Tannuri, 2002)

O subsistema de sensoriamento é composto pelos sensores de posição, conhecidos como sistemas de referência de posição, que medem a posição de um ponto da embarcação no plano horizontal. Existem diversas tecnologias empregadas para este fim, destacando-se os sistemas de localização por satélite diferencial (DGPS), sistemas hidroacústicos, radares por microondas, dentre outros. O aproamento da embarcação é medido por girocompassos. Em geral, os Sistemas DP possuem mais de um sensor de posição e aproamento, valendo-se desta redundância para obter medidas mais precisas e com maior confiabilidade. Existem também os sensores responsáveis pela medição de velocidade e direção de vento (anemômetros), que são encontrados em todos os Sistemas DP atuais e são utilizados na malha de pré-alimentação.

\subsection{Sistemas DP e efeito de sombra de onda em simuladores comerciais}

Comercialmente existem vários simuladores de operações oceânicas, sendo que os principais serão citados a seguir. Esta pesquisa foi feita com base em dados disponíveis publicamente, não se obtendo, portanto, informações precisas a respeito da formulação ou metodologia adotada para o cálculo dos efeitos de interação, caso existam.

Cita-se, por exemplo, SIMO do "Norwegian Marine Technology Research Institute" (Marintek) que não leva em conta o efeito de sombra de onda na simulação de operações oceânicas envolvendo múltiplos corpos flutuantes (com ou sem Sistemas DP) segundo Marintek (2008). 
Outro simulador é o LIFSIM/LIFMOT do Marin, que embora seja específico para içamento de carga, não permite a simulação de Sistemas DP, nem tão pouco, leva em conta efeitos de interação hidrodinâmicos, segundo Marin (2008). Também do Marin destaca-se o Anysim (Ansym, 2006) um simulador mais geral e não apenas para operações de alívio de carga. Segundo Marin (2008), o simulador leva em conta os efeitos de interação hidrodinâmicos entre corpos, inclusive efeitos de sombra de onda. Também é possível simular Sistemas DP com este simulador.

O Deepc do DNV, de acordo com DNV (2008), só faz simulação de múltiplos corpos com efeitos de interação hidrodinâmicos se adicionada uma extensão ao simulador original. Existe uma menção não muito clara a respeito de console DP na referência.

Já o AQWA da Ansys é um dos mais completos simuladores comerciais existentes no mercado com relação a efeitos hidrodinâmicos, efeito de sombra de onda inclusive. Porém não foi mencionado nada a respeito de simulação de operações com console DP, segundo Ansys (2008).

Outro simulador de destaque é o Ariane-3Dynamic do MCS, que embora seja referência no segmento apresenta muito pouca informação a respeito, como pode ser verificado em MCS (2008). Desta forma não foi possível verificar se o mesmo leva em conta efeito de sombra de onda ou Sistemas DP na simulação. 


\subsection{O Simulador TPN}

O simulador dinâmico não-linear TPN vem sendo desenvolvido na escola Politécnica da Universidade de São Paulo desde 1998. O projeto foi concebido com base em pesquisas e desenvolvimento, e executa a integração no tempo das equações diferenciais que representam a dinâmica de corpos flutuantes sob a ação ambiental. Considera também a ação de linhas de amarração e risers (dutos que transportam petróleos), bem como a possibilidade de operação com Sistema DP.

Como entrada o simulador recebe as características principais dos corpos (dimensões, matriz de massas, etc.), os coeficientes aerodinâmicos da parte emersa (padrão OCIMF), os coeficientes de correnteza (padrão OCIMF) ou derivadas hidrodinâmicas, os coeficientes hidrodinâmicos (amortecimento potencial, massas adicionais, funções de transferência de 1a e 2a ordem), as condições ambientais que devem ser simuladas, as características das linhas de amarração e risers, as características e posições dos propulsores e os modos de operação DP e seus parâmetros. Para calcular a massa adicional, o amortecimento potencial e as funções de transferência de onda o TPN utiliza o software Wamit. Como saída o simulador calcula as séries temporais do movimento do corpo (nos seus seis graus de liberdade), a tensão nas linhas, a potência e empuxo nos propulsores, etc.. Há também um resumo estatístico de todas as séries.

Para obter a força de onda de $1^{a}$ ordem no domínio do tempo, o TPN realiza a transformação inversa de Fourier do cruzamento do espectro de energia do mar com as funções de transferência de força de excitação (EWF). O espectro de energia é calculado conforme os modelos teóricos de PiersonMoskovitz ou JONSWAP. Já as forças de deriva média e lenta são obtidas das SDFs sendo que o TPN utiliza a simplificação proposta por Aranha e Fernandes 1995 para o cálculo da força de deriva lenta. Forças de vento e de correnteza também podem ser consideradas.

O TPN também e capaz de realizar simulações DP. O simulador possui algoritmos utilizados nos sistemas DP comerciais, de modo a representar a dinâmica dos navios da Petrobrás dotados deste sistema. Como filtro de onda o TPN utiliza um Extended Kalman Filter (EKF), que incorpora um modelo do 
sistema. No EKF, o movimento do navio é considerado como a soma de duas parcelas linearmente independentes. O modelo de baixa freqüência (LF) é excitado pelas forças de correnteza, vento e pelas forças de deriva de onda. $\mathrm{O}$ modelo de alta freqüência (HF) é excitado pelas parcelas de primeira ordem das forças de onda. O controlador implementado no TPN é do tipo PD (proporcional derivativo), desacoplado para cada um dos 3 eixos. Adicionalmente, há uma malha de compensação de vento. Os ganhos do controle são calculados automaticamente pelo método da alocação de pólos. $O$ algoritmo de alocação de empuxo utilizado baseia-se no método da matriz pseudo-inversa, com alguns recursos extras, tais como zona morta para o ângulo de azimute, realocação em caso de saturação e filtros. $O$ simulador inclui também modelos para propulsores CPP e FPP. Leva em conta a dinâmica do sistema motor+hélice e as curvas de torque e empuxo do hélice (Kt e Kq). Uma descrição detalhada dos algoritmos de DP implementados no TPN pode ser encontrada em Tannuri e Morishita (2006). 


\section{ESTUDO DE CASO - OPERAÇÃO DE ALÍVIO}

Uma operação de alívio em tandem típica é adotada, com o navio aliviador dotado de um sistema DP, conectado a uma plataforma do tipo FPSO utilizando um sistema de amarração espalhada (Spread Mooring System SMS) (Figura 16). As análises foram feitas sob duas condições: com o navio aliviador em condição de lastro e o FPSO em condição carregada e na condição oposta com o navio aliviador em condição carregado e o FPSO em condição de lastro. As características dos corpos em cada situação são apresentadas na Tabela 1.

Tabela 1 - Características do navio aliviador e do FPSO

\begin{tabular}{|c|c|c|c|c|}
\hline Propriedades & \multicolumn{2}{|c|}{ Navio Aliviador } & \multicolumn{2}{c|}{ FPSO } \\
\hline & $\begin{array}{c}\text { Condição de } \\
\text { lastro }\end{array}$ & $\begin{array}{c}\text { Condição } \\
\text { carregado }\end{array}$ & $\begin{array}{c}\text { Condição } \\
\text { de lastro }\end{array}$ & $\begin{array}{c}\text { Condição } \\
\text { carregado }\end{array}$ \\
\hline Massa (M) & $75694 \mathrm{ton}$ & $169390 \mathrm{ton}$ & 125000 ton & $310720 \mathrm{ton}$ \\
\hline Comprimento (L) & $260 \mathrm{~m}$ & $260 \mathrm{~m}$ & $320 \mathrm{~m}$ & $320 \mathrm{~m}$ \\
\hline Calado (T) & $8,0 \mathrm{~m}$ & $16,0 \mathrm{~m}$ & $9,0 \mathrm{~m}$ & $21,0 \mathrm{~m}$ \\
\hline Boca (B) & $44,5 \mathrm{~m}$ & $44,5 \mathrm{~m}$ & $54,5 \mathrm{~m}$ & $54,5 \mathrm{~m}$ \\
\hline
\end{tabular}

Para realizar suas operações de alívio em tandem a Petrobras define que o navio aliviador deve estar posicionado dentro da "zona verde" (Figura 15). Esta zona é definida por um setor angular a partir da estação de alívio do FPSO (na popa ou proa), e é obtida a partir de análises de riscos de operação. A posição relativa entre o navio aliviador e a plataforma FPSO é mantida por um sistema DP. 


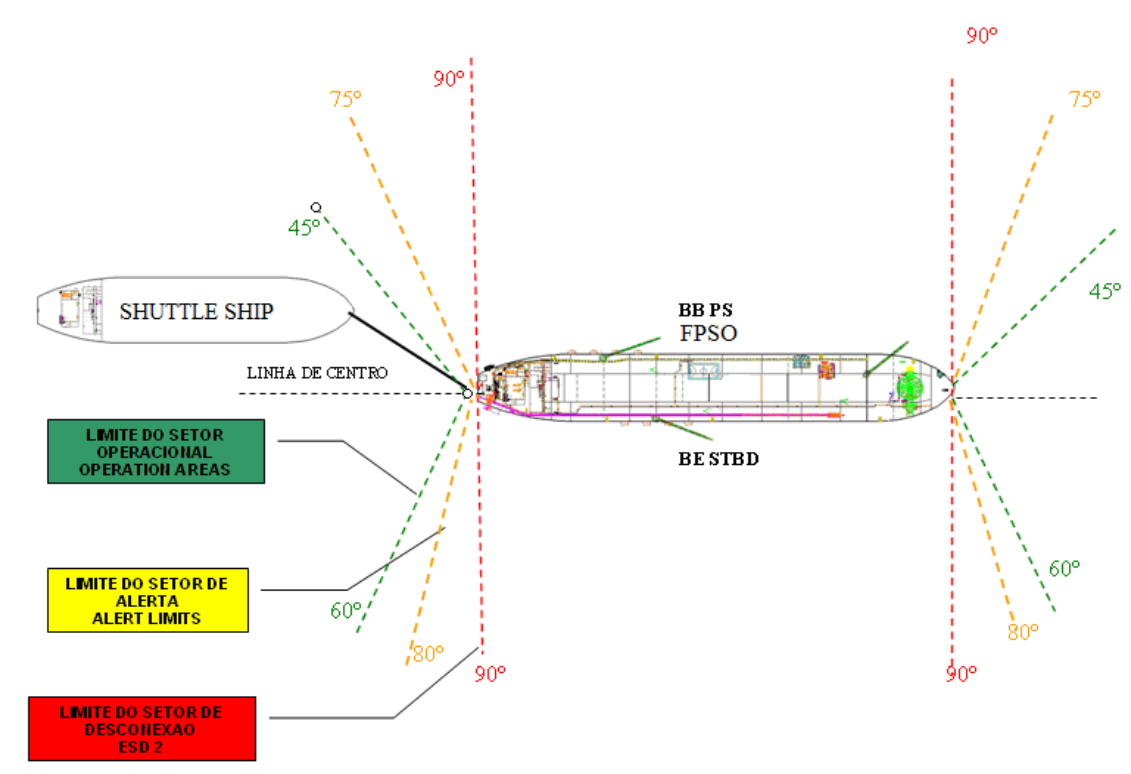

Figura 15 - Setores operacionais de operações de alívio tipo tandem para FPSO em com sistema de amarração espalhado. (Tannuri ET. al. 2009)

Como o objetivo do presente estudo é verificar-se a influência da interação hidrodinâmica devido à ação de ondas entre o navio aliviador e o FPSO, nas análises subseqüentes apenas a ação das ondas é incluída nas simulações. Três incidências de onda são consideradas como mostrado na Figura 16. Para todas as ondas foi considerado um espectro de JONSWAP com período de pico variando de 5 até 13s. Para cada período de pico foi considerado a altura significativa de onda mais provável na Bacia de Campos (Tabela 2). Foi feito ainda uma análise do caso em que o FPSO está carregado e o navio aliviador em condição de lastro considerando-se altura significativa de $3 \mathrm{~m}$ para os períodos de onda citados acima. Embora a análise com altura significativa de onda de $3 \mathrm{~m}$ seja hipotética para períodos de $5 \mathrm{~s}$, por exemplo, seu objetivo é explicar o efeito de sombra, visto que é mais fácil observar a influência do mesmo quando a altura significativa não varia junto com o período de pico. Para todos os casos o navio aliviador foi posicionado à $60^{\circ} \mathrm{com}$ relação ao FPSO, como mostra a Figura 16. Esta posição angular corresponde ao limite da "zona verde", conforme foi mostrado na Figura 15. A distância entre os navios $(d)$ foi considerada como $160 \mathrm{~m}$ ou $80 \mathrm{~m}$, representando as fases de transferência de óleo e de conexão com o FPSO respectivamente. 
Tabela 2 - Alturas significativas mais prováveis (PETROBRAS, 2005)

\begin{tabular}{|l|l|}
\hline Tp - Período de pico (s) & Hs - Altura significativa (m) \\
\hline 5 & 1,06 \\
\hline 7 & 1,38 \\
\hline 9 & 1,59 \\
\hline 11 & 1,81 \\
\hline 13 & 2,0 \\
\hline
\end{tabular}
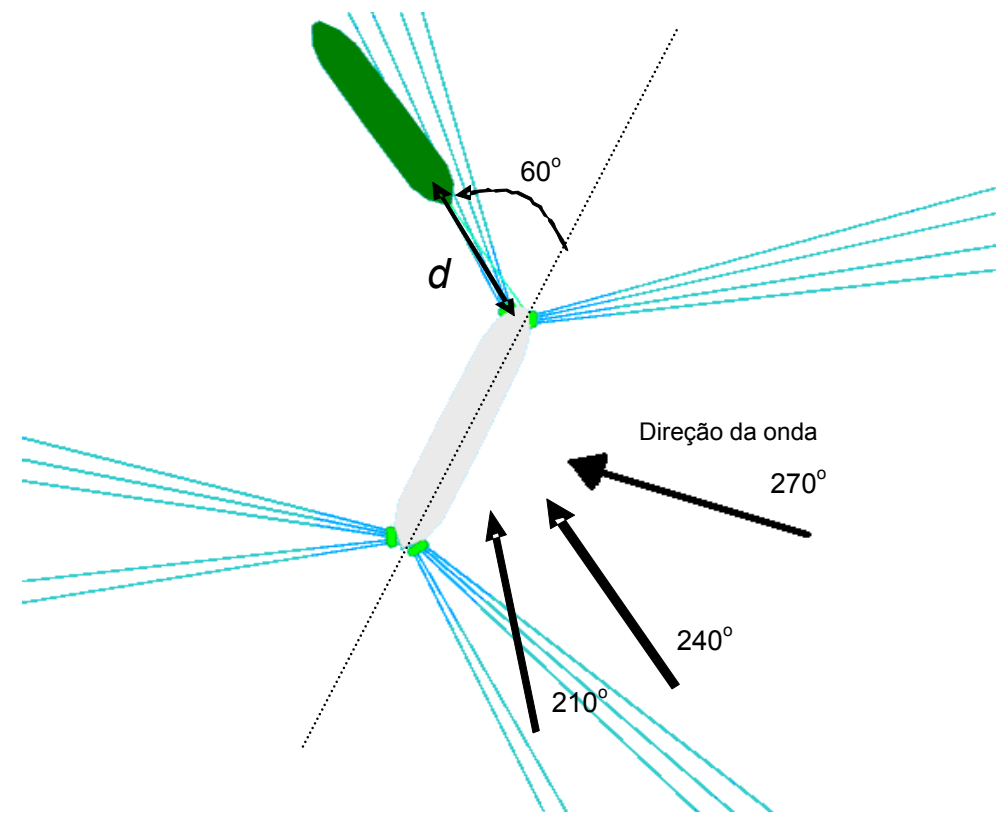

Figura 16 - Configuração adotada

No navio aliviador uma configuração típica de DP é adotada. A posição, potência e o empuxo estimado dos propulsores estão mostrados na Figura 17. O sistema consiste em um propulsor de túnel e um propulsor azimutal na proa e na popa. O sistema de propulsão principal junto com leme também é utilizado pelo sistema DP. 


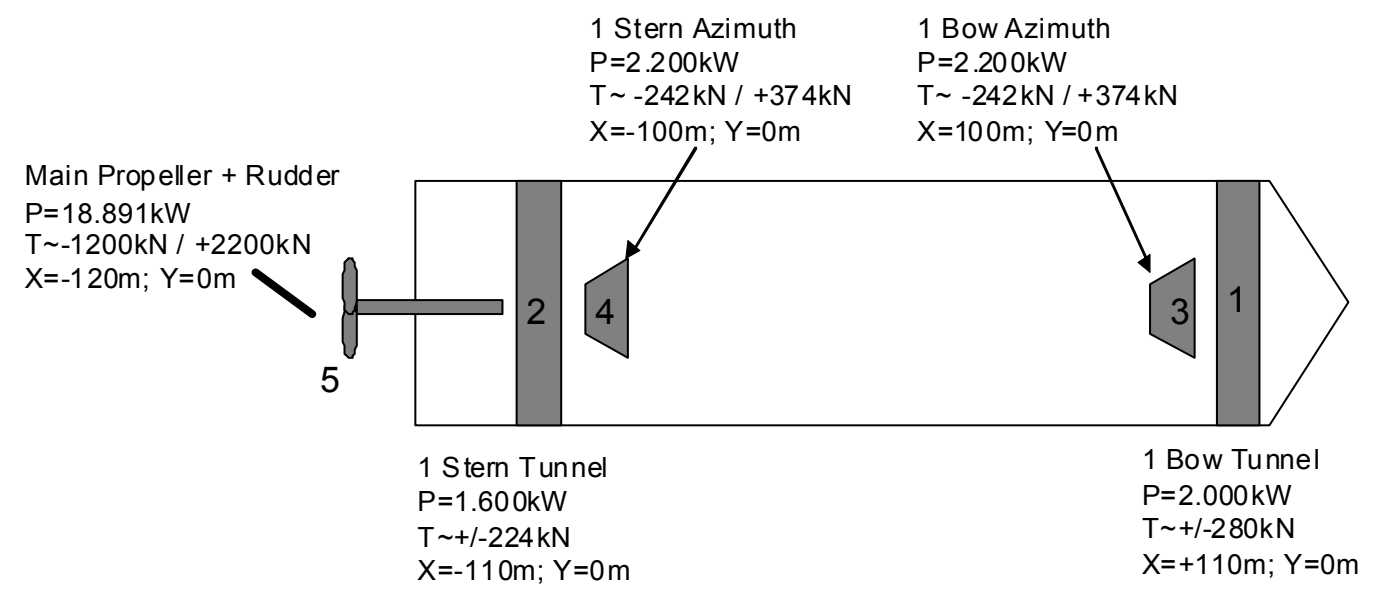

Figura 17 - Posição dos propulsores em metros (com relação ao CG do navio), potência em cada propulsor (P) e máximo e mínimo empuxo estimado(T).

Várias simulações foram feitas, conforme as seguintes combinações:

1. Altura significativa de onda de $3 \mathrm{~m}$ :

a) Carregamento:

i) FPSO carregado e navio aliviador em condição de lastro;

b) Direção da onda de $270^{\circ}, 240^{\circ}$, e $210^{\circ}$ em relação ao FPSO;

c) Período de onda de 5, 7, 9, 11 e 13s;

d) Efeito de sombra:

i) Sem efeito de sombra;

ii) Com efeito de sombra durante a fase de transferência de petróleo $(\mathrm{d}=160 \mathrm{~m})$;

iii) Com efeito de sombra, durante a fase de conexão com o FPSO $(d=80 m)$;

2. Altura significativa de onda mais provável:

a) Carregamento

i) FPSO carregado e navio aliviador em condição de lastro;

ii) FPSO em condição de lastro e navio aliviador carregado;

b) Direção da onda de $270^{\circ}, 240^{\circ}$, e $210^{\circ}$ em relação ao FPSO;

d) Período de onda de 5, 7, 9, 11 e 13s;

e) Efeito de sombra:

i) Sem efeito de sombra; 
ii) Com efeito de sombra durante a fase de transferência de petróleo $(\mathrm{d}=160 \mathrm{~m})$;

iii) Com efeito de sombra, durante a fase de conexão com o FPSO $(\mathrm{d}=80 \mathrm{~m})$ apenas para FPSO carregado e navio aliviador em condição de lastro;

Para cada simulação, uma análise completa no domínio do tempo é realizada.

\subsection{Simulação Completa}

Como ilustração, são apresentados nesta seção os resultados completos de uma simulação. As próximas figuras mostram um conjunto completo de resultados obtidos na simulação de um caso (direção de onda de $270^{\circ}$, período de pico de $9 \mathrm{~s}$, altura significativa de $3 \mathrm{~m}$, sem efeito de sombra). Na Figura 18a é mostrado como a posição do sistema varia durante a simulação, Figura 18b mostra-se a utilização média dos propulsores e na Figura 18c a distância relativa dos dois corpos que no caso da simulação foi adotada 160m. Séries temporais da posição do navio aliviador são apresentadas na Figura 19; na Figura 20 são apresentadas as séries temporais de força nos propulsores e na Figura 21 são mostradas as séries temporais das forças resultantes do sistema DP no navio aliviador. Por ultimo é apresentada uma tabela contendo a força média e desvio padrão de cada propulsor.

(m)

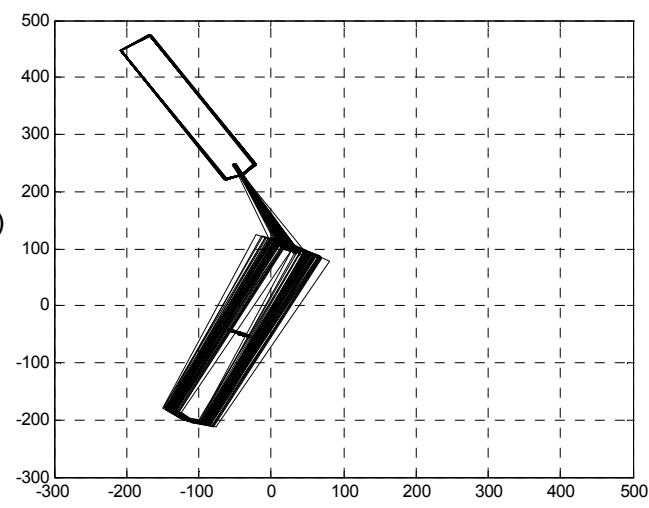

(m)

(a)

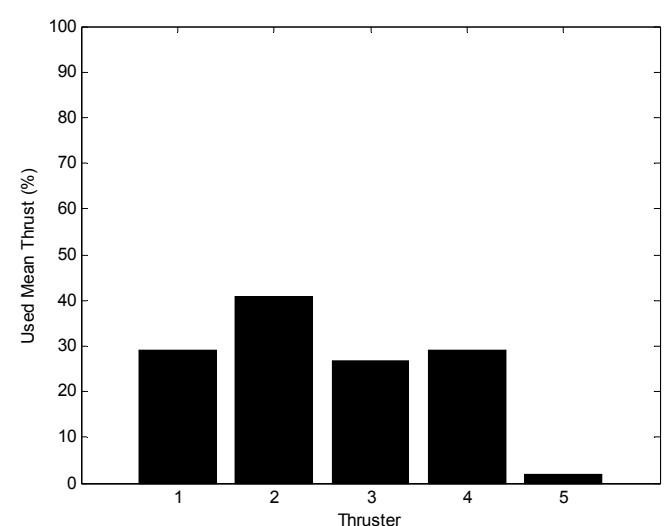

(b) 


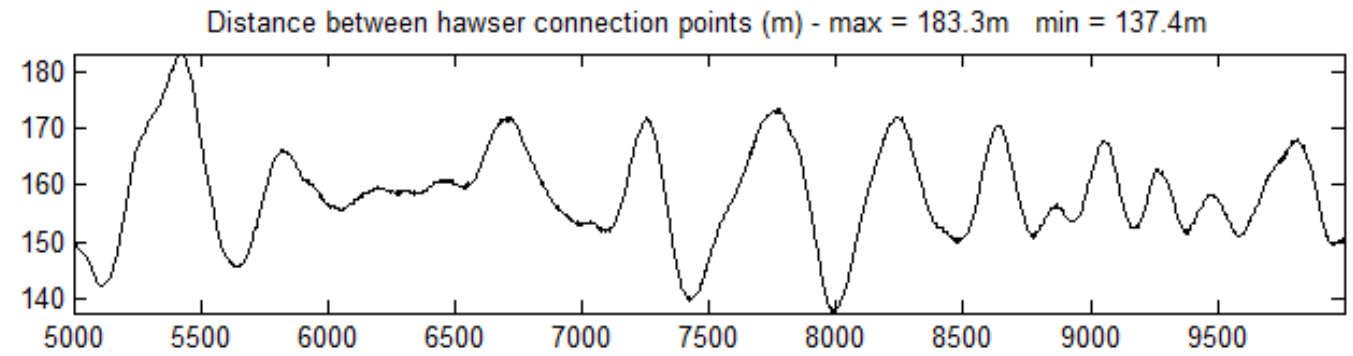

(c)

Figura 18 - Movimentação do sistema (a); utilização média dos propulsores (b); distância relativa entre o navio aliviador e o FPSO (c)
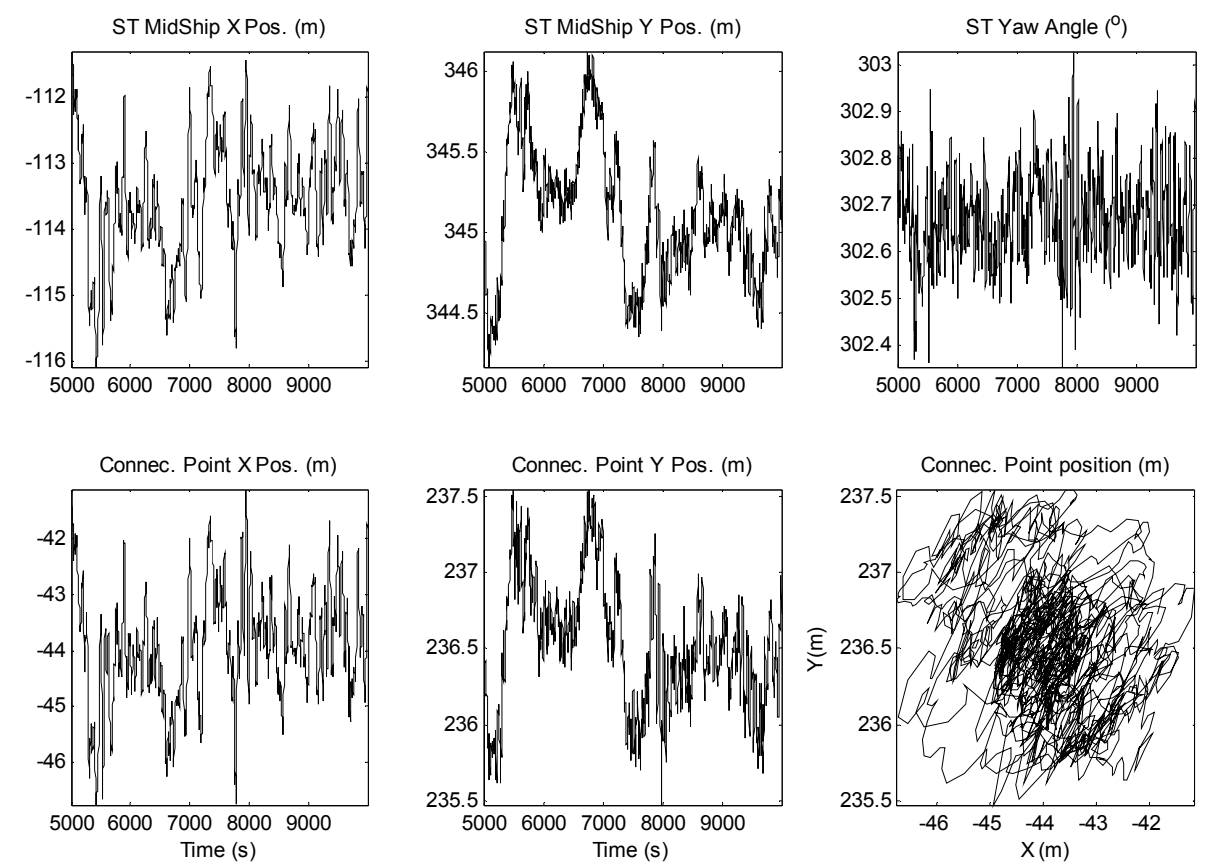

Figura 19 - Séries temporais da posição do navio aliviador
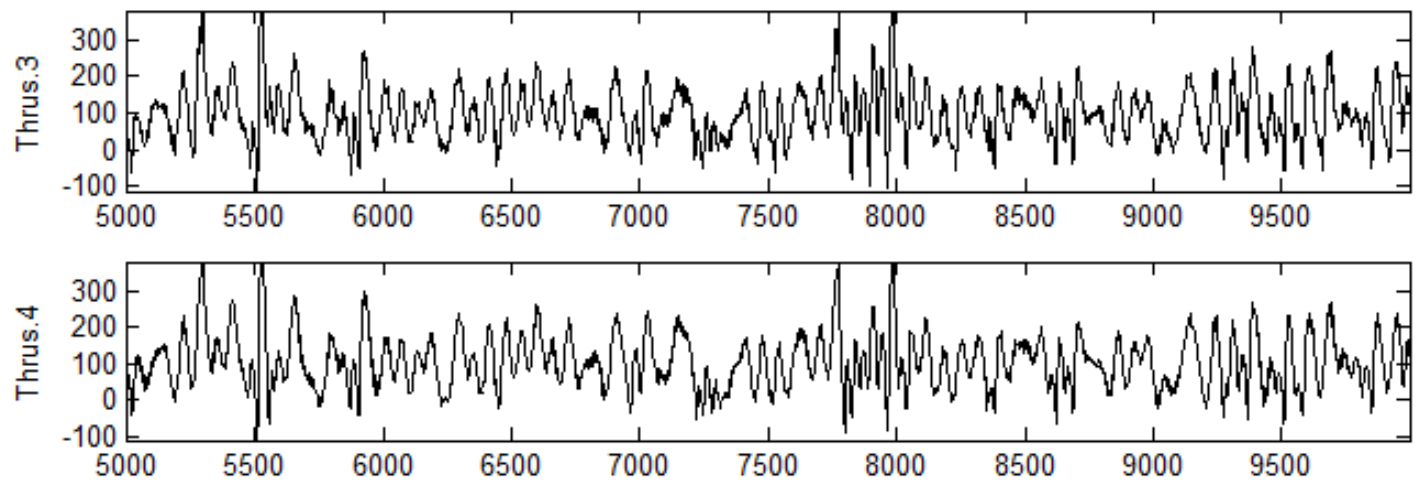

Figura 20 - Forças nos propulsores 4 e $5(\mathrm{kN})$ 

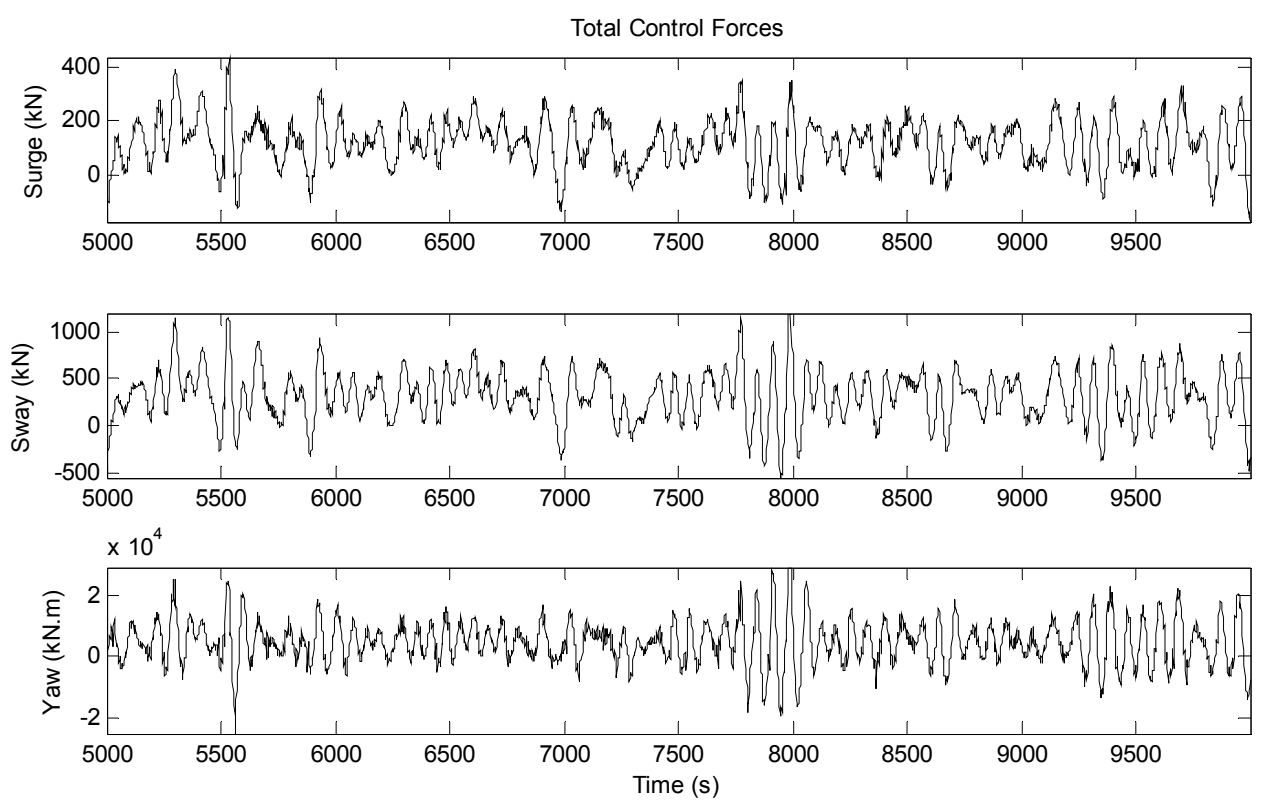

Figura 21 - Força resultante do sistema DP

Tabela 3 - Força média e desvio padrão em cada propulsor

\begin{tabular}{|l|c|c|}
\hline Propulsor & Força Média (kN) & Desvio Padrão (kN) \\
\hline P1 & 20,42 & 17,05 \\
\hline P2 & 23,20 & 17,22 \\
\hline P3 & 27,48 & 18,61 \\
\hline P4 & 29,40 & 18,67 \\
\hline P5 & 9,67 & 7,17 \\
\hline
\end{tabular}

\subsection{Resultados}

Para cada direção de onda é apresentado um gráfico barras, com uma comparação para cada período de onda da potência do sistema DP. A comparação é feita entre os três casos: não se considerando o efeito de sombra, considerando o efeito de sombra na fase de transferência de petróleo (160m de distância entre o navio aliviador e o FPSO) e considerando o efeito de sombra na fase de conexão com a plataforma (80m de distância). 


\subsubsection{FPSO carregado e navio aliviador em condição de lastro com altura significativa de onda de $3,0 \mathrm{~m}$}

A seguir serão apresentados os resultados para altura significativa de $3 \mathrm{~m}$. Na seqüencia serão apresentados os resultados para os casos com altura variável.

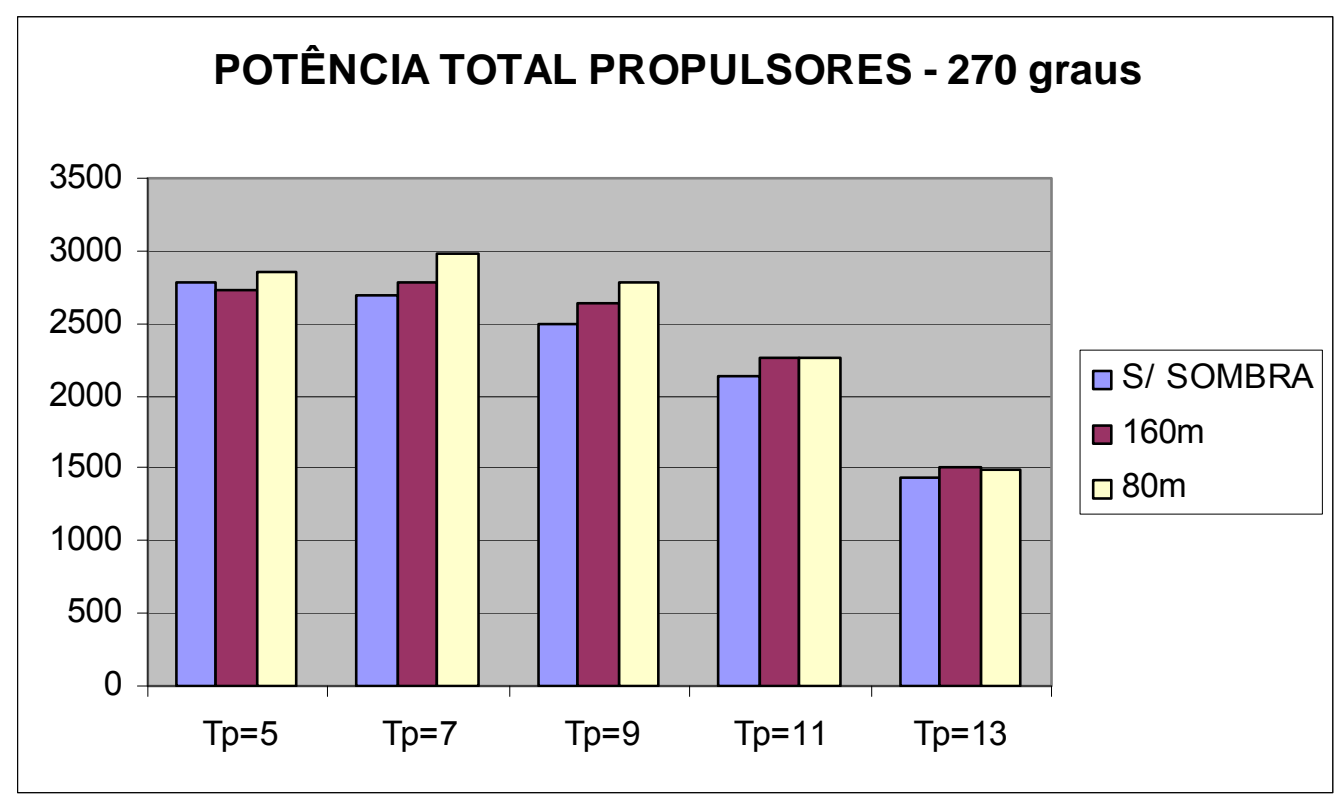

Figura 22 - Potência total do sistema DP para Hs=3.0m e incidência de $270^{\circ}$

Figura 22 mostra a potência média total no sistema DP durante a simulação para direção de onda de $270^{\circ}$, considerando o período de pico de 5 a 13s. Como esperado a potência no DP decai conforme o período de onda aumenta. Isto ocorre devido aos coeficientes de deriva para períodos grandes serem pequenos (vide apêndice $B$ ). Para período de onda de $5 \mathrm{~s}$, pode-se notar que praticamente não há variação no DP comparando com e sem efeito de sombra. De fato no mapa de elevação de onda (Figura 23 e Figura 24) mostra que o navio aliviador está em uma posição fora da zona de sombra. Já para o período de 13s, as dimensões do FPSO são pequenas se comparadas ao comprimento de onda, portanto o FPSO não se comporta com uma barreira deixando as ondas passarem por ela, reduzindo o efeito de sombra. 


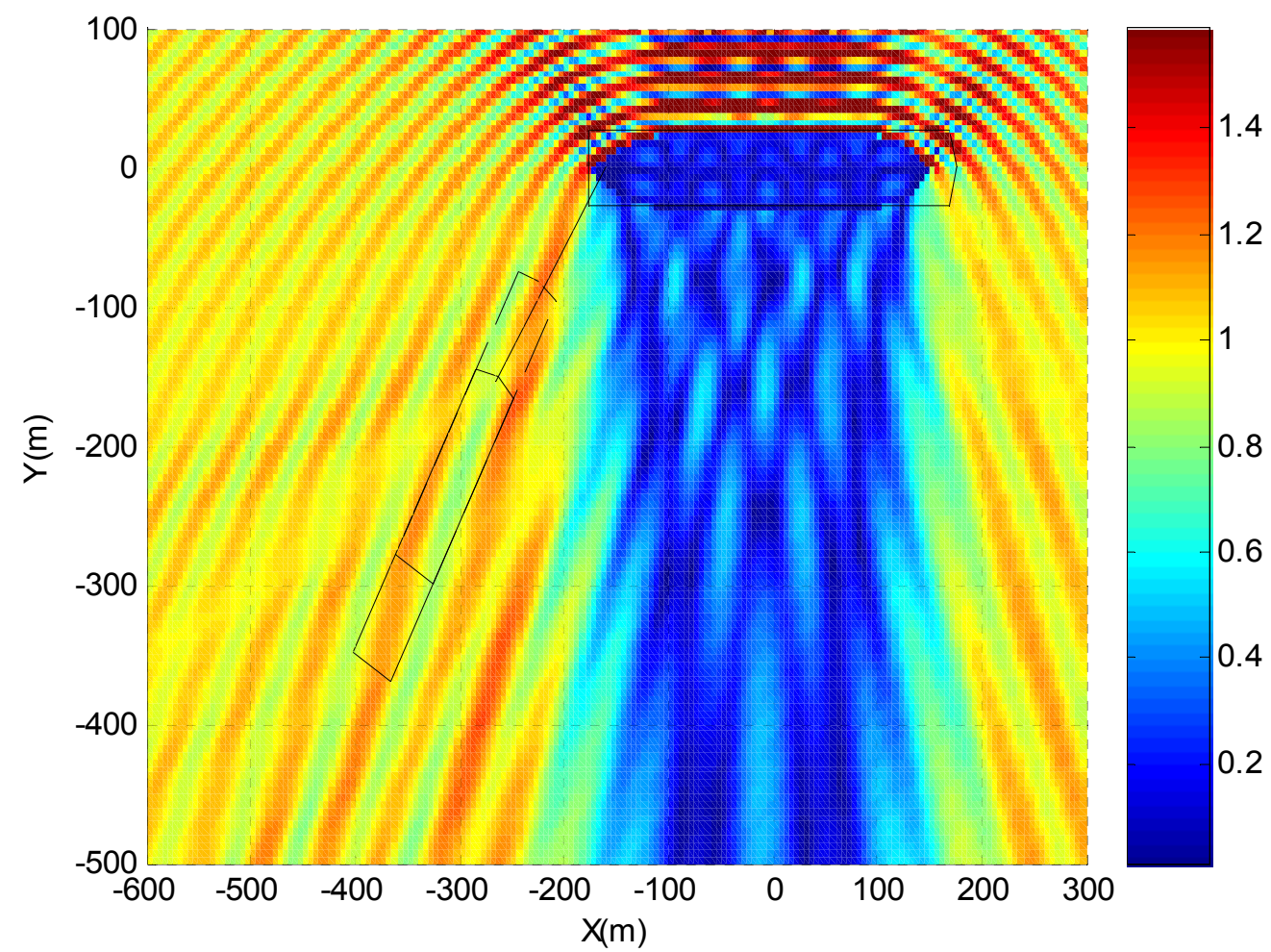

Figura 23 - Mapa de elevação de onda não considerando a influência do navio aliviador para incidência de $270^{\circ}$ e 5 s de período (regular).

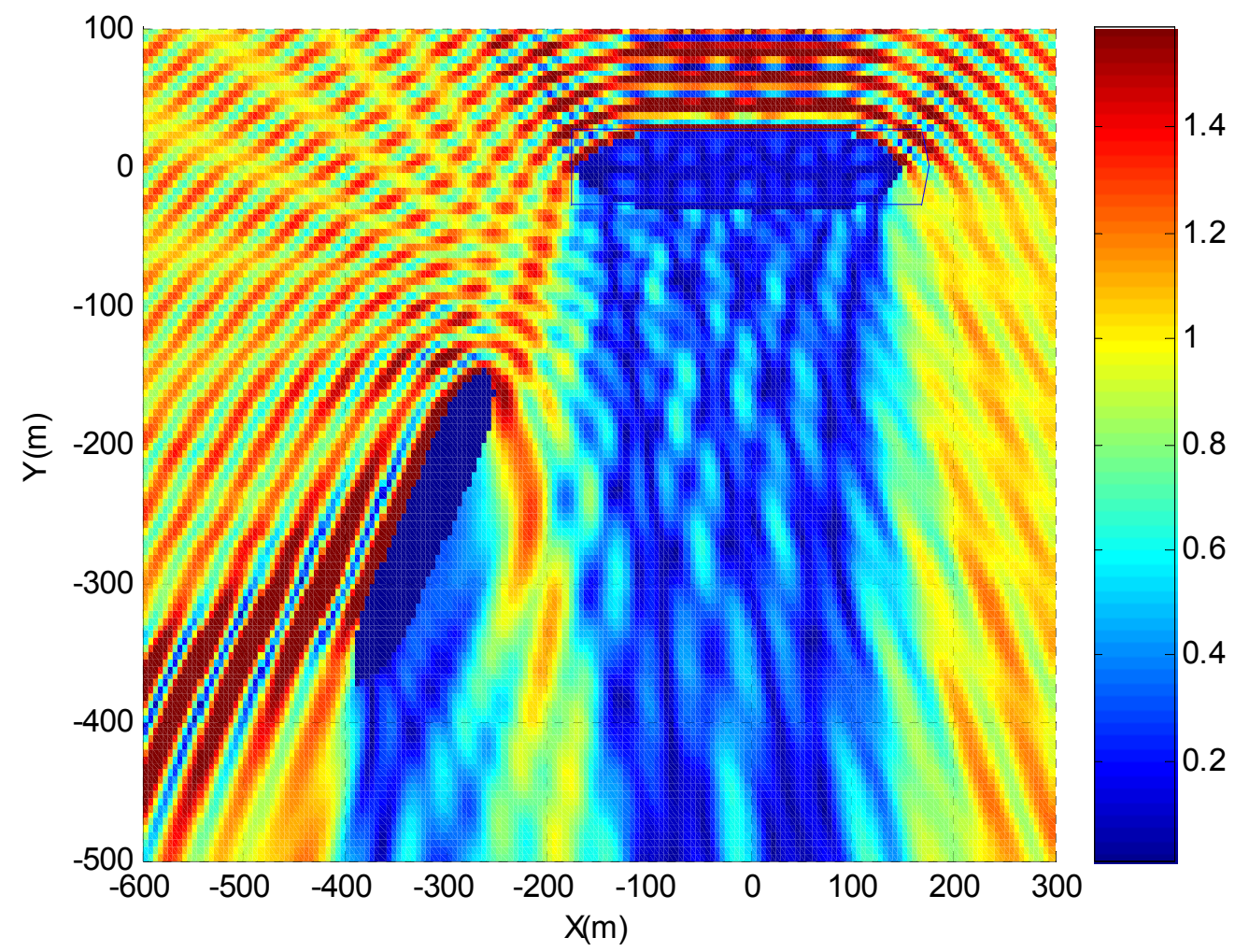

Figura 24 - Mapa de elevação de onda considerando a influência do navio aliviador para incidência de $\mathbf{2 7 0}^{\circ}$, 5 s de período (regular) e d=160m. 
Para os períodos de $7 \mathrm{a}$ 11s, um fenômeno a princípio não esperado, é observado. A potência gasta pelo sistema DP com efeito de sombra é maior que a obtida pela simulação quando o efeito de sombra é desprezado. Neste caso dimensionando o sistema DP pelo procedimento padrão resultaria em uma subestimação da potência total necessária. A Figura 25 mostra que o navio aliviador está em uma região onde o campo de onda está amplificado por um fator de aproximadamente 1,2 devido à presença do FPSO. Todos os mapas de elevação de onda podem ser encontrados no apêndice $A$.

Pode-se concluir para este caso, que para a fase de transferência de petróleo $(d=160 m)$, sob condições de onda de $H_{s}=3,0 m$ e $T_{p}$ de 7 a $11 \mathrm{~s}$, o efeito de sombra aumenta a potência necessária ao sistema DP em até 146 $\mathrm{kW}$. Durante a fase de conexão $(\mathrm{d}=80 \mathrm{~m})$ estas diferenças aumentam para 290 kW. Os erros de simulação em relação à simulação sem efeito de sombra são de $5,9 \%$ e $11,7 \%$ respectivamente.

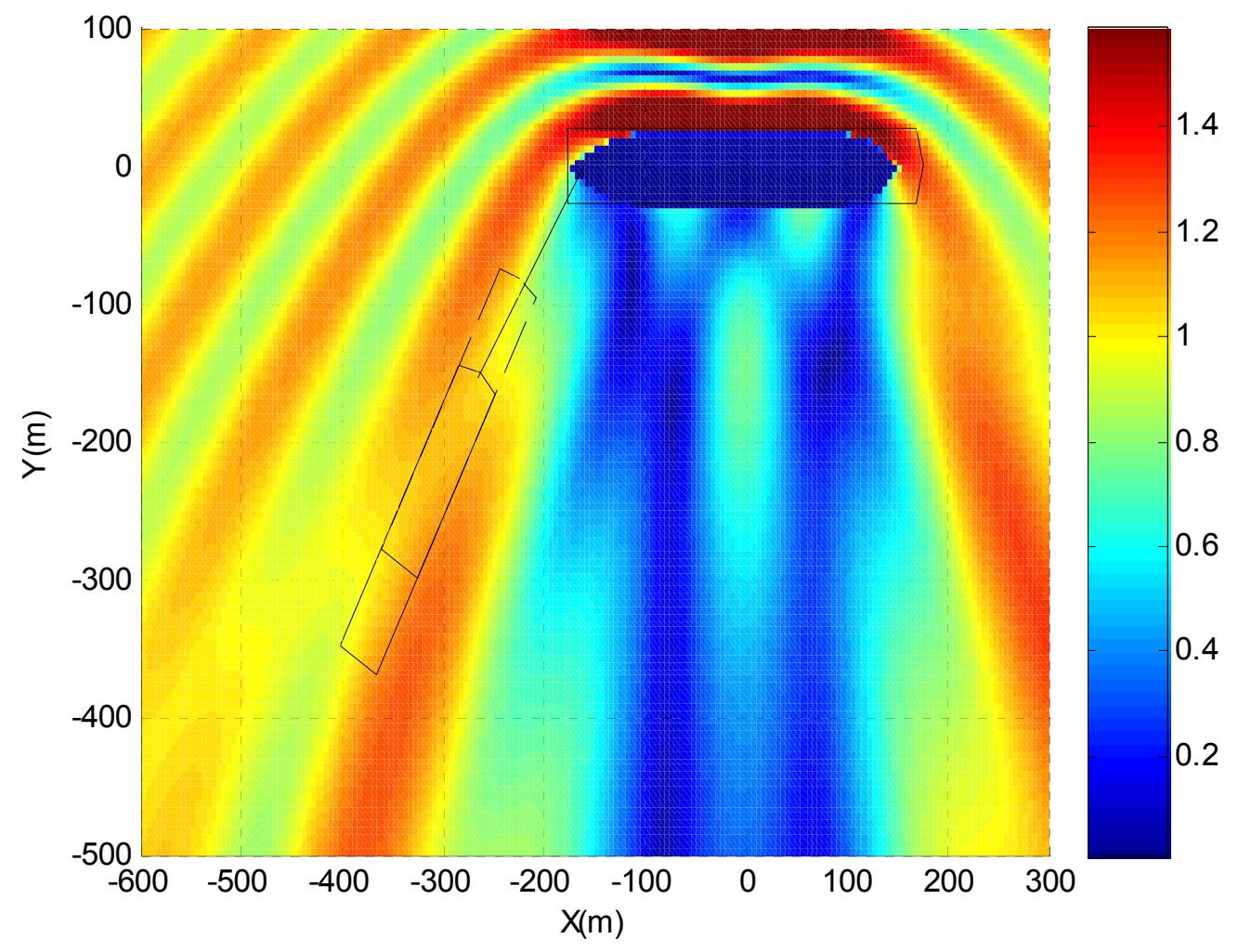

Figura 25 - Mapa de elevação de onda não considerando a influência do navio aliviador para incidência de $270^{\circ}$ e 9 s de período (regular).

Será considerada a potência total do sistema DP de $8000 \mathrm{~kW}$ (soma das potencias dos propulsores, excetuando-se o propulsor principal) para o cálculo 
das diferenças percentuais (Figura 17). O motivo disto é que o propulsor principal não contribui com esforços laterais que são os mais significativos para os casos críticos. Portanto, as diferenças encontradas, quando se considera ou não o efeito de sombra, representam 3,6\%, no pior caso, da potência instalada. O dimensionamento da potência do sistema DP normalmente é feito baseado em dados provenientes de uma análise estática, usando modelos hidrodinâmicos simples. Para corrigir efeitos não modelados e efeitos dinâmicos, a potência calculada é aumentada em $20 \%$. Os resultados obtidos por esta análise mostram que parte desta potência extra pode ser consumida devido à amplificação da onda gerada pelo efeito de sombra não modelado.

Figura 26 mostra a potência média total para incidência de onda de $240^{\circ}$. Este é o caso em que a direção da onda incidente sobre o navio aliviador é de $180^{\circ}$ (proa).

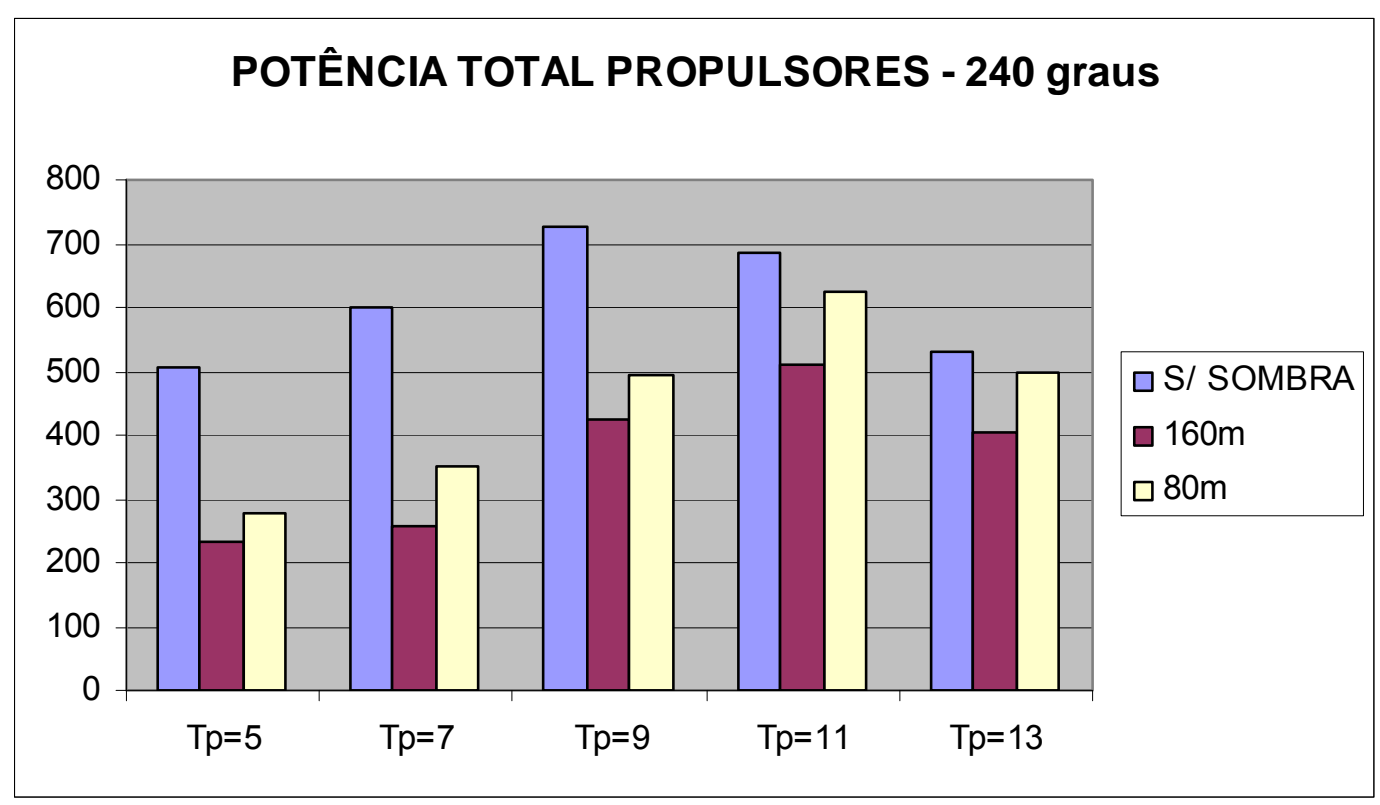

Figura 26 - Potência total do sistema DP para Hs=3,0m e incidência de $240^{\circ}$

É interessante notar que para simulação sem efeito de sombra, há um pico na potência do sistema DP por volta do período de 9s. Este fenômeno coincide com um máximo nos coeficientes de deriva de surge (Figura 27) do navio aliviador. 


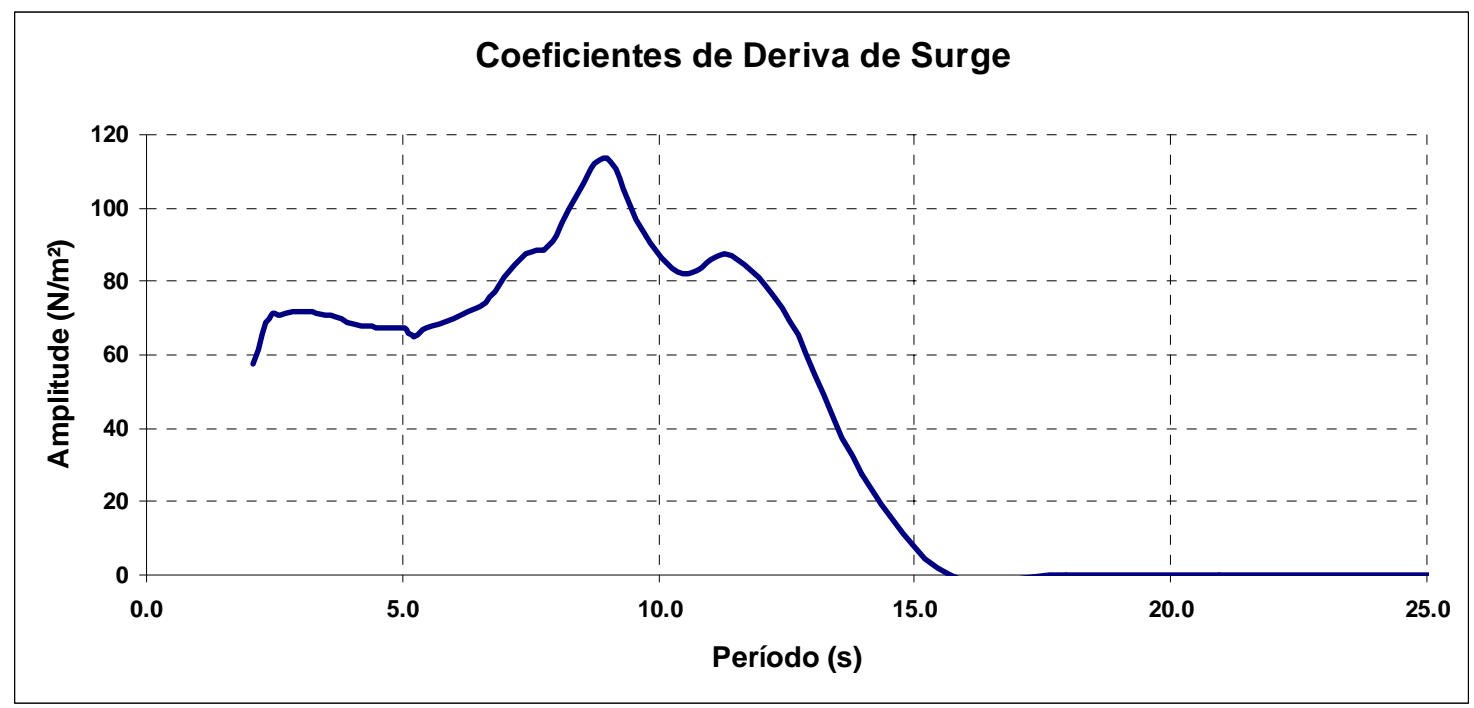

Figura 27 - Coeficientes de deriva de surge do navio aliviador para incidencia de $180^{\circ}$

Para todos os períodos de onda, a potência obtida pela simulação com efeito de sombra é menor que a obtida quando o efeito de sombra não é considerado. Neste caso dimensionando o sistema DP pelo procedimento padrão resultaria em uma potência superestimada.

A diferença máxima é de $341 \mathrm{~kW}$ para a fase de transferência de petróleo e $248 \mathrm{~kW}$ para a fase de conexão com o FPSO. Os máximos erros de simulação, por não se considerar o efeito de sombra são de 57,9\% e 44,8\% respectivamente. Considerando uma configuração de um sistema DP típica para um navio aliviador (Figura 17), estas diferenças representam aproximadamente $4,3 \%$ da potência total instalada no pior caso.

As Figura 28 e Figura 29 mostram que o navio aliviador está na fronteira da zona de sombra gerada pela FPSO. 


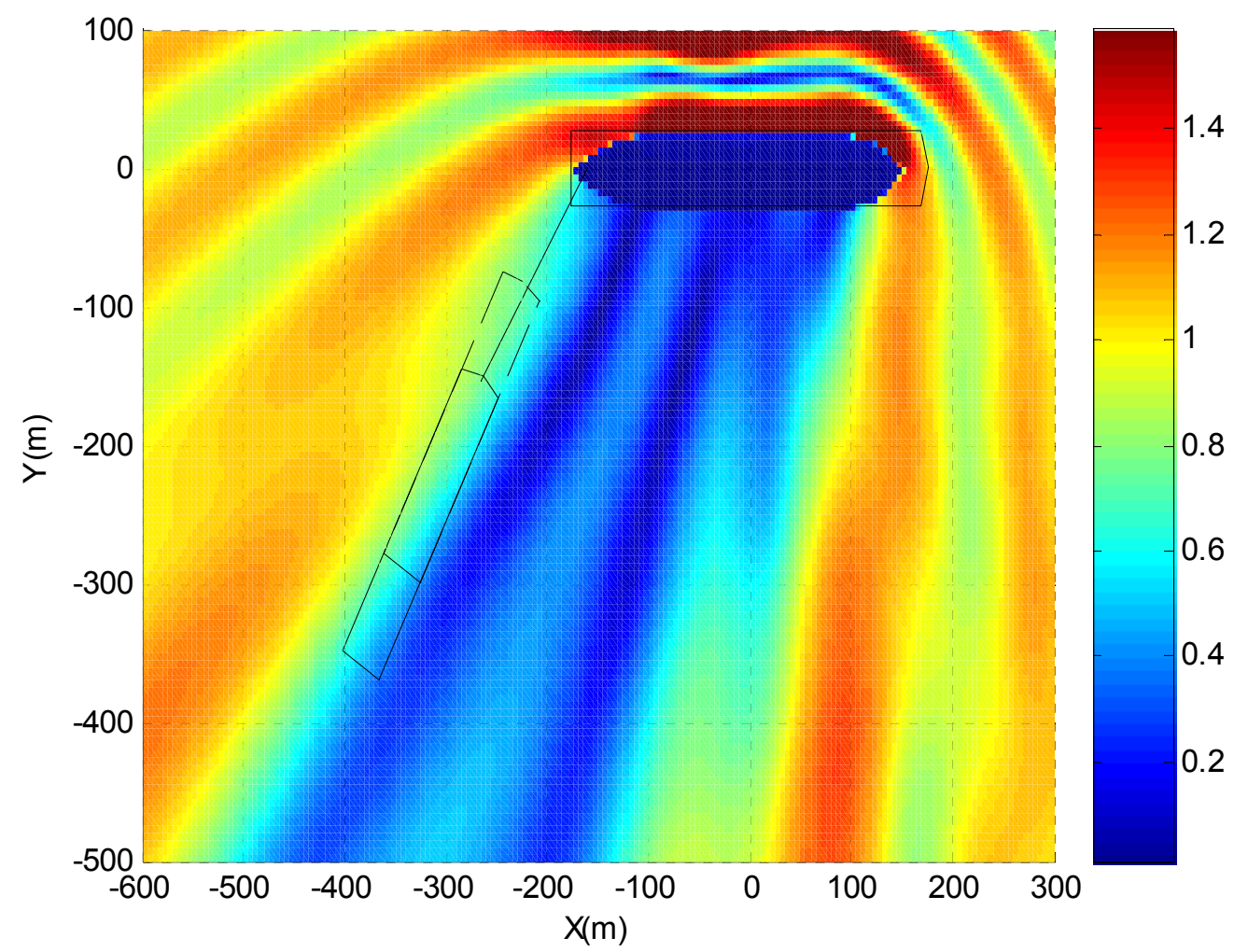

Figura 28 - Mapa de elevação de onda não considerando a influência do navio aliviador para incidência de $240^{\circ}$ e 9 s de período (regular).

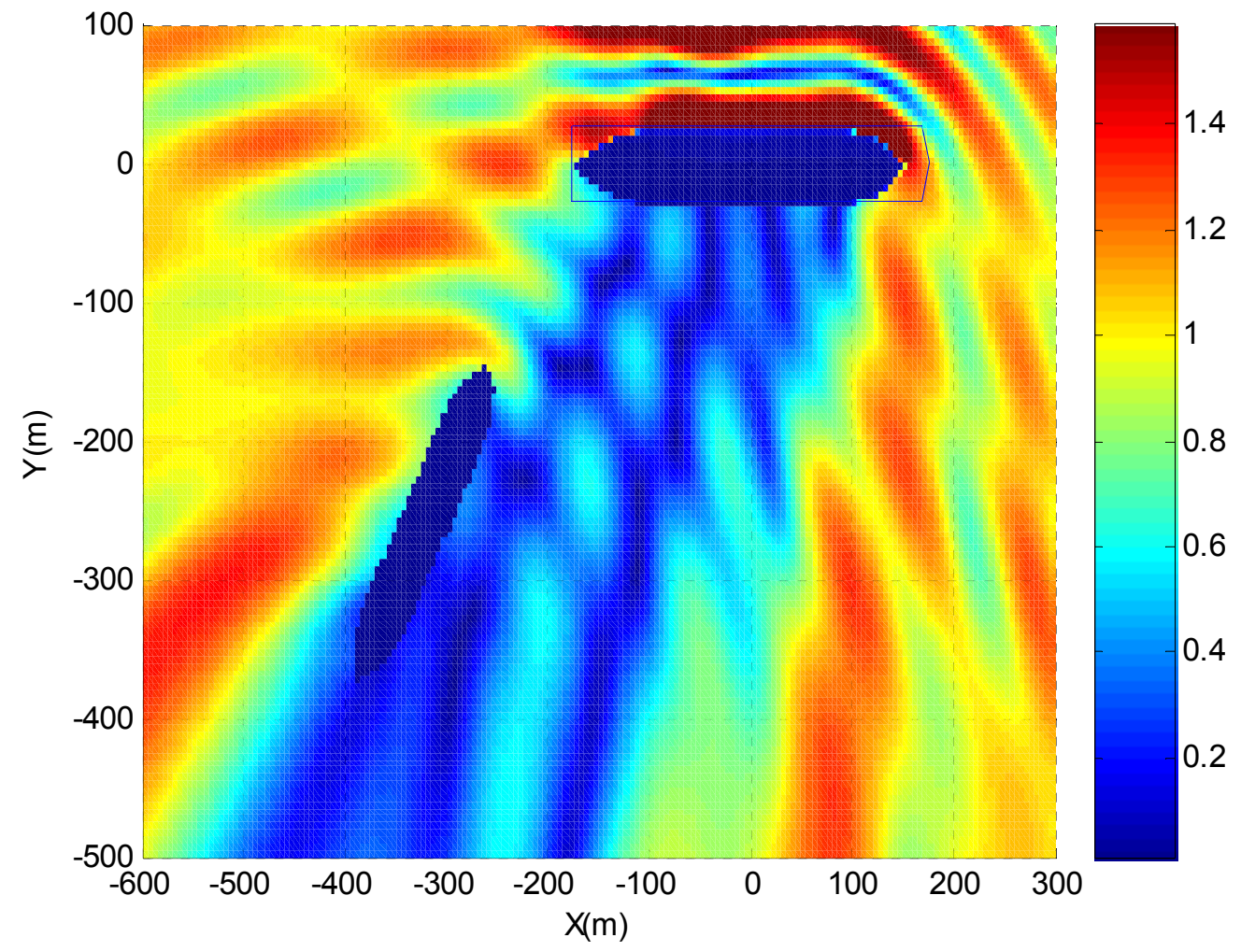

Figura 29 - Mapa de elevação de onda considerando a influência do navio aliviador para incidência de $240^{\circ}$, 9 s de período (regular) e d=160m. 
Para este caso foi observado também que ao se comparar os dois casos onde a sombra é considerada $(80 \mathrm{~m}$ e $160 \mathrm{~m})$, há um aumento substancial da potência quando o navio aliviador se aproxima do FPSO, o que aparentemente é incoerente com o fato de o navio aliviador estar se adentrando mais intensamente à zona de sombra induzida pelo FPSO.

Isto pode ser explicado devido ao fato de que incidência de onda de $240^{\circ} \mathrm{em}$ relação ao FPSO é o caso em que a onda incide sobre o navio aliviador exatamente de proa (incidência relativa de $180^{\circ}$ ). Esta é a condição de mínima energia no sistema DP, pois é a condição em que há menor força total de deriva. Porém quando o efeito de sombra é considerado, a presença do FPSO distorce o campo de onda ao redor, não garantido mais que a onda incidente sobre o navio aliviador seja exatamente de proa. Portanto, à medida que o navio aliviador se aproxima do FPSO mais distorcido fica o campo de ondas, pois mais intensa é a onda irradiada pelo FPSO.

Apenas para ilustrar a grande sensibilidade da potência requerida do Sistema DP para incidência de onda próxima a $180^{\circ}$, realizaram-se simulações para ondas de $\mathrm{Hs}=3,0 \mathrm{~m}$ e $\mathrm{Tp}=11 \mathrm{~s}$, com incidências de $180^{\circ}$ (proa) e $190^{\circ}\left(10^{\circ}\right.$ de incidência com a proa), não considerando a sombra. Para o primeiro caso, a potência total obtida foi de $686 \mathrm{~kW}$ (Figura 26), e para o segundo caso a potência apresenta um aumento expressivo, alcançando 1050kW. Para o caso de período $T p=13 \mathrm{~s}$, o aumento é de $510 \mathrm{~kW}$ para $770 \mathrm{~kW}$, também bastante expressivo.

A Figura 30 mostra a potência DP média total para incidência de onda de $210^{\circ}$. Neste caso o navio aliviador está posicionado praticamente no meio da região de sombra como mostram as Figura 31 e Figura 32. Devido a este fato, é verificada uma redução acentuada da potência requerida do sistema DP comparando as simulações com e sem efeito de sombra. As diferenças atingem $2145 \mathrm{~kW}$ para a fase de transferência de petróleo e $2565 \mathrm{~kW}$ para a fase de conexão. Os erros de simulação chegam a $77,3 \%$ se a simulação não considera o efeito de sombra. Isto representa $32 \%$ da potência instalada. 


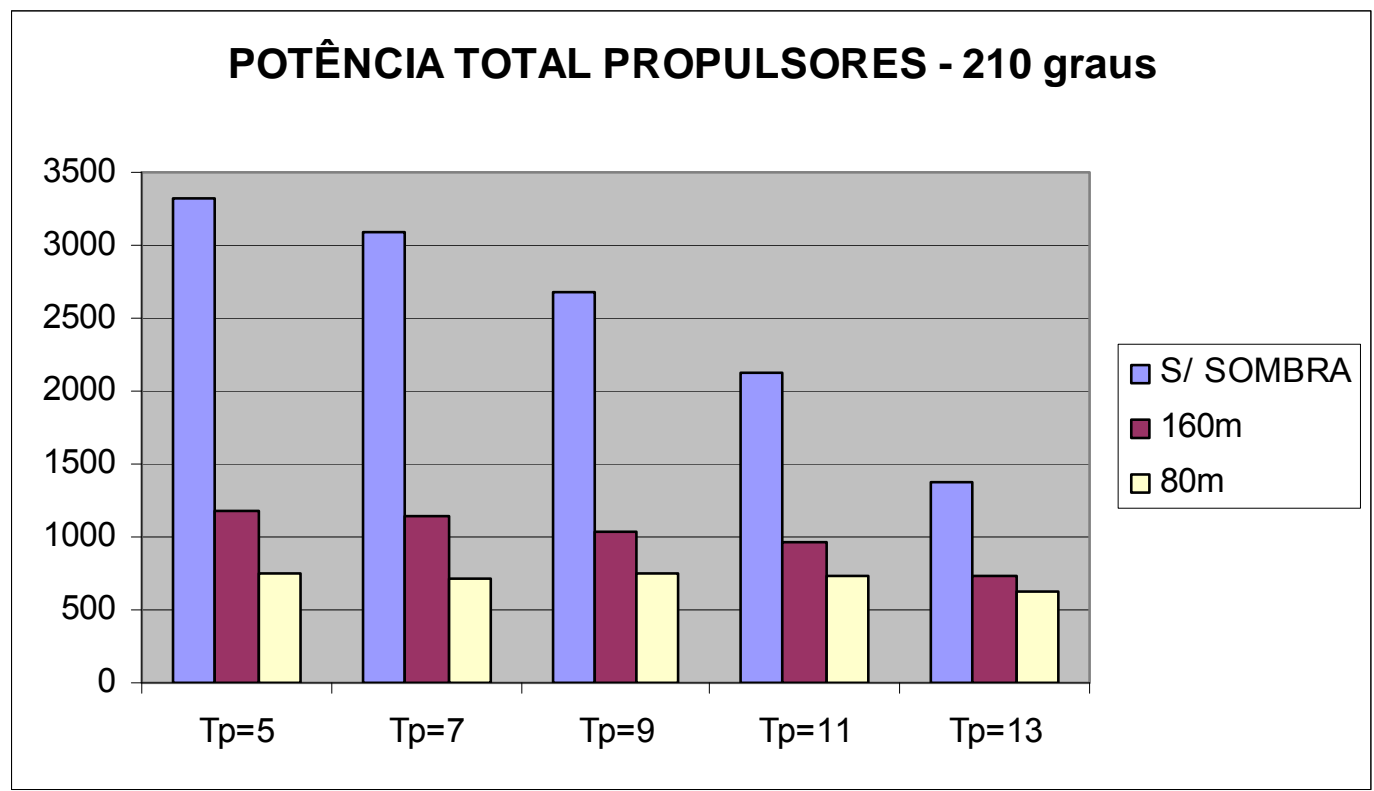

Figura 30 - Potência total do sistema DP para Hs=3.0m e incidência de $210^{\circ}$.

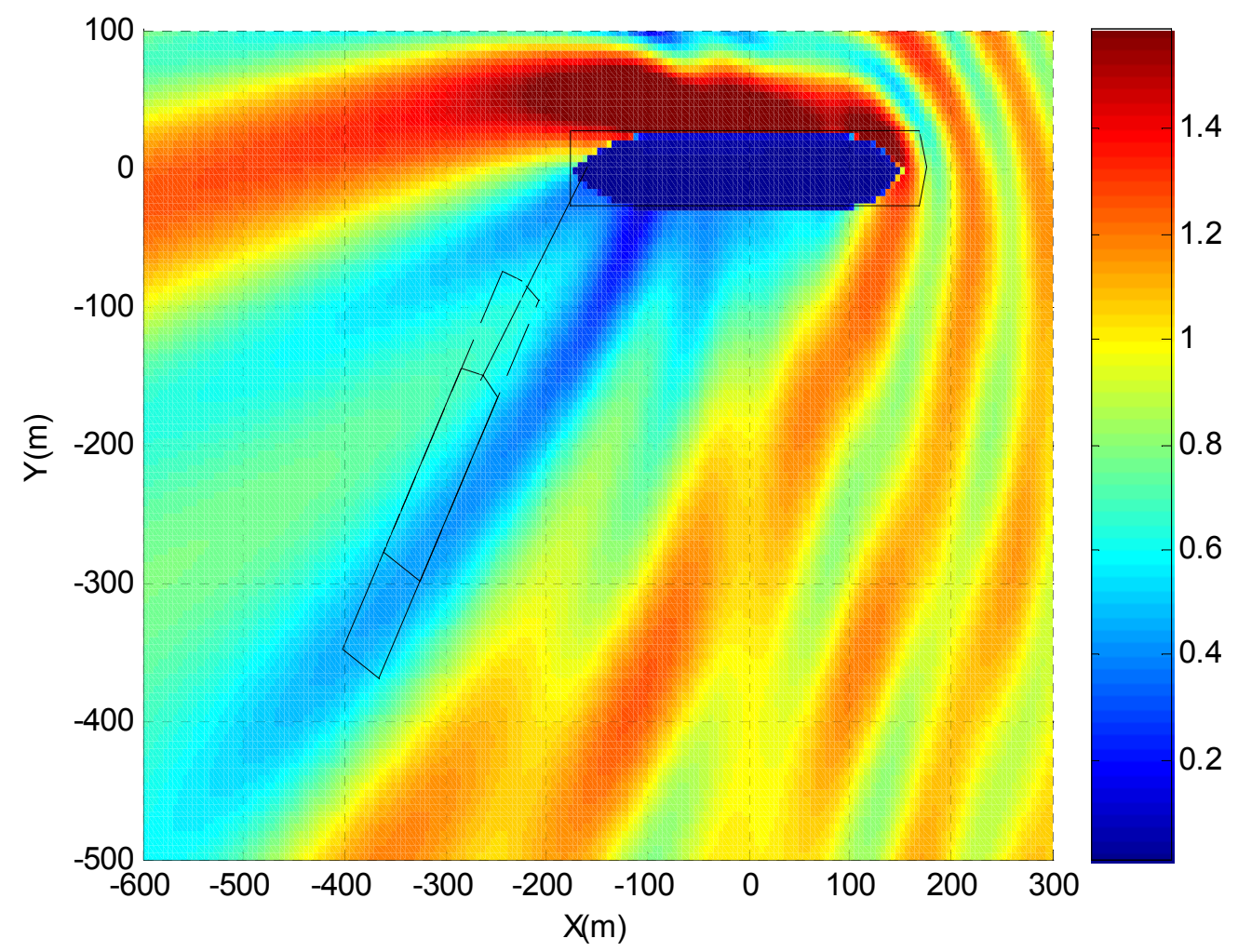

Figura 31 - Mapa de elevação de onda não considerando a influência do navio aliviador para incidência de $210^{\circ}$ e 9s de período (regular). 


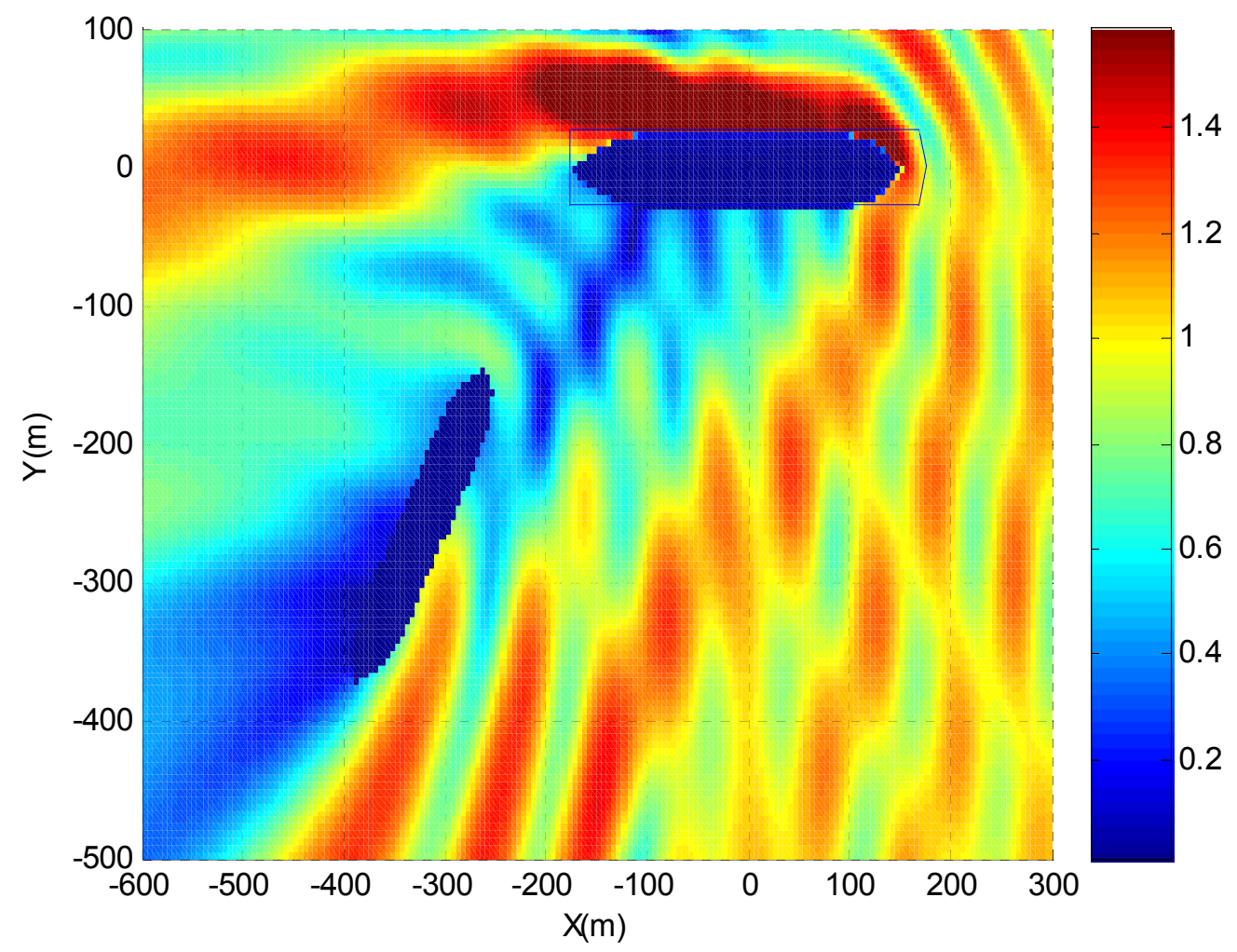

Figura 32 - Mapa de elevação de onda considerando a influência do navio aliviador para incidência de $210^{\circ}, 9$ s de período (regular) e d=160m. 


\subsubsection{FPSO carregado e navio aliviador em condição de lastro com altura significativa de onda mais provável para cada período simulado}

A seguir serão apresentados os resultados para altura significativa de onda mais provável considerando o FPSO carregado e o navio aliviador em condição de lastro. A Figura 33 mostra a potência média total do sistema DP para incidência de $270^{\circ}$.

Como no caso de $\mathrm{H}_{\mathrm{s}}=3,0 \mathrm{~m}$, a simulação sem efeito de sombra resulta em uma maior potência necessária ao sistema DP, com uma diferença de até $52,3 \mathrm{~kW}$ para a fase de transferência de petróleo e 78,2 kW para a fase de conexão com o FPSO. Os máximos erros de simulação são 7,3\% e 11,0\% respectivamente. Considerando uma configuração de um sistema DP típica para um navio aliviador (Figura 17), estas diferenças representam aproximadamente $1,0 \%$ da potência total instalada no pior caso.

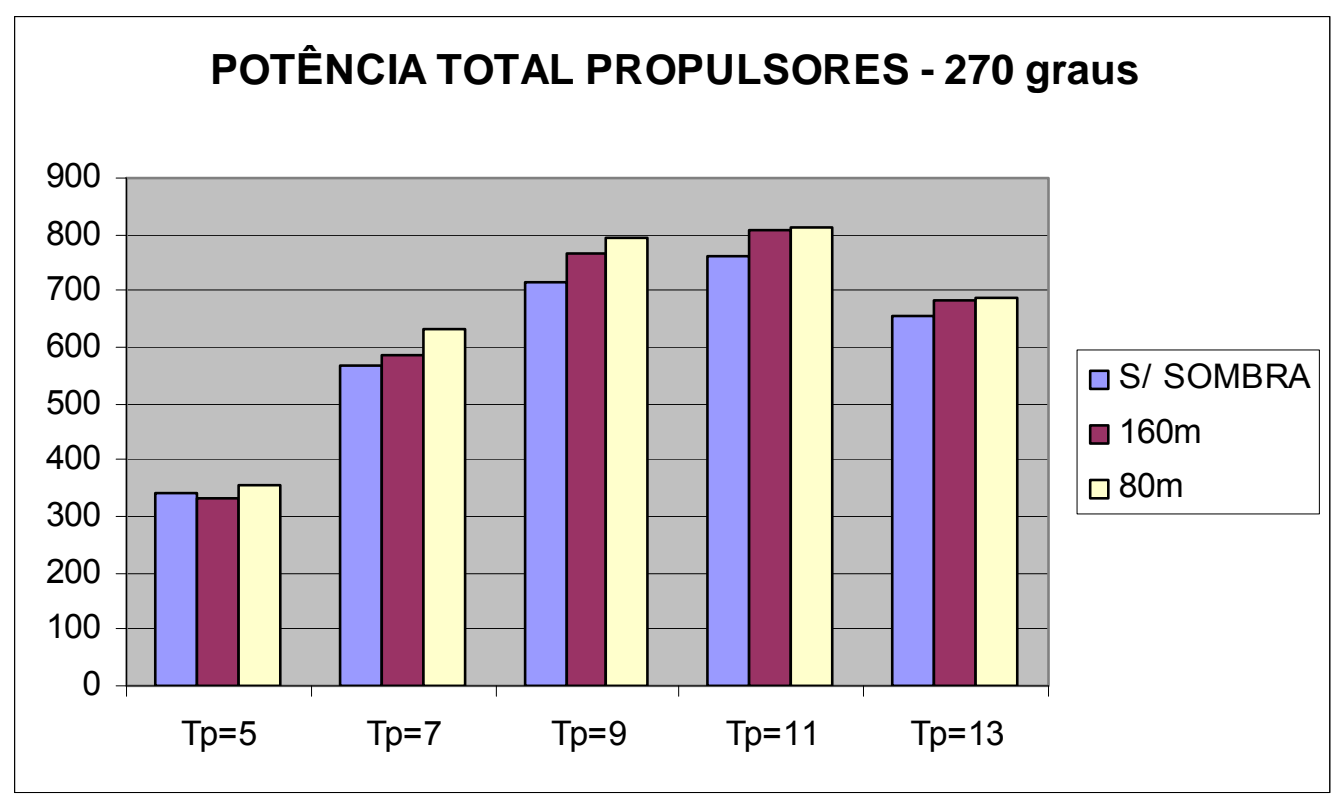

Figura 33 - Potência total do sistema DP para Hs variável e incidência de $270^{\circ}$.

A Figura 34 mostra a potência média total do sistema DP para incidência de $240^{\circ}$. Para este caso, durante a fase de transferência de petróleo $(\mathrm{d}=160 \mathrm{~m})$, o efeito de sombra reduz a potência necessária ao sistema DP em até $86,5 \mathrm{~kW}$. Durante a fase de conexão $(\mathrm{d}=80 \mathrm{~m})$ estas diferenças caem para $68,0 \mathrm{~kW}$. Os erros de simulação em relação à simulação sem efeito de sombra são de 
$43,0 \%$ e $33,8 \%$ respectivamente. Estas diferenças representam 1,1\%, no pior caso, da potência instalada.

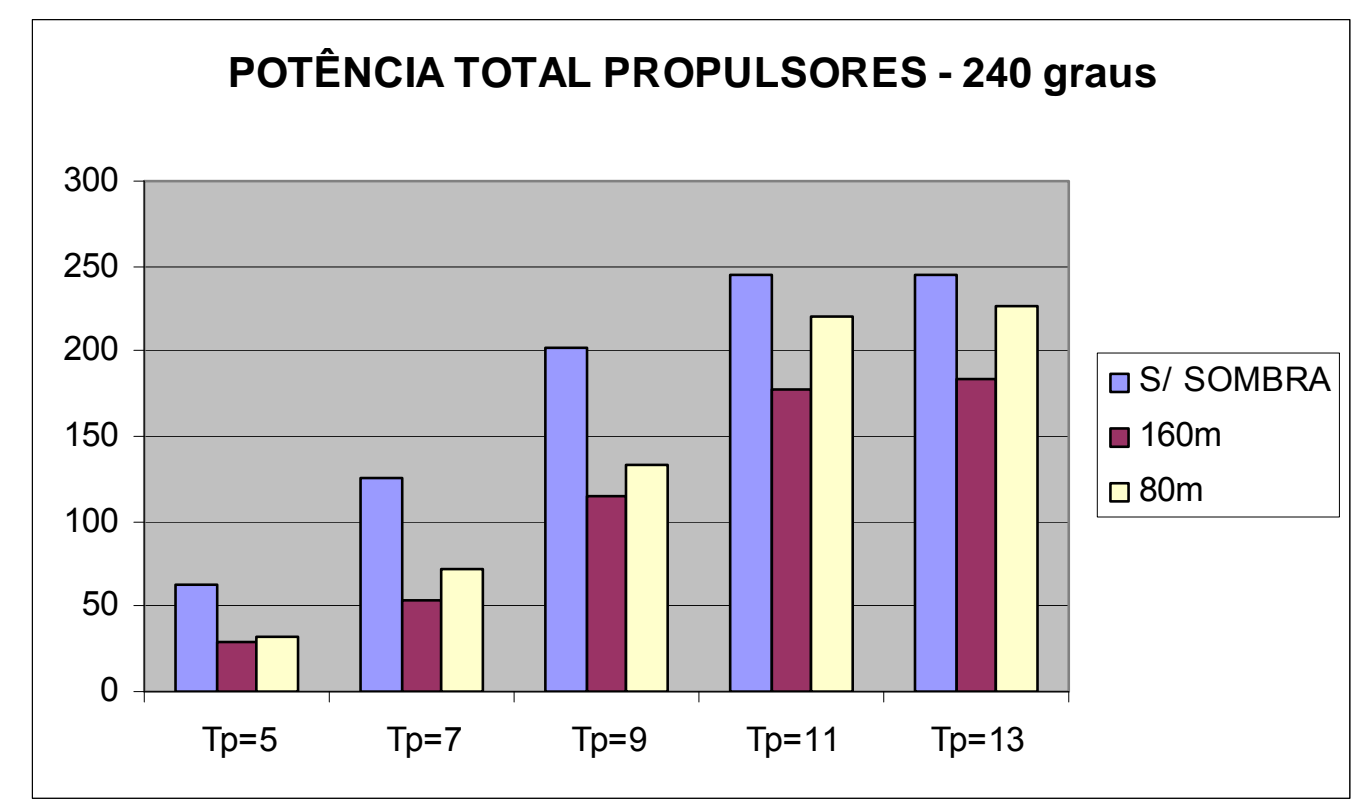

Figura 34 - Potência total do sistema DP para Hs variável e incidência de $240^{\circ}$.

A Figura 35 mostra a potência média total do sistema DP para incidência de $210^{\circ}$. Da mesma maneira que no caso com $\mathrm{H}_{\mathrm{s}}=3,0 \mathrm{~m}$ este é o caso em que o navio aliviador está posicionado no meio da região de sombra, portanto observa-se que há uma queda brusca na potência do sistema DP se comparado o caso com e sem sombra. As diferenças atingem $442 \mathrm{~kW}$ para a fase de transferência de petróleo e 529 kW para a fase de conexão. Os erros de simulação chegam a $60,0 \%$ e $71,8 \%$ respectivamente se a simulação não considera o efeito de sombra. Isto representa $6,6 \%$ da potência instalada. 


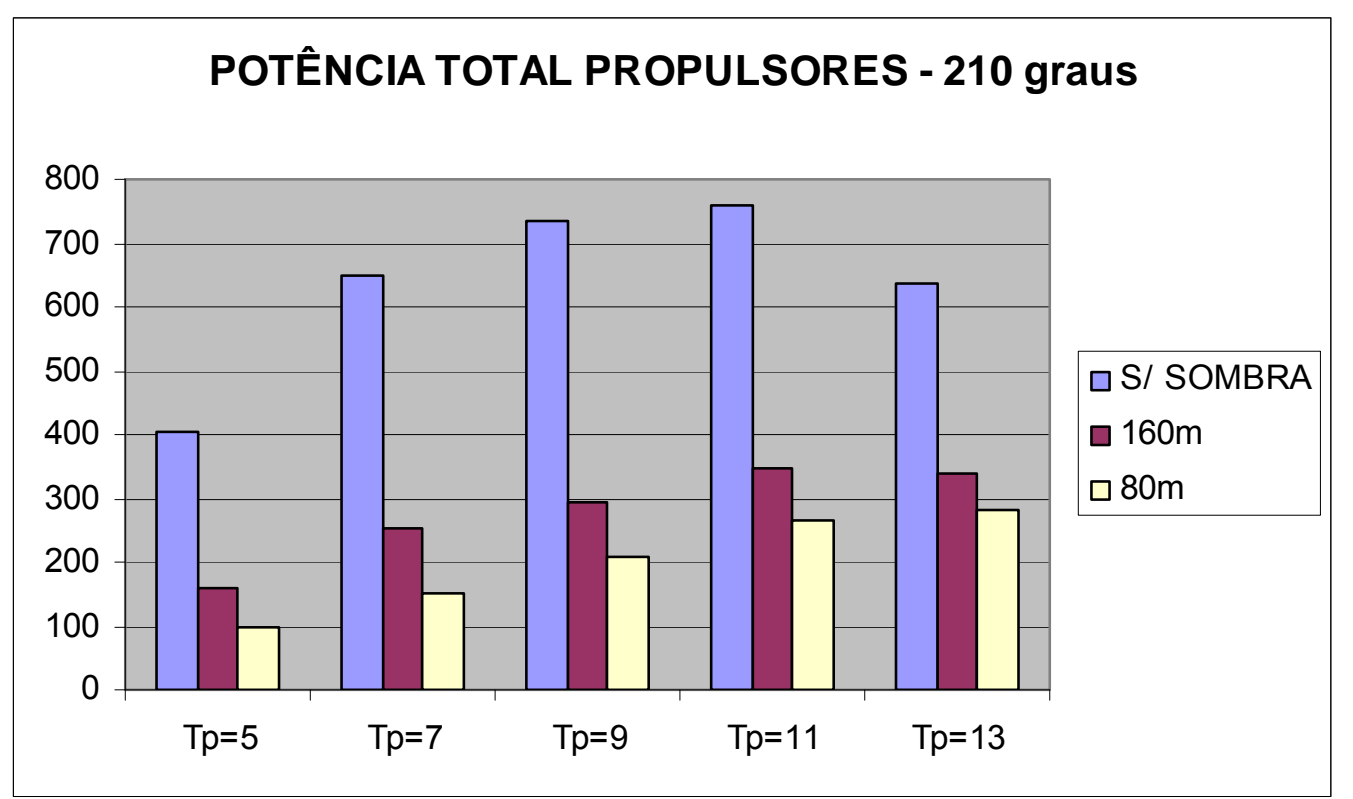

Figura 35 - Potência total do sistema DP para Hs variável e incidência de $210^{\circ}$. 


\subsubsection{FPSO em condição de lastro e navio aliviador carregado com altura significativa de onda mais provável para cada período simulado}

A seguir os resultados para o FPSO em condição de lastro e o navio aliviador cheio são mostrados. Para estes casos apenas a distância de 160m entre o navio aliviador e o FPSO é considerada, pois nesta situação o navio aliviador não se aproxima do FPSO para fazer conexão.

A Figura 36 mostra a potência total média do sistema DP para incidência de $270^{\circ}$. Pode-se observar que para este caso a diferença na potência total média comparando-se o caso com e sem sombra para períodos de 5 a 9 s é quase nenhuma. A Figura 37 mostra que o navio aliviador sofre pouca influência da região de sombra para esses períodos.

Já para os períodos de 11 e 13s observa-se um aumento considerável da potência requerida pelo sistema DP. A Figura 38 mostra que parte do navio aliviador encontra-se em uma região onde o mar é amplificado o que não ocorre para os períodos anteriores. Por isso é observado para esses períodos um aumento da potência no sistema DP. Para esta simulação, no pior caso a diferença de potência atinge 286 kW significando um erro de simulação de $36 \%$ ou $3,6 \%$ da potencia instalada.

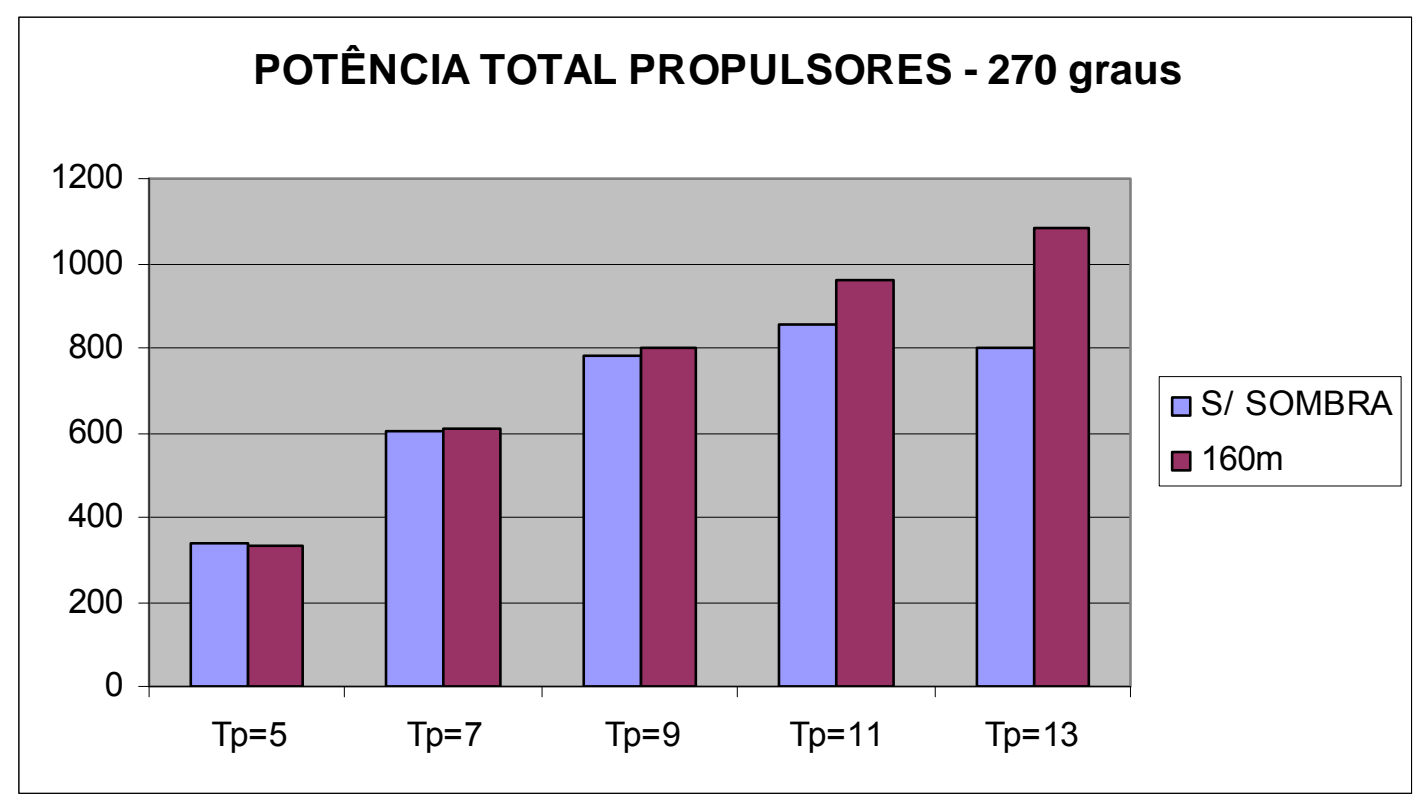

Figura 36 - Potência total do sistema DP para Hs variável e incidência de $210^{\circ}$. 


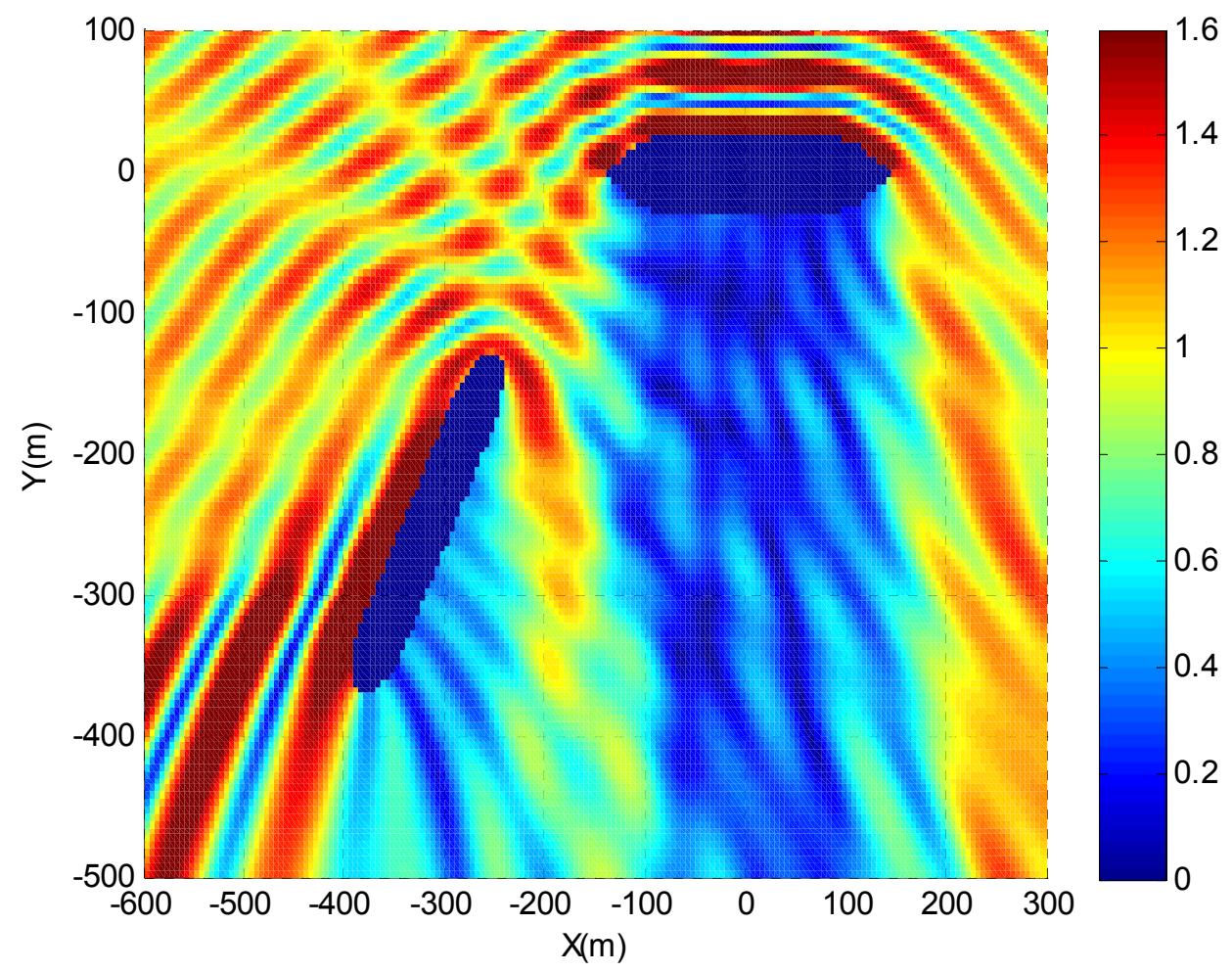

Figura 37 - Mapa de elevação de onda considerando a influência do navio aliviador para incidência de $270^{\circ}, 7 \mathrm{~s}$ de período (regular) e d=160m.

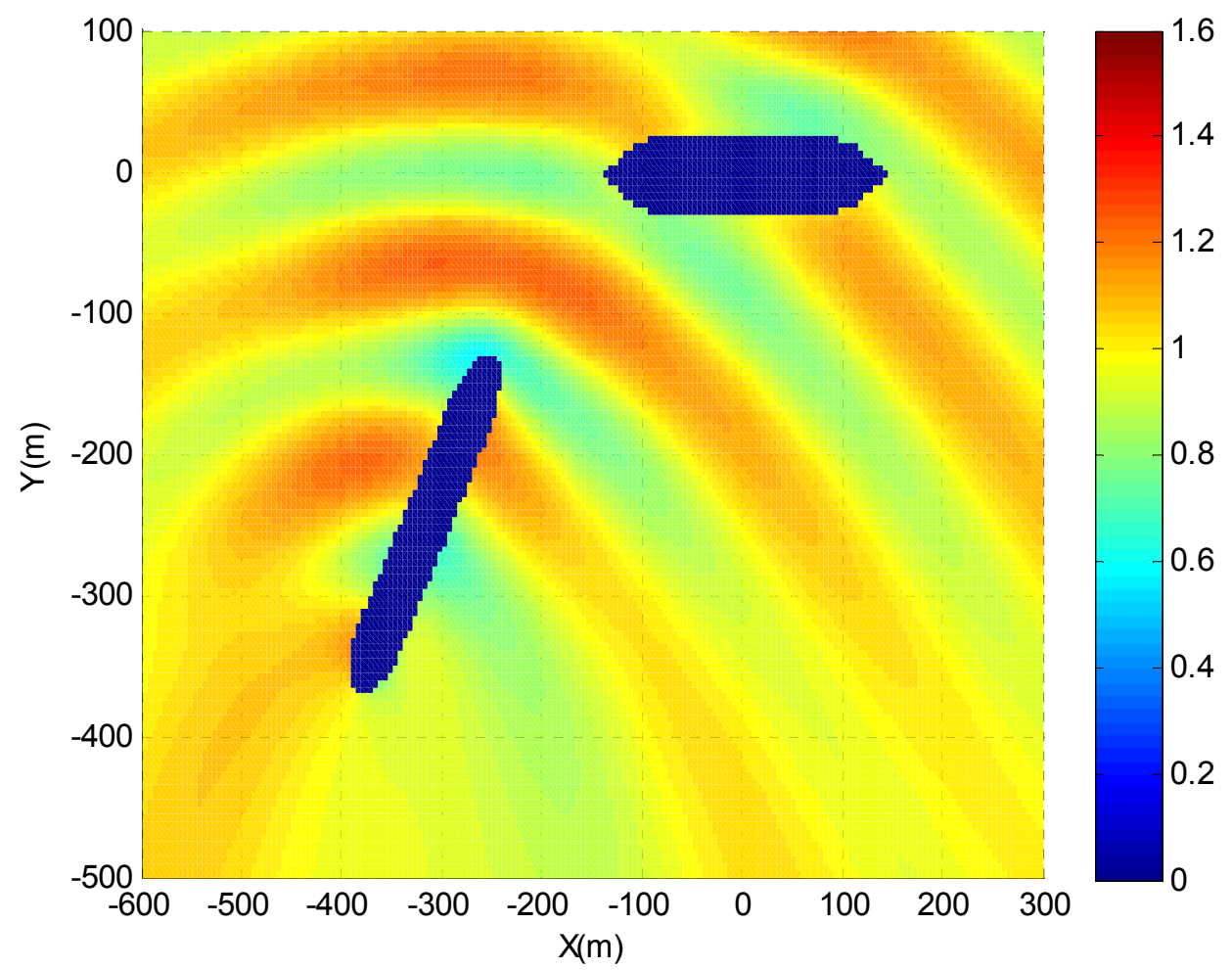

Figura 38 - Mapa de elevação de onda considerando a influência do navio aliviador para incidência de $270^{\circ}, 13$ s de período (regular) e d=160m. 
A Figura 39 mostra a potência total média no sistema DP para incidência de $240^{\circ}$. Comparando-se os casos com e sem sobra para os períodos de 5 a 11s é observado que há uma diminuição na potência do sistema DP quando o efeito de sombra é considerado. De fato a Figura 40 mostra que o navio aliviador já se encontra sob o efeito da zona de sombra produzida pelo FPSO.

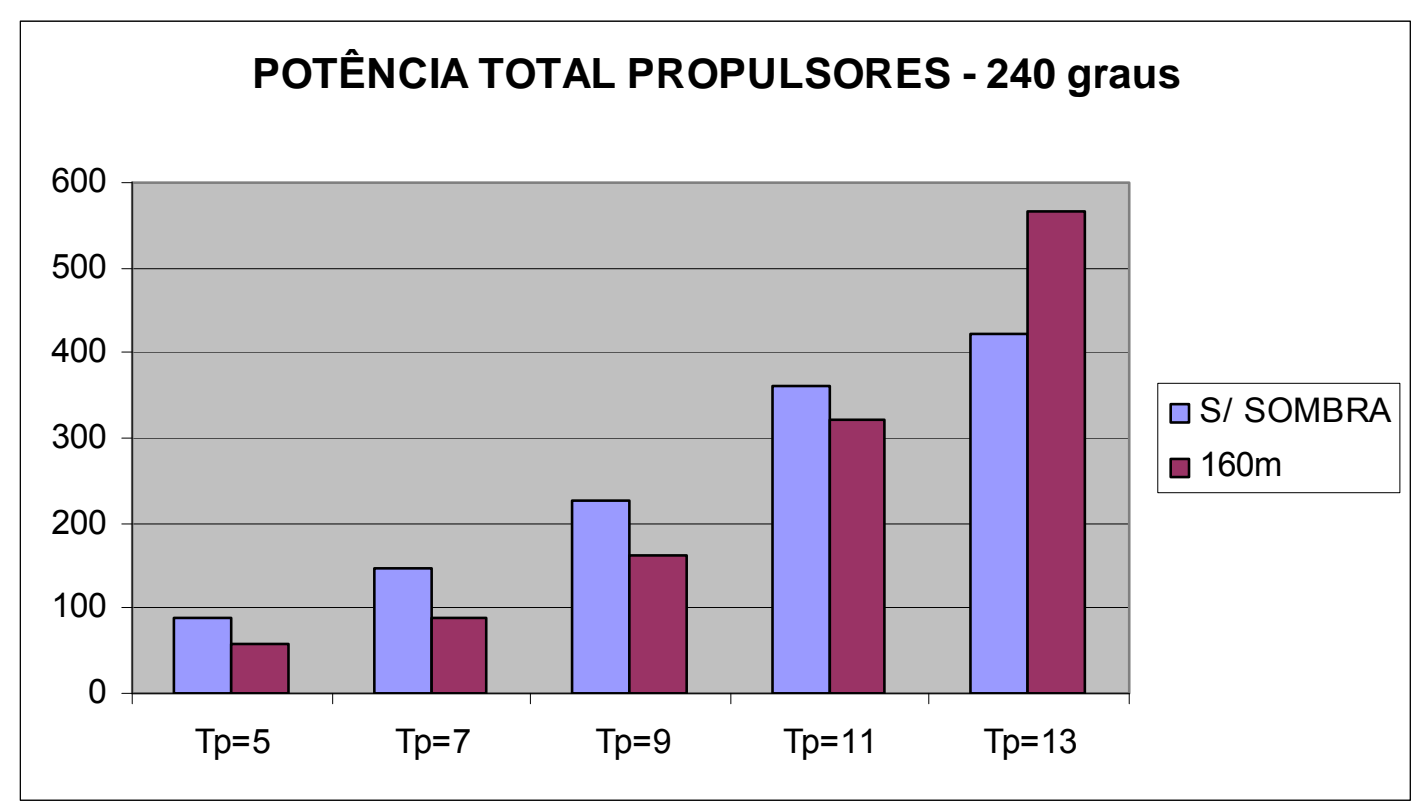

Figura 39 - Potência total do sistema DP para Hs variável e incidência de $240^{\circ}$.

Para período de 13s observa-se uma inversão. A simulação com efeito de sombra requer maior potência ao sistema DP do que a simulação sem efeito de sombra. Isso pode ser explicado pelo fato deste ser o caso em que a onda incide exatamente de proa no navio aliviador quando o efeito de sombra não é considerado. Portanto esta será a condição de mínima energia no sistema DP. No entanto, devido à presença do FPSO não há mais garantia de que a onda incida exatamente de proa no navio aliviador. Alia-se a isto, o fato de para período de $13 \mathrm{~s}$ a sombra produzida pelo FPSO ser muito pouco intensa. Aliás, ao observar-se a Figura 40 nota-se que parte do navio aliviador se encontra em uma região onde o mar está amplificado por um fator de aproximadamente 1,1. Por isso, somente é observado para este período um aumento na potência do sistema DP comparando o caso com e sem sombra. 
Para este caso a diferença na potência chega a 142 kW e o erro de simulação chega a $39,9 \%$, no pior caso. Isto representa $1,8 \%$ da potência instalada.

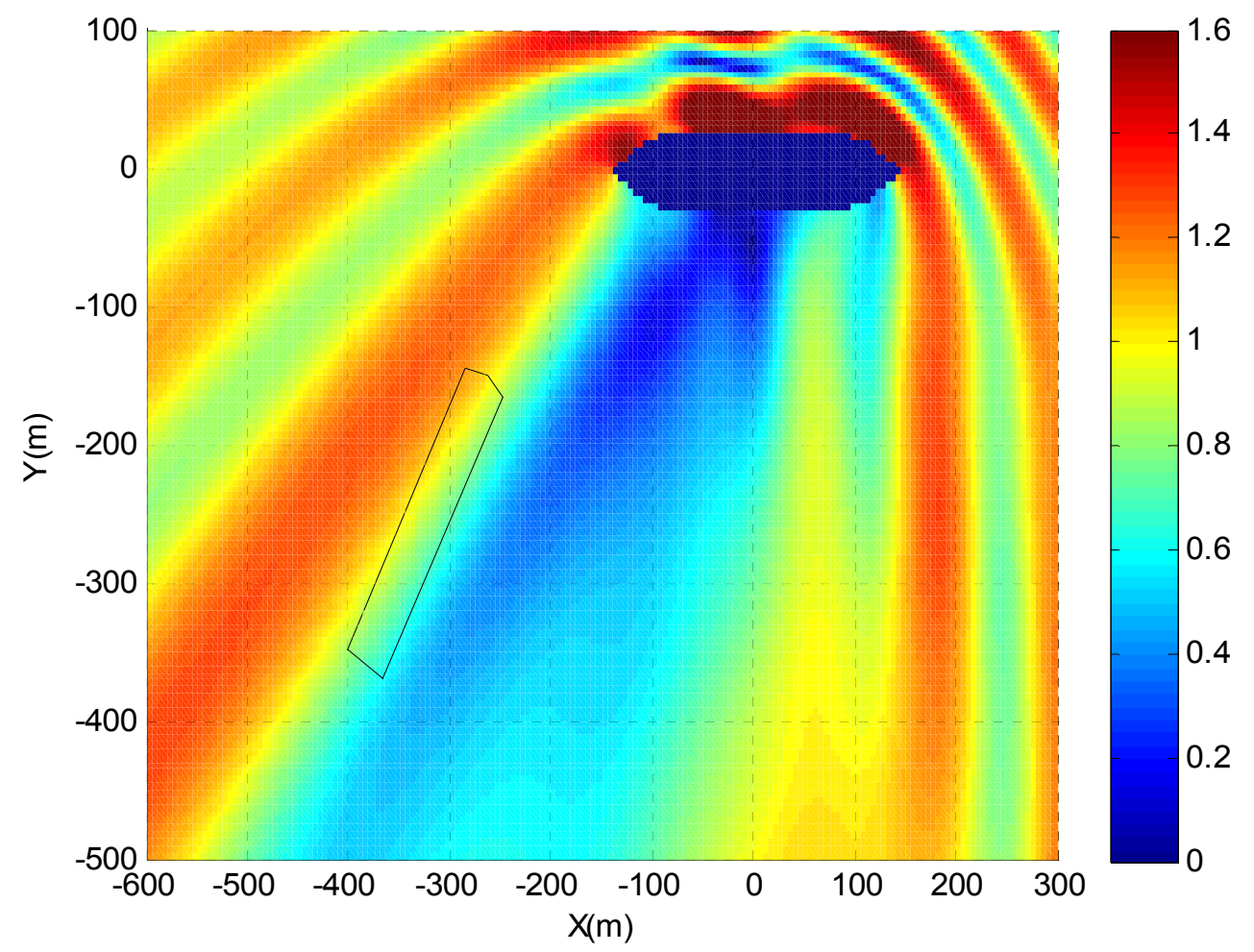

Figura 40 - Mapa de elevação de onda não considerando a influência do navio aliviador para incidência de $240^{\circ}$, 9s de período (regular) e d=160m. 


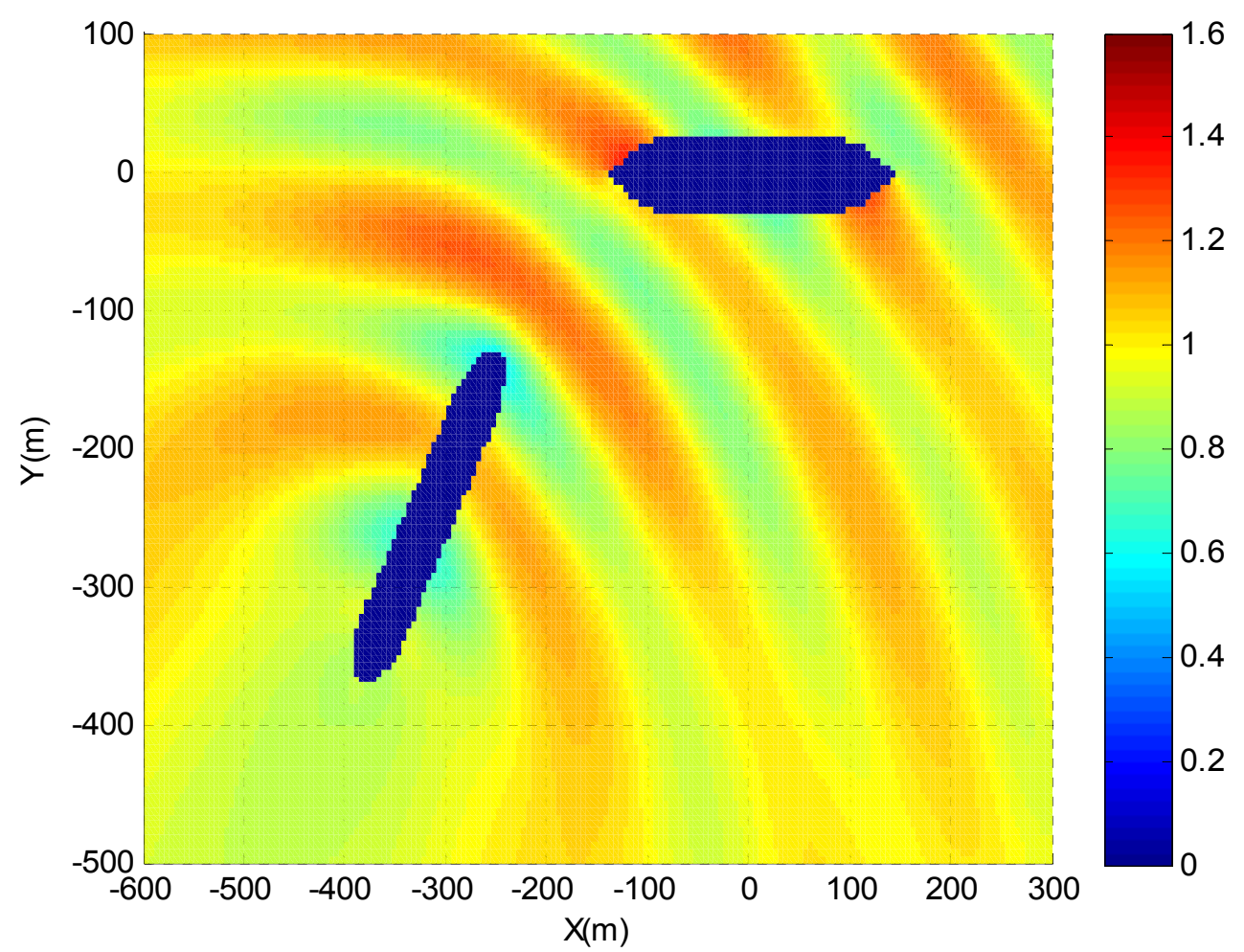

Figura 41 - Mapa de elevação de onda considerando a influência do navio aliviador para incidência de $240^{\circ}, 13$ s de período (regular) e d=160m.

A Figura 42 mostra a potência total no sistema DP para incidência de $210^{\circ}$.

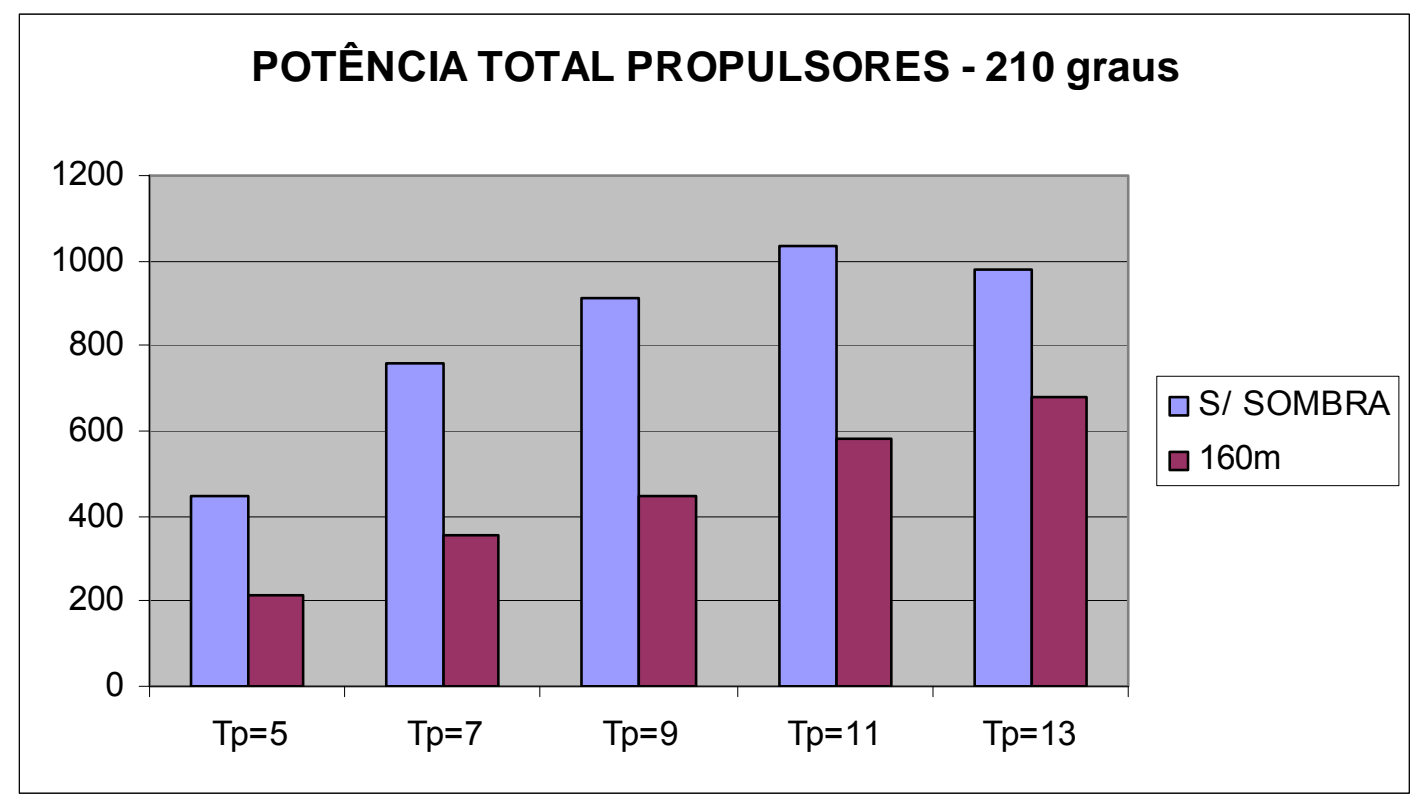

Figura 42 - Potência total do sistema DP para Hs variável e incidência de $240^{\circ}$. 
Para este caso o navio aliviador se encontra no meio da zona de sombra (Figura 43 e Figura 44), por isso é observada uma acentuada redução de potência no sistema DP. Para este caso a diferença de potência atinge os 465 kW e os erros de simulação chegam a $53 \%$ no pior caso. Isto representa $5,8 \%$ da potência total instalada.

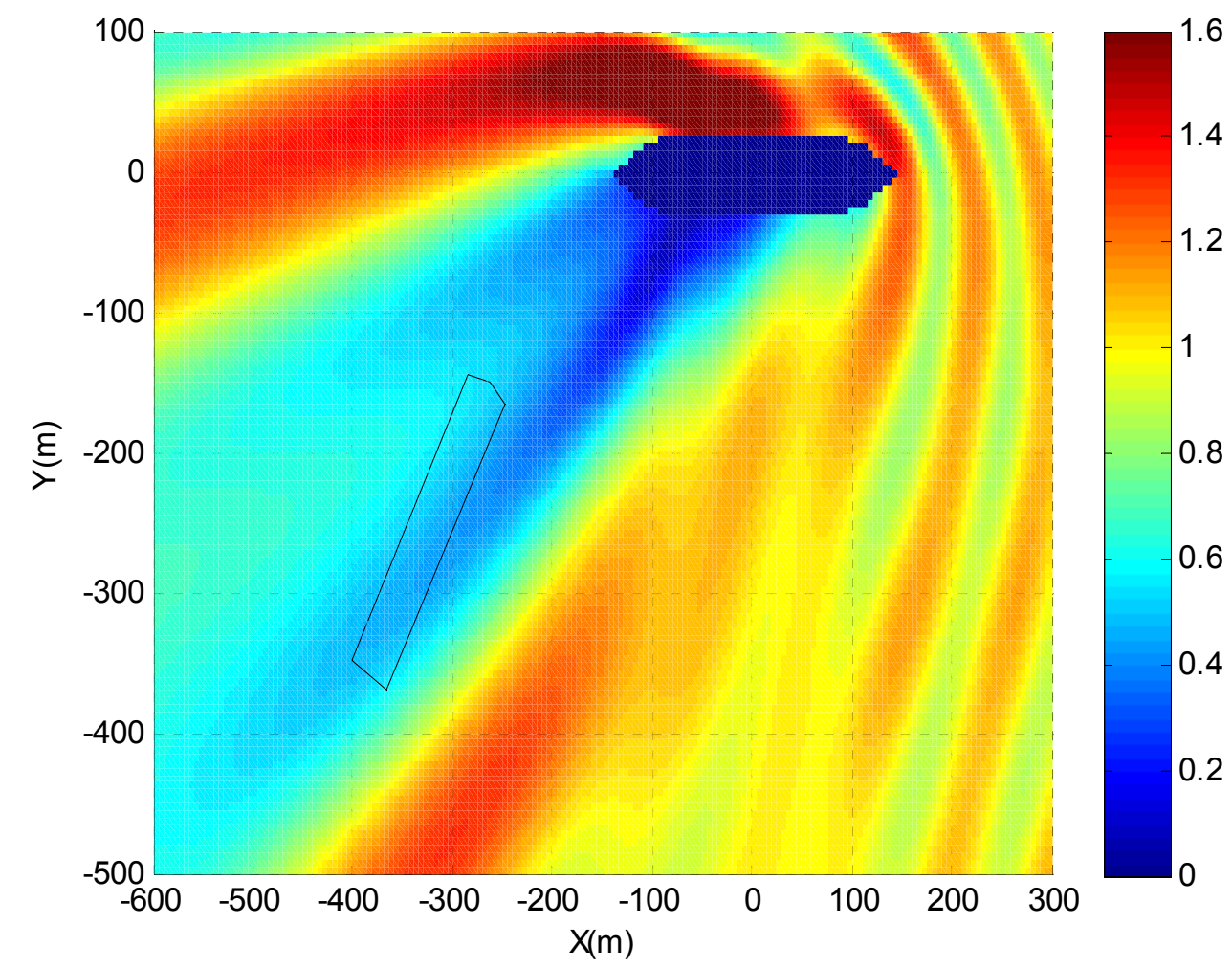

Figura 43 - Mapa de elevação de onda não considerando a influência do navio aliviador para incidência de $210^{\circ}$, 9 s de período (regular) e d=160m. 


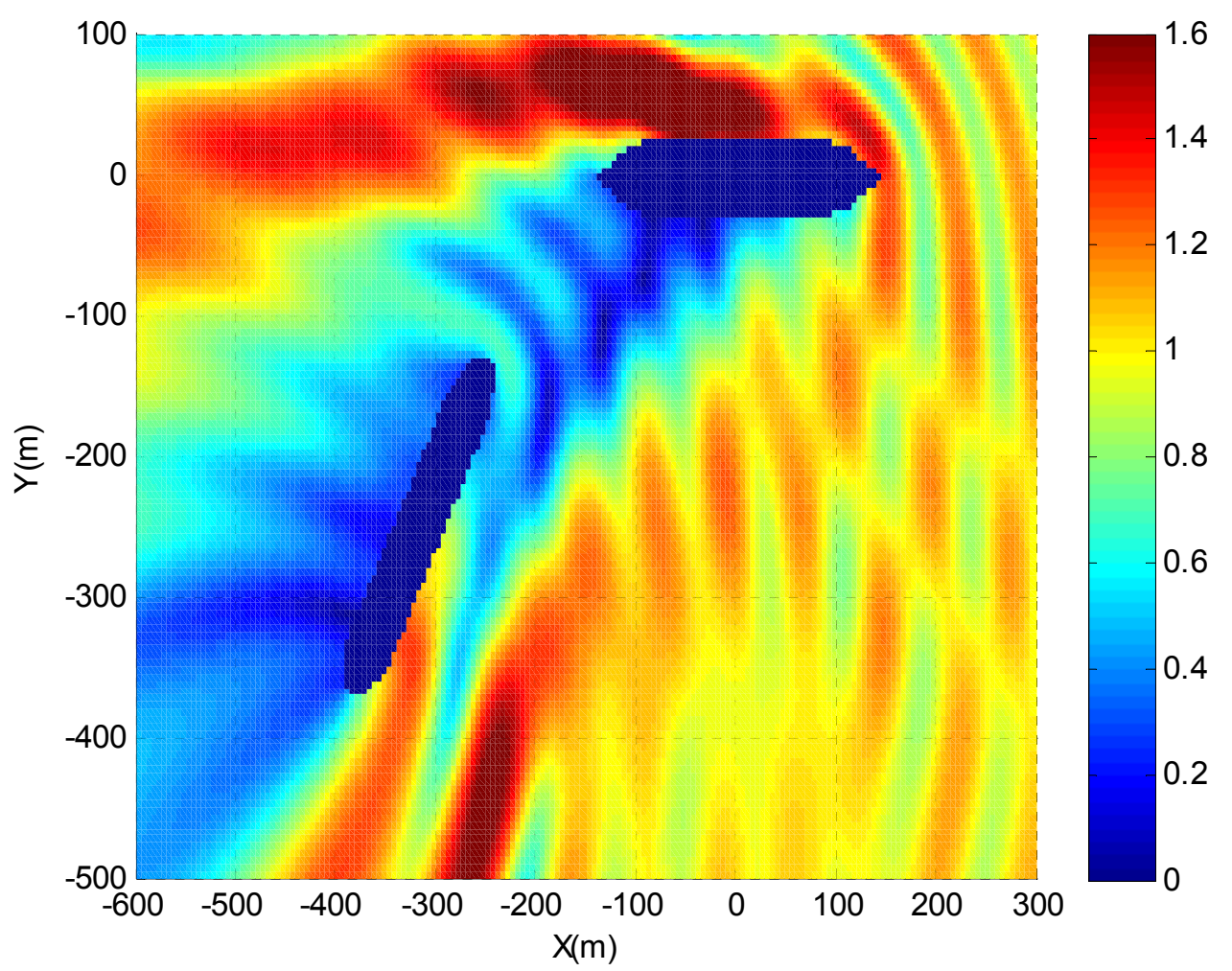

Figura 44 - Mapa de elevação de onda considerando a influência do navio aliviador para incidência de $210^{\circ}, 9$ s de período (regular) e d=160m. 


\subsubsection{Tabela resumo}

A seguir é apresentada para cada situação de carregamento, de forma resumida, a porcentagem relativa à potência instalada para o pior caso de cada incidência de onda.

Nesta tabela assume-se uma diferença positiva quando a potência obtida na simulação que leva em conta o efeito de sombra resulta um valor superior à simulação que não considera tal efeito. Esta situação equivale a casos em que o projeto e dimensionamento do sistema DP não será conservador no caso de se utilizar simulações convencionais.

Analogamente, valores negativos equivalem a casos em que a potência resultante da simulação com efeito de sombra é inferior à obtida quando não se leva em conta tal efeito. Nestes casos, o dimensionamento do sistema DP com métodos convencionais (que não levam em conta a sombra) é por demais conservador.

Tabela 4 - Porcentagem relativa a potencia instalada.

\begin{tabular}{|c|c|c|c|}
\hline FPSO / Navio Aliviador & $\mathbf{2 7 0 ^ { \circ }}$ & $\mathbf{2 4 0 ^ { \circ }}$ & $\mathbf{2 1 0}^{\circ}$ \\
\hline Cheio / Vazio & $+1,0 \%$ & $-1,1 \%$ & $-6,6 \%$ \\
\hline Vazio / Cheio & $+3,6 \%$ & $+1,8 \%$ & $-5,8 \%$ \\
\hline
\end{tabular}




\section{CONCLUSÃO}

Analisando os casos de simulação de operação de alívio DP em modo tandem foi observado que os resultados obtidos com e sem efeito de sombra são bem distintos.

Os resultados indicam que normalmente o efeito de sombra reduz a demanda por potência do sistema DP, se o navio aliviador estiver dentro da sombra. Neste caso, a simulação sem efeito de sombra subestima a potência necessária ao sistema DP. Considerando altura de onda mais provável para cada período simulado estas diferenças chegam a $6,6 \%$ da potência total instalada em um típico navio aliviador.

No entanto há regiões no entorno do FPSO onde há o aumento das ondas devido aos fenômenos de difração e irradiação causados pela presença do FPSO. Caso o navio aliviador esteja em uma dessas regiões se observará um aumento na potência necessária ao sistema DP se comparado ao caso onde o efeito de sombra não é considerado, podendo chegar a até 1,8\% da potência instalada.

Em resumo, os resultados do presente trabalho indicam a necessidade de se incorporar os efeitos de interação hidrodinâmica causados pelas ondas para a análise de operações de alívio em tandem. 


\section{SUGESTÕES DE CONTINUIDADE}

Como sugestões de continuação da atual linha pesquisa propõem-se:

- Realização de simulações considerando-se outras posições relativas FPSO-aliviador;

- Realização de simulações considerando-se outras classes de navio aliviador (Aframax, por exemplo);

- Realização de simulações considerando-se outros arranjos de sistemas DP;

- Realização de simulações considerando-se outras direções e incidência de ondas;

- Realização de simulações numéricas acrescentando-se a ação de outros agentes ambientais (vento e correnteza);

- Reprodução das simulações numéricas em tanque de provas comparação com os atuais resultados. 


\section{REFERÊNCIAS}

AGOSTINHO, A.C. Controle por modos deslizantes aplicado a sistema de posicionamento dinâmico. São Paulo, 2009. 1v. Dissertação (mestrado) Escola Politécnica, Universidade de São Paulo.

ANSYS. AQWA. Disponível em: <http://www.ansys.com/assets/brochures/ aqwa-industry-brochure.pdf>. Acesso em 15 Out. 2008.

ARANHA, J.A.P.; FERNANDES, A.C. On the second-order slow drift force spectrum. Applied Ocean Research, Vol.17, pp.311-313, 1995.

BRAY, D. Dynamic Positioning, The Oilfield Seamanship Series, Volume 9. Oilfield Publications Ltd. (OPL), 1998.

DNV. Deepc. Disponível em <http://www.dnv.com/binaries/DeepC\%20lores_tcm4-75873.pdf>. Acesso em 18 Out. 2008.

FALTINSEN, O., M. Sea Loads on Ships and Offshore Structures Cambridge University Press 1990.

FOSSEN, T. I.; STRAND J. P. Nonlinear Ship Control. Tutorial Session at IFAC CAMS'98, Fukuoka, Japan: 27 October, 1998 pp. 1-75.

FUCATU, C.H. Desenvolvimento de um Simulador Dinâmico para Análise de Dois Navios Amarrados em Tandem. Tese de Doutorado apresentada à EPUSP, Depto. Eng. Naval; Julho/2003.

HUIJSMANS, R.H.M.; PINKSTER, J.A.; WILDE, J.J. Diffraction and Radiation of Waves around Side-by-side Moored Vessels. International Offshore and Polar Engineering Conference, ISOPE'01, 2002, Stavanger, 2001 
ITTC Report of the Seakeeping Committee. In: Proceedings of the 15th International Towing Tank Conference, pp.531-534, 1984.

JIP. Offloading Operability I. MARIN, Holanda. Disponível em <http://www.marin.nl/web/show/id=88948>. Acesso em 22 Set. 2008.

JIP. Offloading Operability II. MARIN, Holanda. Disponível em <http://www.marin.nl/web/show/id=91080>. Acesso em 22 Set. de 2008.

KASHIWAGI, M.; ENDO, K.; YAMAGUCHI, H. Wave drift forces and moments on two ships arranged side by side in waves. Ocean Engineering, 32, pp. 529-555, 2005.

KONGSBERG MARITIME. Dynamic Positioning Systems. Disponível em <http://www.km.kongsberg.com/>. Acesso em: 27 de abril de 2009.

MARIN. Anysim. Disponível em <http://www.marin.nl/web/show/id=70090>. Acesso em 08 Out. 2008.

MARIN, Lifsim/Lifmot. Disponível em <http://www.sintef.no/Home/Marine/ MARINTEK/Software-developed-at-MARINTEK/SIMO/>. Acesso em 08 Out. 2008.

MARINTEK, Simo. Disponível em <http://www.marin.nl/web/show/id=70090>. Acesso em 08 Out. 2008.

MCS. Ariane-3Dynamic. Disponível em <http://www.mcs.com/site.php?page =6\&name=Ariane-3Dynamic $>$. Acesso em 10 Out. 2008.

OROZCO, J.M., CHEN, X.B. Offloading Operability JIP - Wave shielding effect (phase 1). Technical Note, Bureau Veritas, 2003. 
NEWMAN, J. N. Second Order, slowly varying forces on vessels in irregular waves In proc. Int. Symp Dynamics of Marine Vehicles and Structures in Waves, 1974.

Nishimoto, K. et al. (2003). Numerical Offshore Tank: Development of Numerical Offshore Tank for Ultra Deep Water Oil Production Systems. Proceedings of the $22^{\text {nd }}$ International Conference on Offshore Mechanics \& Arctic Engineering OMAE 2003.

SIMOS, A. N. Estudo de Modelagem de Efeitos de Esteira de Correnteza em Simulações Dinâmicas de Sistemas FPSO-Aliviador. Relatório Técnico USP/Petrobrás, 2008.

PETROBRAS, Campos Basin - Metocean Data, I-ET-3000.00-1000-941PPC-001_revB, Relatório Técnico, 2005.

PIERSON, W.J. \& MOSKOWITZ, L. A Proposed Spectral Form for Fully Developed Wind Seas Based on the Similarity Theory of S.A. Kitaigorodsku, J. Geophys. Res., vol. 69, pp. 5181 -5190, 1964.

TANNURI, E.A. Desenvolvimento metodologia de projeto de sistema de posicionamento dinâmico aplicado a operações em alto-mar. São Paulo, 2002. 1v. Dissertação (doutorado) - Escola Politécnica, Universidade de São Paulo.

TANNURI, E. A.; SIMOS, A.N.; NISHIMOTO, K.; BRAVIN, T. T.; ALVES, K.H.; FERREIRA, M.D. Dynamic simulation of offloading operation considering wave interaction between vessels. Proceedings of 23rd International Conference on Offshore Mechanics and Arctic Engineering OMAE, 2004.

TANNURI, E. A.; MORISHITA, H.M.; Experimental and Numerical Evaluation of a Typical Dynamic Positioning System. Applied Ocean Research, v. 28, p. 133-146, 2006. 
TANNURI, E. A.; SAAD, A. C.; CORREA DA SILVA, S.H.S.; MATOS, V. L. F.; MORISHITA, H.M. ; SIMOS, A.N. ; SPHAIER, S. H.; DP Assisted Offloading Operations in Brazilian Waters. In: DYNAMIC POSITIONING CONFERENCE, 2009, Houston. DYNAMIC POSITIONING CONFERENCE, 2009.

WAMIT, Inc. Wave Analysis Program: Reference Manual, WAMIT, Inc. 2000. 


\section{APÊNDICE A - MAPAS DE ALTURA DE ONDA}

\subsection{FPSO carregado e navio aliviador em condição de lastro}

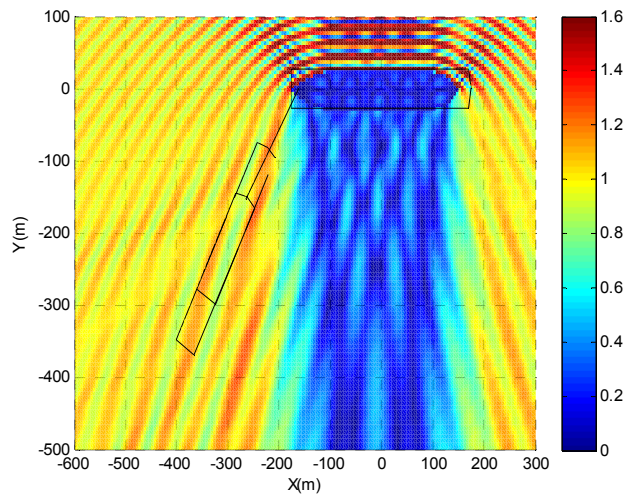

Figura 45 - Mapa de elevação de onda não considerando o navio aliviador para incidência de $270^{\circ}$ e 5 s de período.

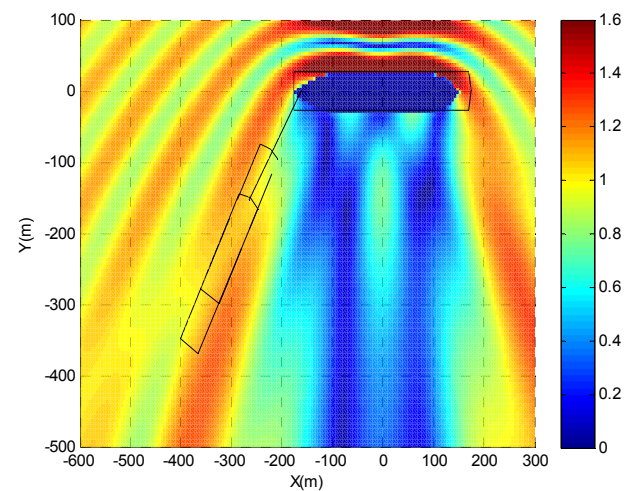

Figura 47 - Mapa de elevação de onda não considerando o navio aliviador para incidência de $270^{\circ}$ e 9s de período.

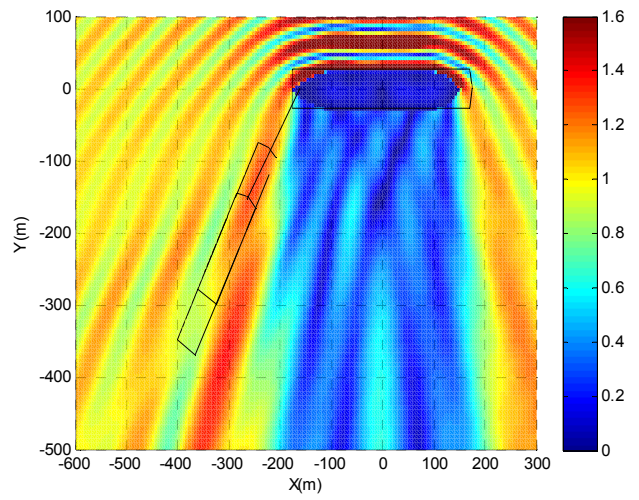

Figura 46 - Mapa de elevação de onda não considerando o navio aliviador para incidência de $270^{\circ}$ e 7 s de período.

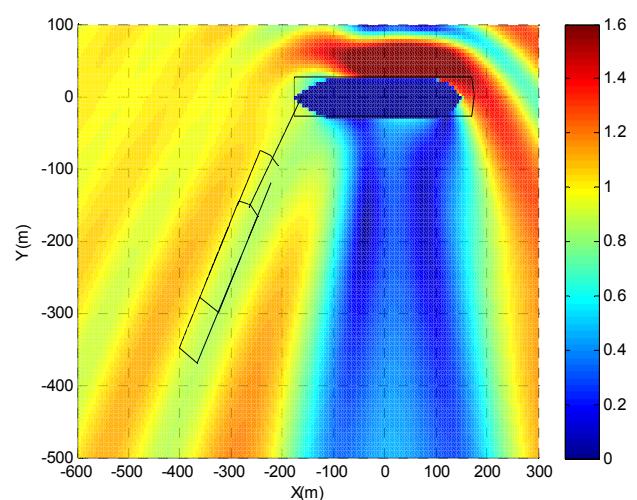

Figura 48 - Mapa de elevação de onda não considerando o navio aliviador para incidência de $270^{\circ}$ e 11 s de período.

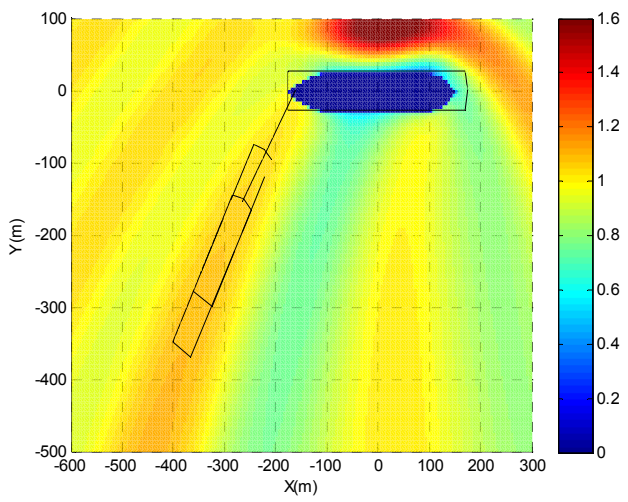

Figura 49 - Mapa de elevação de onda não considerando o navio aliviador para incidência de $270^{\circ}$ e 13 s de período. 


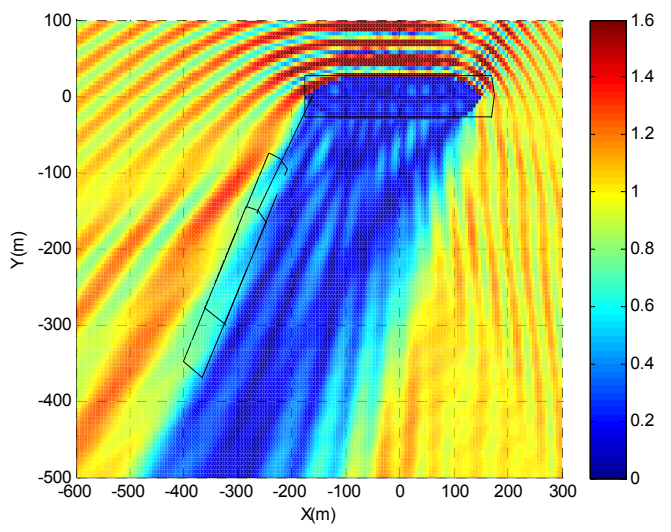

Figura 50 - Mapa de elevação de onda não considerando o navio aliviador para incidência de $240^{\circ}$ e 5 s de período.

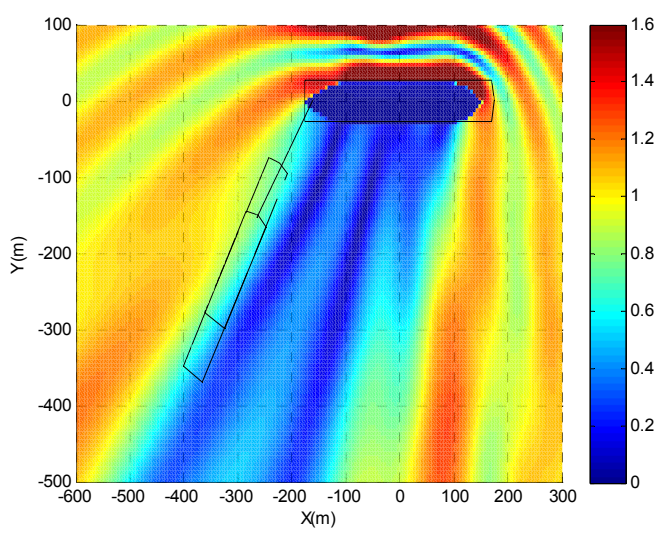

Figura 52 - Mapa de elevação de onda não considerando o navio aliviador para incidência de $240^{\circ}$ e 9s de período.

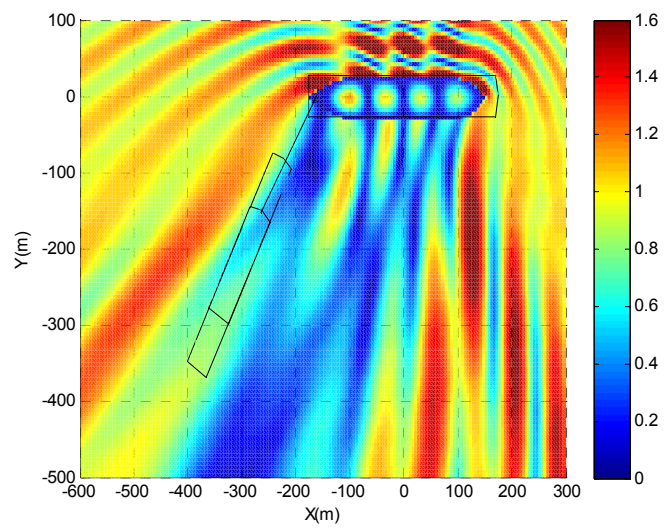

Figura 51 - Mapa de elevação de onda não considerando o navio aliviador para incidência de $240^{\circ}$ e 7 s de período.

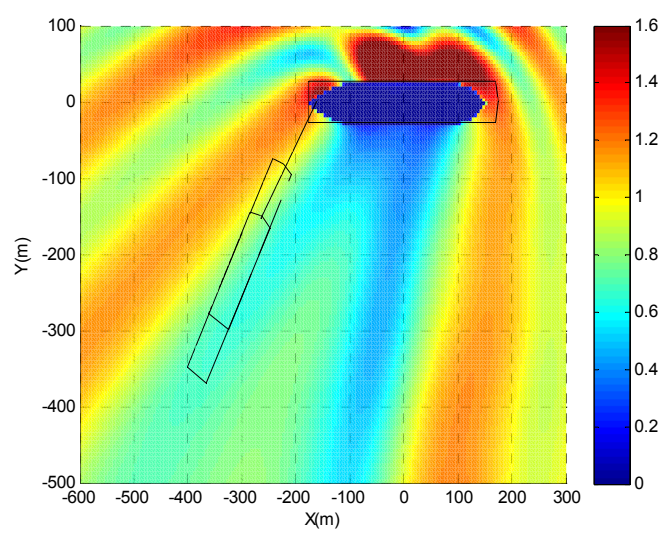

Figura 53 - Mapa de elevação de onda não considerando o navio aliviador para incidência de $240^{\circ}$ e $11 s$ de período.

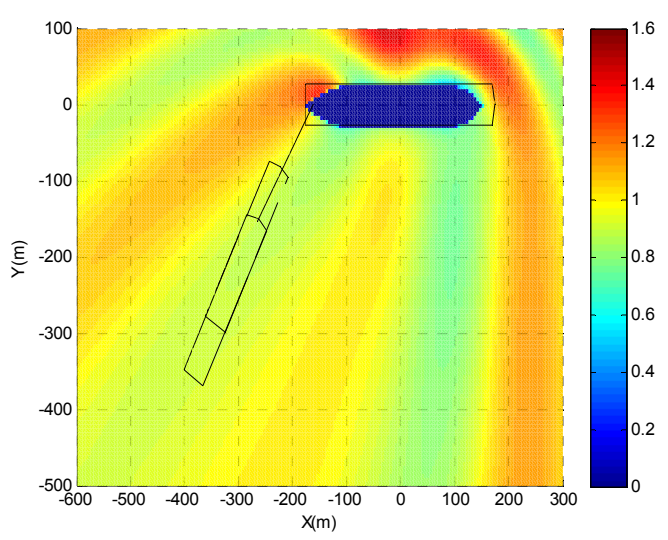

Figura 54 - Mapa de elevação de onda não considerando o navio aliviador para incidência de $240^{\circ}$ e 13 s de período. 


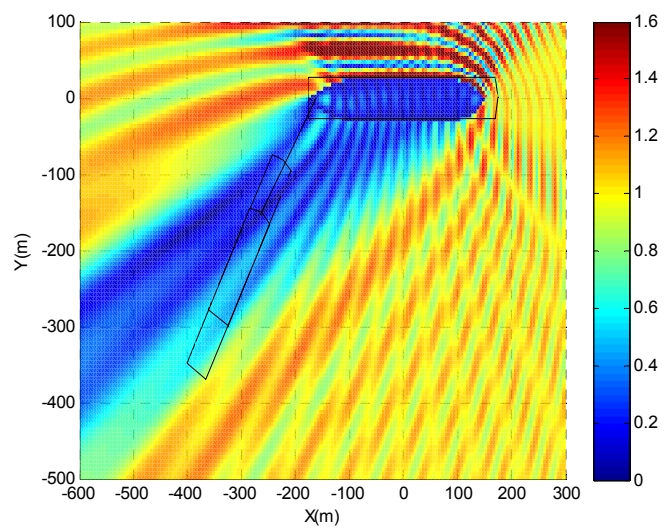

Figura 55 - Mapa de elevação de onda não considerando o navio aliviador para incidência de $210^{\circ}$ e 5 s de período.

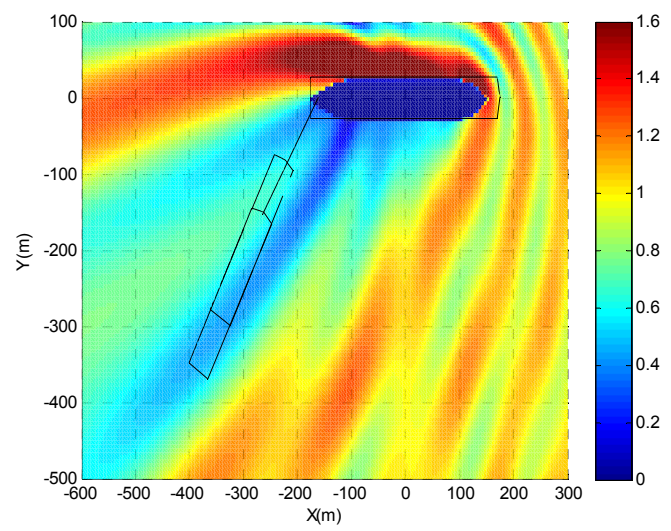

Figura 57 - Mapa de elevação de onda não considerando o navio aliviador para incidência de $210^{\circ}$ e 9 s de período.

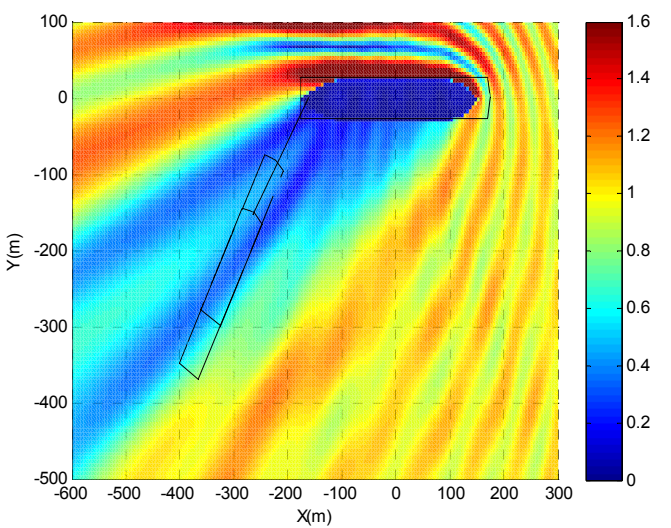

Figura 56 - Mapa de elevação de onda não considerando o navio aliviador para incidência de $210^{\circ}$ e 7 s de período.

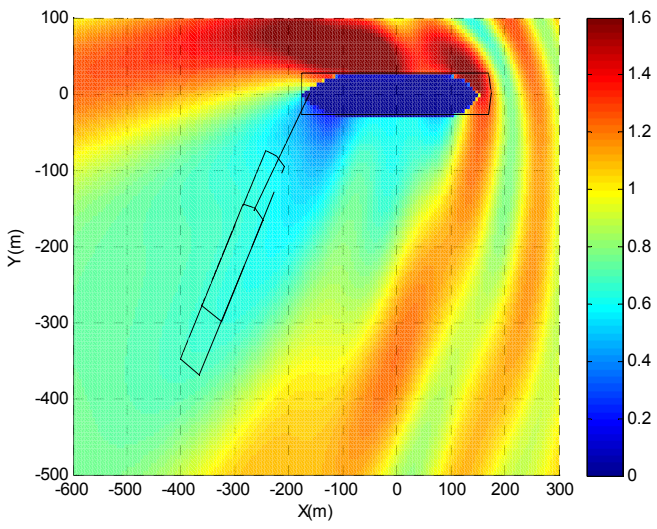

Figura 58 - Mapa de elevação de onda não considerando o navio aliviador para incidência de $210^{\circ}$ e 11 s de período.

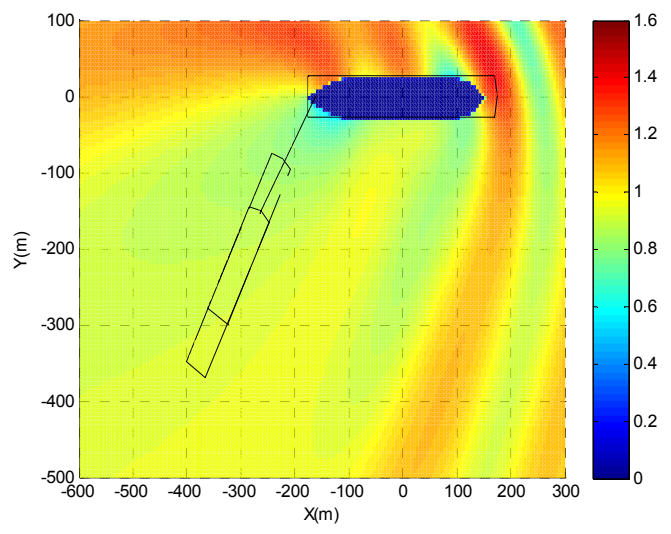

Figura 59 - Mapa de elevação de onda não considerando o navio aliviador para incidência de $210^{\circ}$ e 13 s de período. 


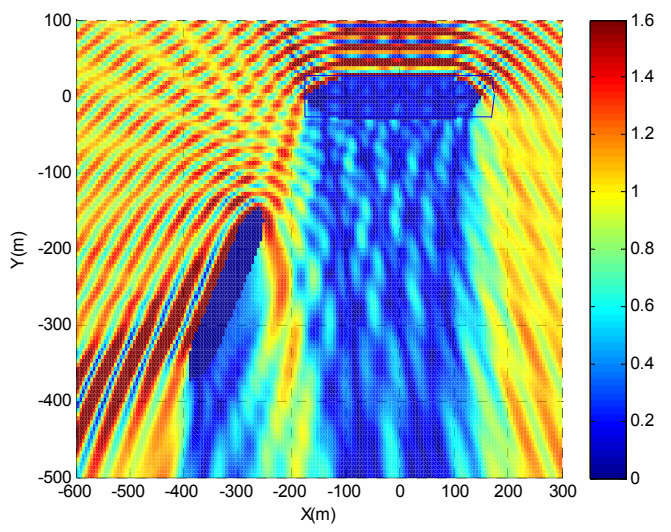

Figura 60 - Mapa de elevação de onda considerando o navio aliviador para incidência de $270^{\circ}, 5 s$ de período e d=160m.

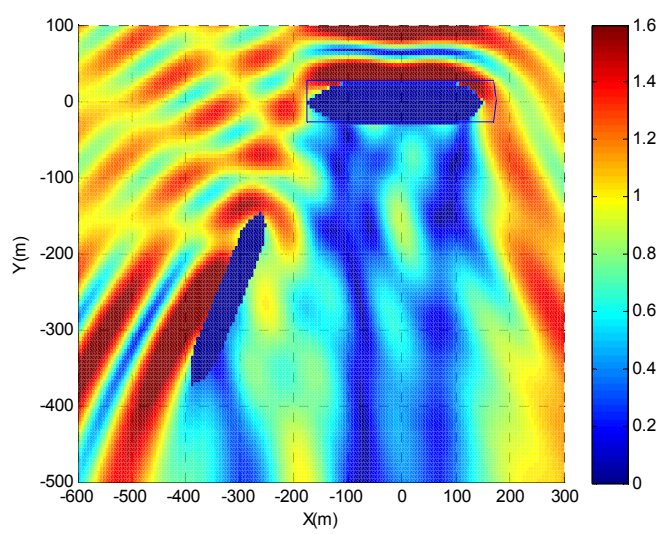

Figura 62 - Mapa de elevação de onda considerando o navio aliviador para incidência de $270^{\circ}$, 9s de período e $\mathrm{d}=160 \mathrm{~m}$.

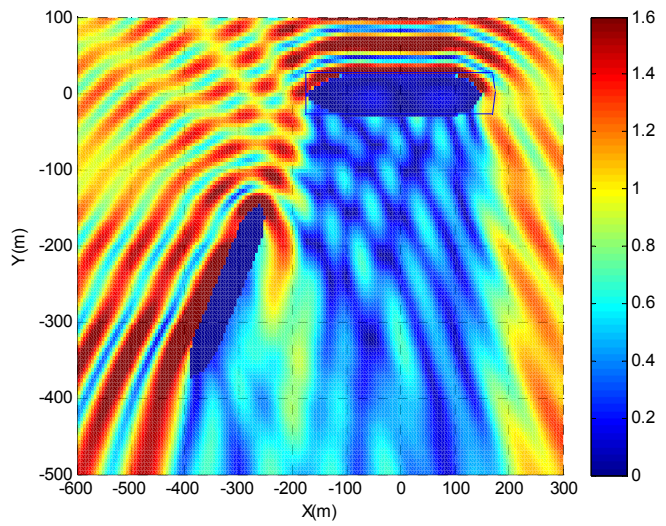

Figura 61 - Mapa de elevação de onda considerando o navio aliviador para incidência de $270^{\circ}$, $7 \mathrm{~s}$ de período e $\mathrm{d}=160 \mathrm{~m}$.

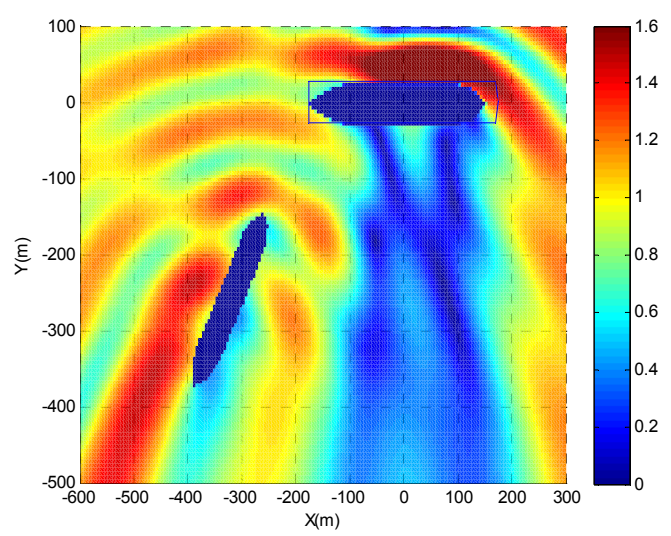

Figura 63 - Mapa de elevação de onda considerando o navio aliviador para incidência de $270^{\circ}$, 11 s de período e $\mathrm{d}=160 \mathrm{~m}$.

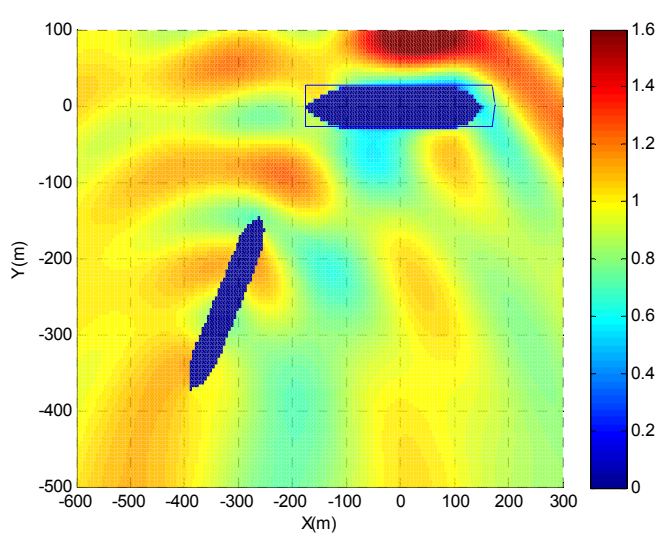

Figura 64 - Mapa de elevação de onda considerando o navio aliviador para incidência de $270^{\circ}$, 13 s de período e d=160m. 


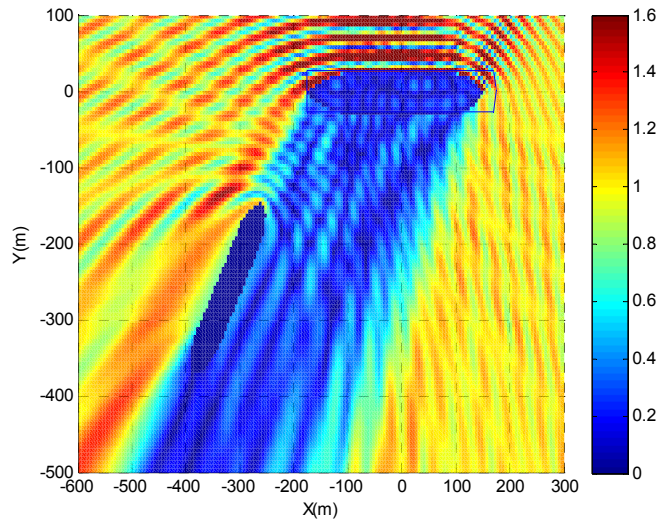

Figura 65 - Mapa de elevação de onda considerando o navio aliviador para incidência de $240^{\circ}$, $5 \mathrm{~s}$ de período e $\mathrm{d}=160 \mathrm{~m}$.

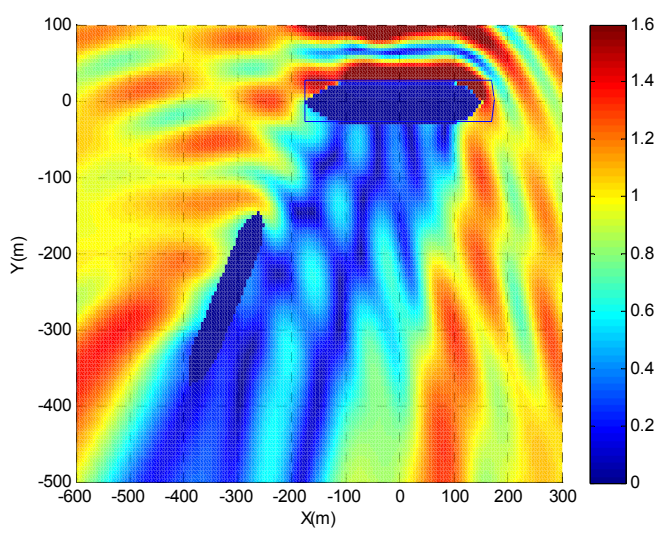

Figura 67 - Mapa de elevação de onda considerando o navio aliviador para incidência de $240^{\circ}$, 9 s de período e $\mathrm{d}=160 \mathrm{~m}$.

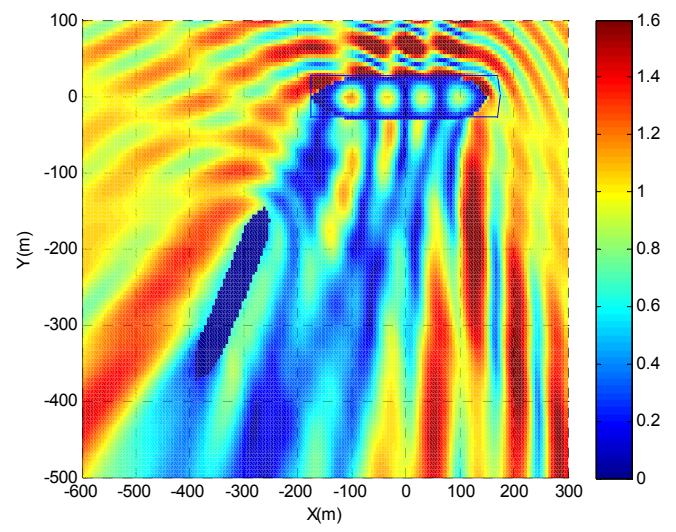

Figura 66 - Mapa de elevação de onda considerando o navio aliviador para incidência de $240^{\circ}$, $7 \mathrm{~s}$ de período e $\mathrm{d}=160 \mathrm{~m}$.

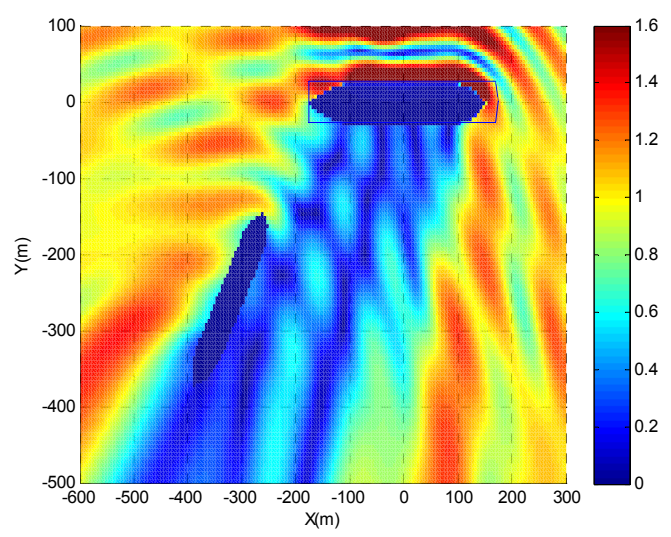

Figura 68 - Mapa de elevação de onda considerando o navio aliviador para incidência de $240^{\circ}$, 11 s de período e $\mathrm{d}=160 \mathrm{~m}$.

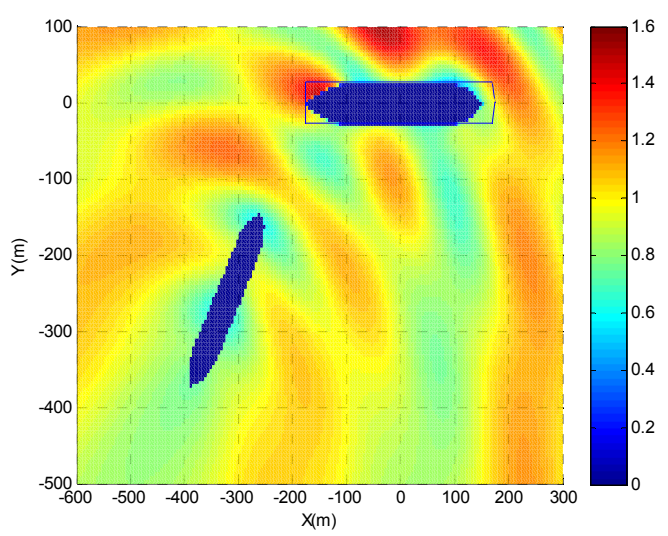

Figura 69 - Mapa de elevação de onda considerando o navio aliviador para incidência de $240^{\circ}$, 13 s de período e $\mathrm{d}=160 \mathrm{~m}$. 


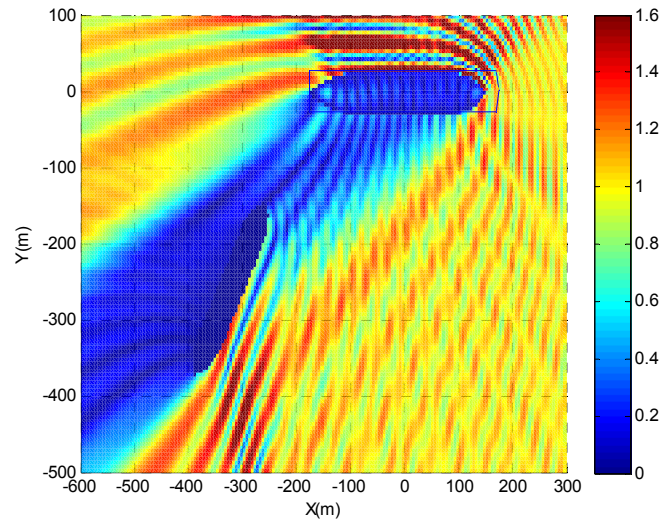

Figura 70 - Mapa de elevação de onda considerando o navio aliviador para incidência de $210^{\circ}$, 5 s de período e $\mathrm{d}=160 \mathrm{~m}$.

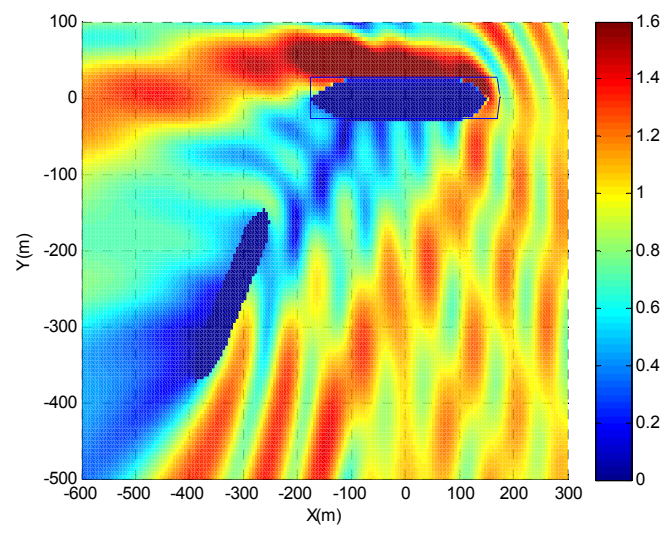

Figura 72 - Mapa de elevação de onda considerando o navio aliviador para incidência de $210^{\circ}$, 9 s de período e $\mathrm{d}=160 \mathrm{~m}$.

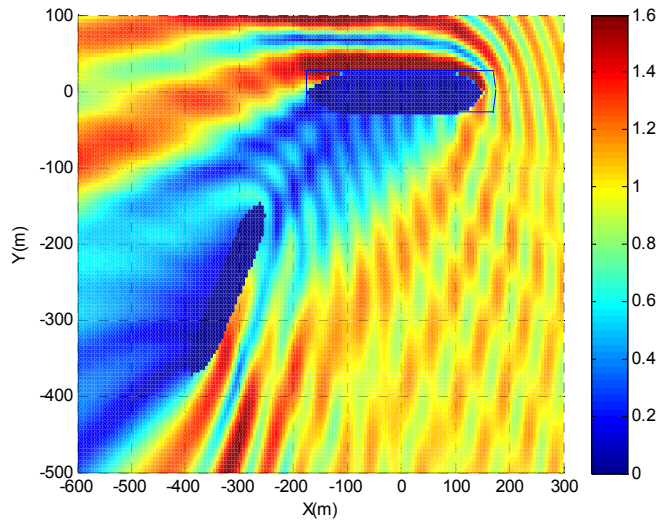

Figura 71 - Mapa de elevação de onda considerando o navio aliviador para incidência de $210^{\circ}$, 7 s de período e $d=160 \mathrm{~m}$.

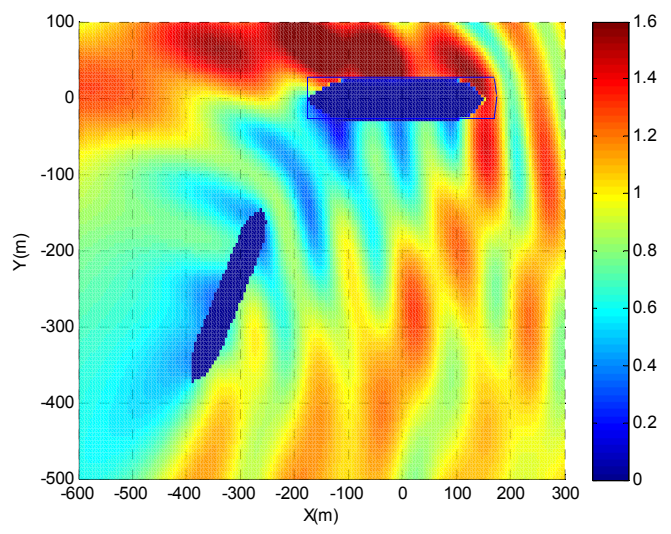

Figura 73 - Mapa de elevação de onda considerando o navio aliviador para incidência de $210^{\circ}$, 11 s de período e $d=160 \mathrm{~m}$.

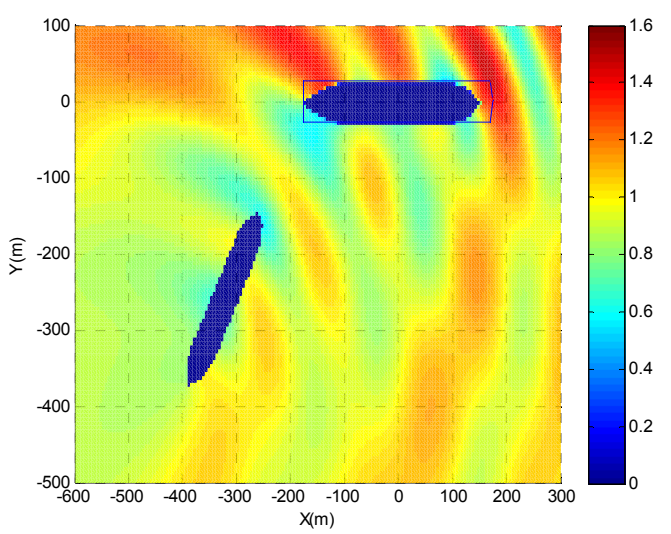

Figura 74 - Mapa de elevação de onda considerando o navio aliviador para incidência de $210^{\circ}$, 13 s de período e $\mathrm{d}=160 \mathrm{~m}$. 


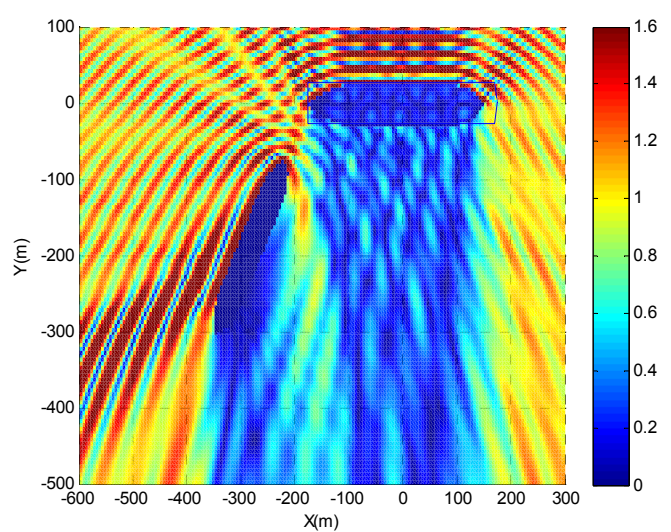

Figura 75 - Mapa de elevação de onda considerando o navio aliviador para incidência de $2 \mathbf{2 7 0}^{\circ}$, 5 s de período e $\mathrm{d}=80 \mathrm{~m}$.

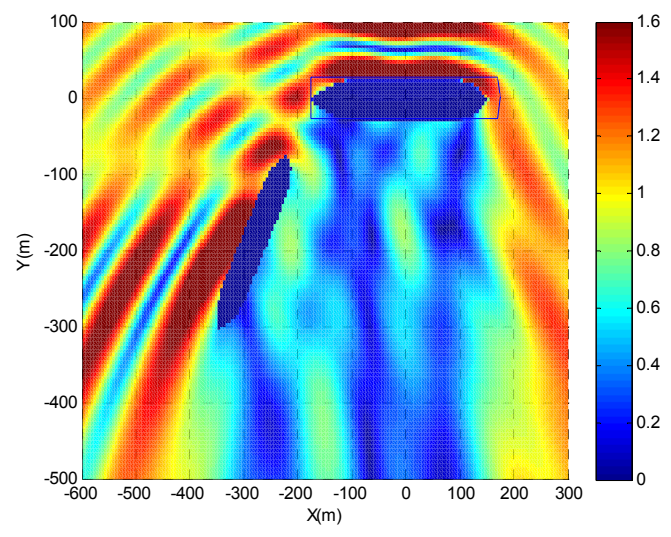

Figura 77 - Mapa de elevação de onda considerando o navio aliviador para incidência de $270^{\circ}$, 9s de período e $\mathrm{d}=80 \mathrm{~m}$.

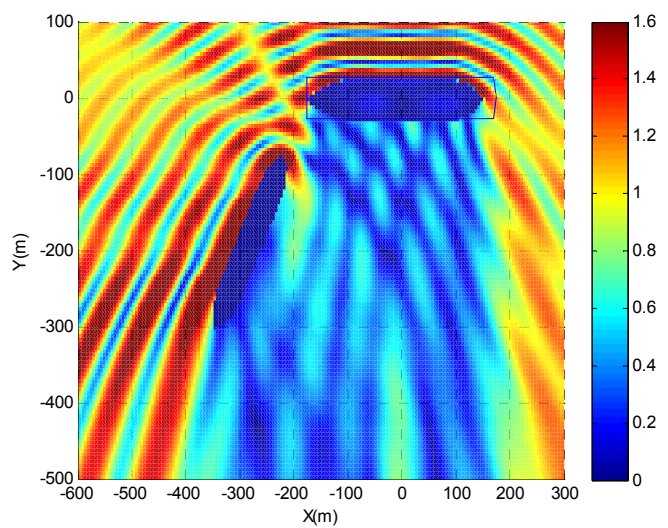

Figura 76 - Mapa de elevação de onda considerando o navio aliviador para incidência de $270^{\circ}$, $7 \mathrm{~s}$ de período e $d=80 \mathrm{~m}$.

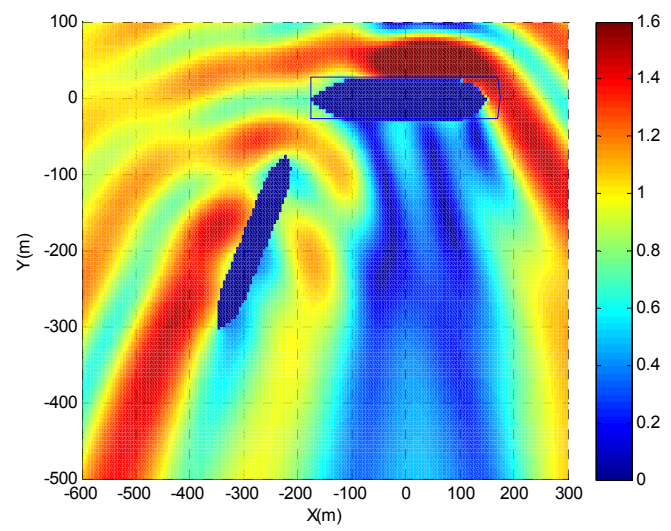

Figura 78 - Mapa de elevação de onda considerando o navio aliviador para incidência de $270^{\circ}$, 11 s de período e $\mathrm{d}=\mathbf{8 0} \mathrm{m}$.

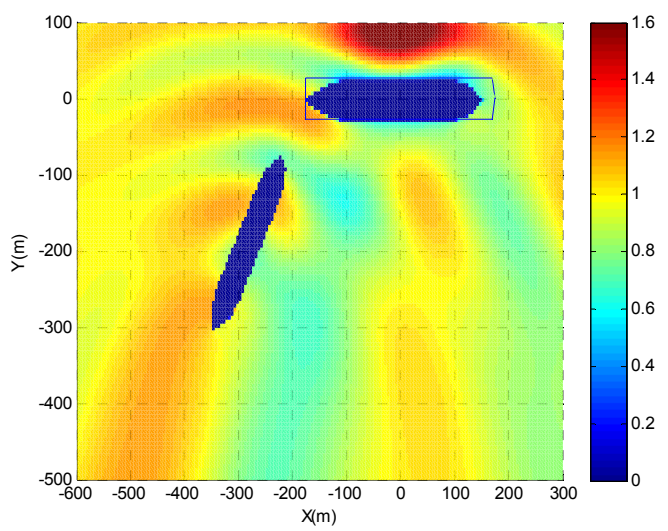

Figura 79 - Mapa de elevação de onda considerando o navio aliviador para incidência de $270^{\circ}$, 13 s de período e d=80m. 


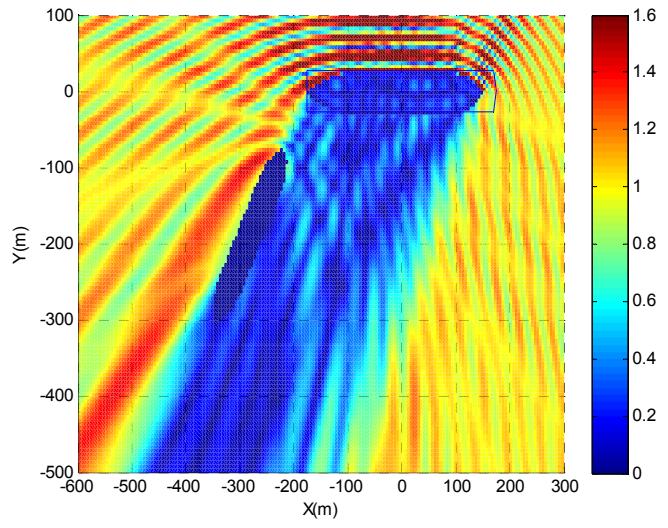

Figura 80 - Mapa de elevação de onda considerando o navio aliviador para incidência de $240^{\circ}$, $5 \mathrm{~s}$ de período e $\mathrm{d}=80 \mathrm{~m}$.

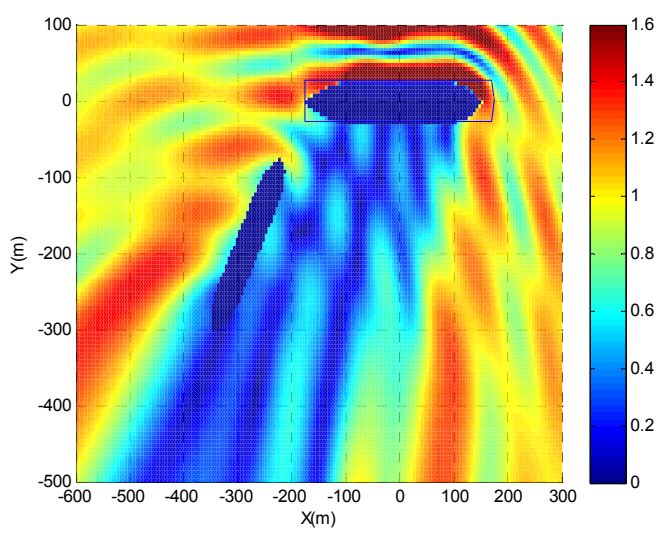

Figura 82 - Mapa de elevação de onda considerando o navio aliviador para incidência de $240^{\circ}$, 9 s de período e $\mathrm{d}=80 \mathrm{~m}$.

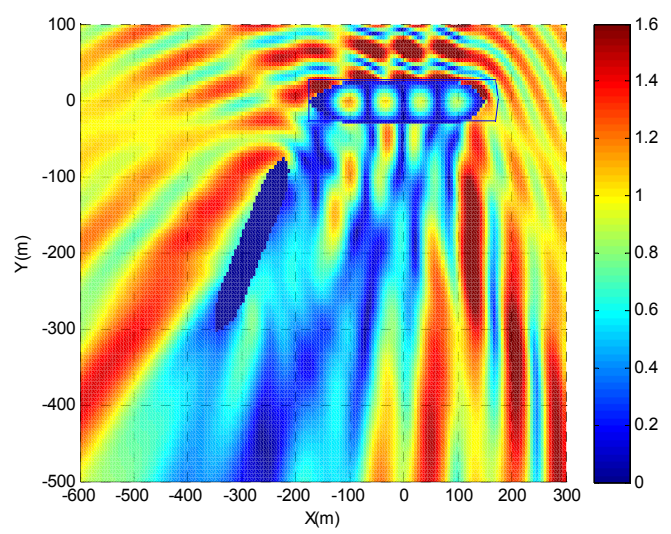

Figura 81 - Mapa de elevação de onda considerando o navio aliviador para incidência de $240^{\circ}$, $7 \mathrm{~s}$ de período e $\mathbf{d = 8 0 m}$.

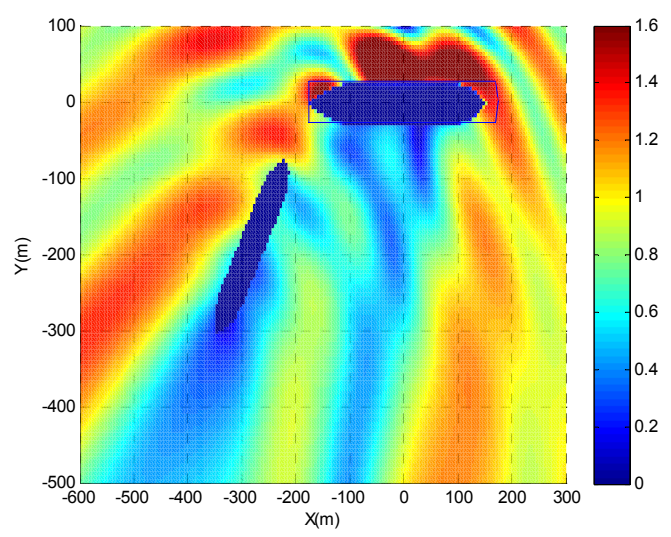

Figura 83 - Mapa de elevação de onda considerando o navio aliviador para incidência de $240^{\circ}$, 11 s de período e $\mathbf{d}=\mathbf{8 0 m}$.

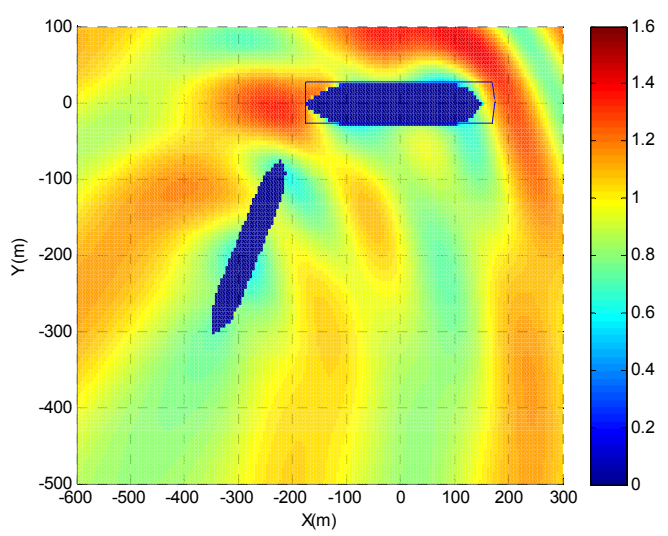

Figura 84 - Mapa de elevação de onda considerando o navio aliviador para incidência de $240^{\circ}$, 13 s de período e d $=80 \mathrm{~m}$. 


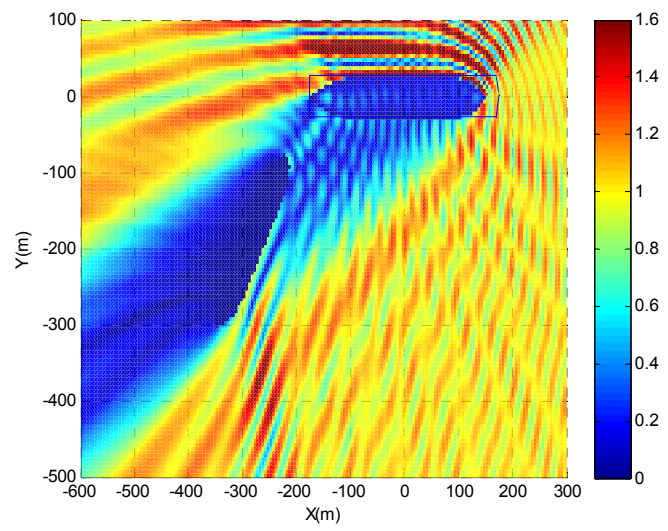

Figura 85 - Mapa de elevação de onda considerando o navio aliviador para incidência de $210^{\circ}$, 5 s de período e $d=80 \mathrm{~m}$.

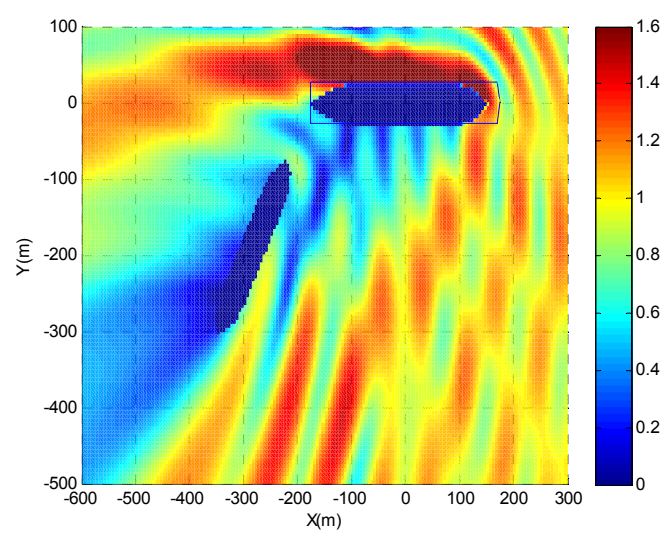

Figura 87 - Mapa de elevação de onda considerando o navio aliviador para incidência de $210^{\circ}$, 9s de período e $d=80 \mathrm{~m}$.

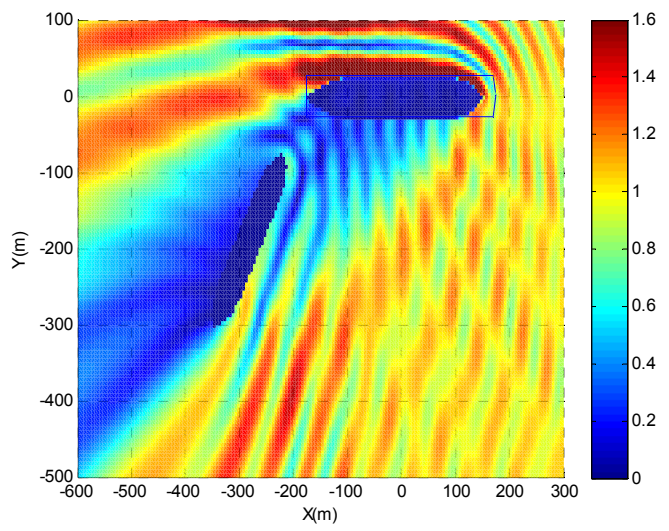

Figura 86 - Mapa de elevação de onda considerando o navio aliviador para incidência de $210^{\circ}$, $7 \mathrm{~s}$ de período e $d=80 \mathrm{~m}$.

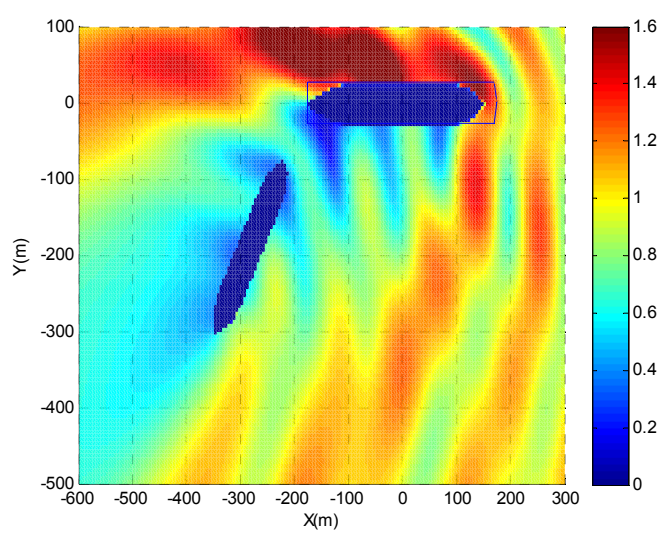

Figura 88 - Mapa de elevação de onda considerando o navio aliviador para incidência de $210^{\circ}$, 11 s de período e $d=80 \mathrm{~m}$.

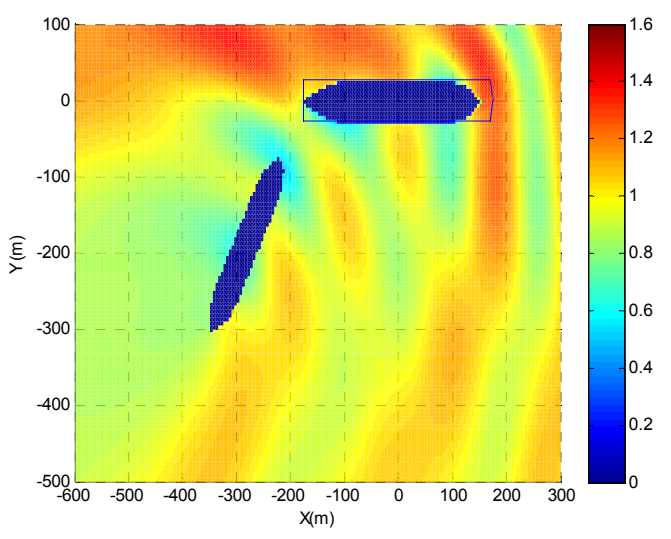

Figura 89 - Mapa de elevação de onda considerando o navio aliviador para incidência de $210^{\circ}$, 13 s de período e $d=80 \mathrm{~m}$. 
9.2 FPSO em condição de lastro e navio aliviador carregado

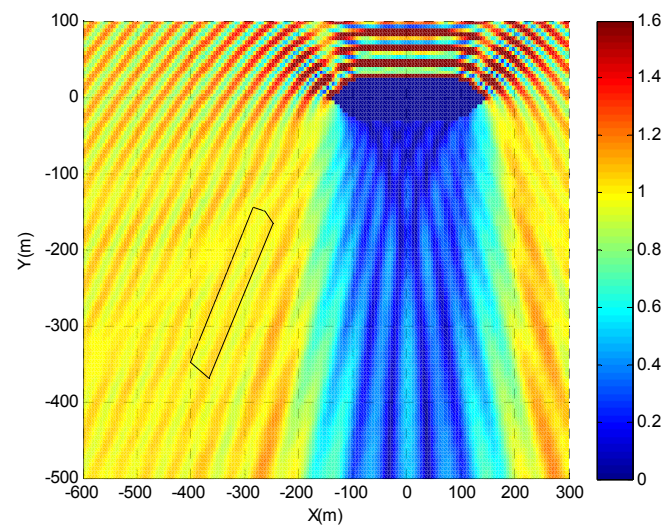

Figura 90 - Mapa de elevação de onda não considerando o navio aliviador para incidência de $270^{\circ}$ e 5 s de período.

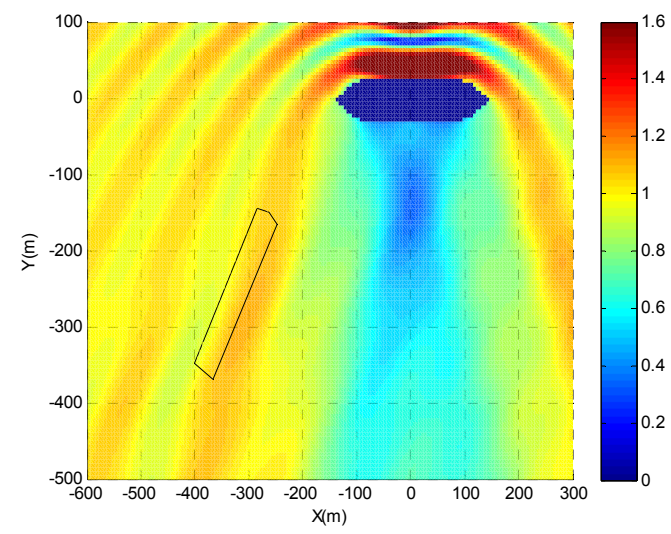

Figura 92 - Mapa de elevação de onda não considerando o navio aliviador para incidência de $270^{\circ}$ e 9 s de período.

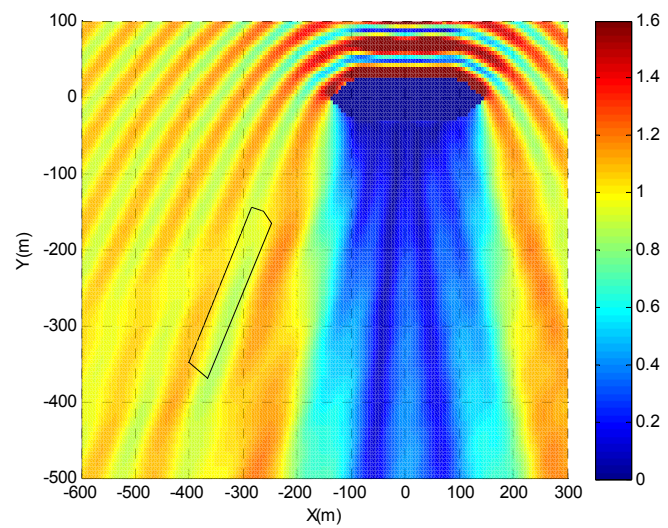

Figura 91 - Mapa de elevação de onda não considerando o navio aliviador para incidência de $270^{\circ}$ e $7 \mathrm{~s}$ de período.

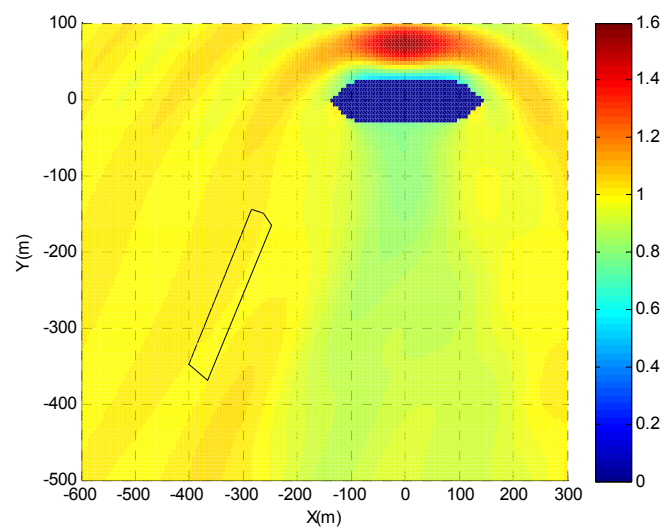

Figura 93 - Mapa de elevação de onda não considerando o navio aliviador para incidência de $270^{\circ}$ e 11 s de período.

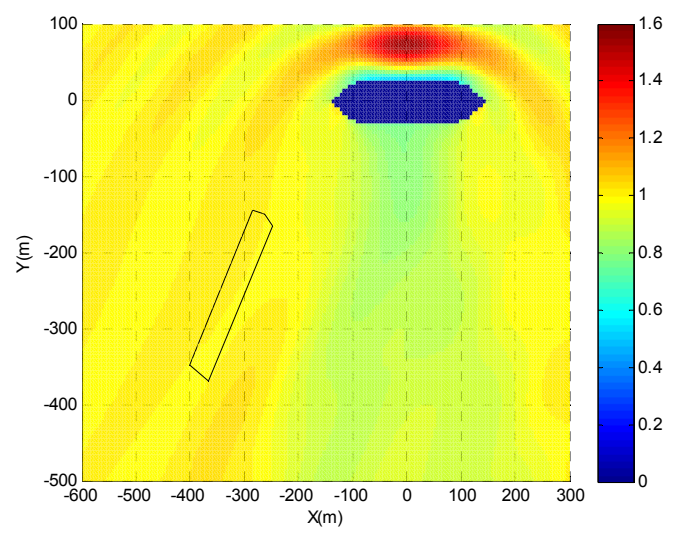

Figura 94 - Mapa de elevação de onda não considerando o navio aliviador para incidência de $270^{\circ}$ e 13 s de período. 


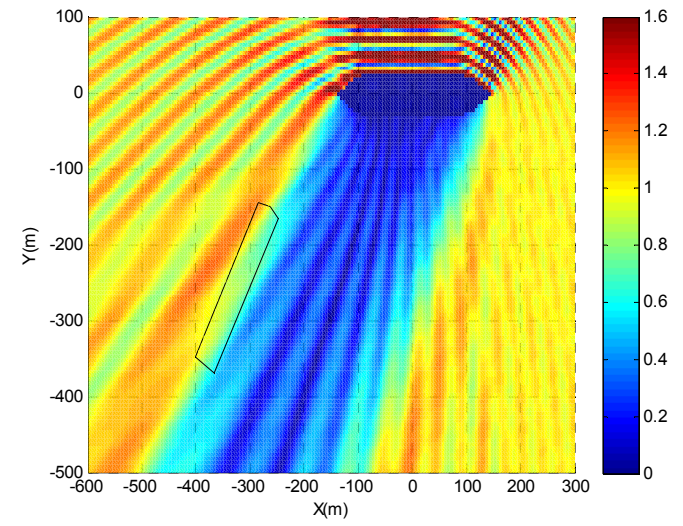

Figura 95 - Mapa de elevação de onda não considerando o navio aliviador para incidência de $240^{\circ}$ e 5 s de período.

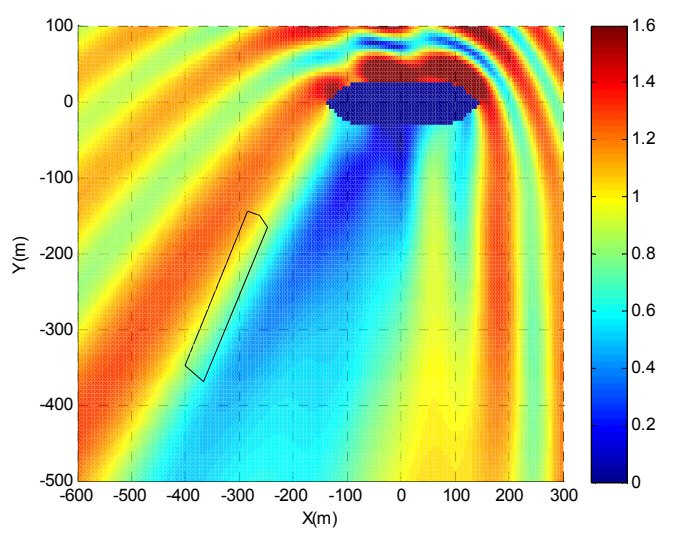

Figura 97 - Mapa de elevação de onda não considerando o navio aliviador para incidência de $240^{\circ}$ e 9 s de período.

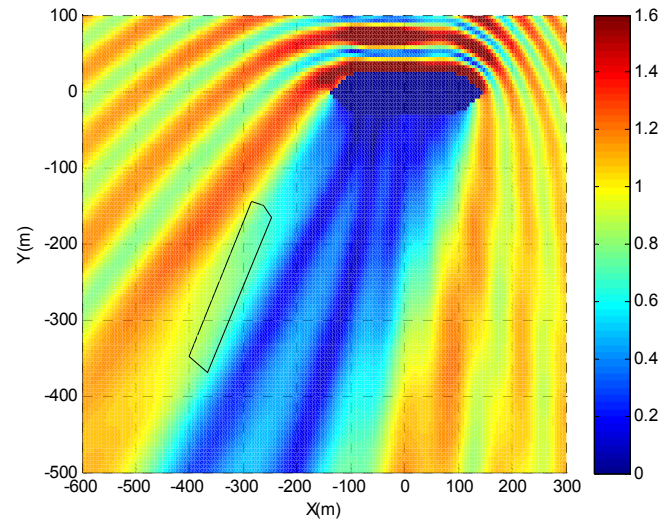

Figura 96 - Mapa de elevação de onda não considerando o navio aliviador para incidência de $240^{\circ}$ e $7 \mathrm{~s}$ de período.

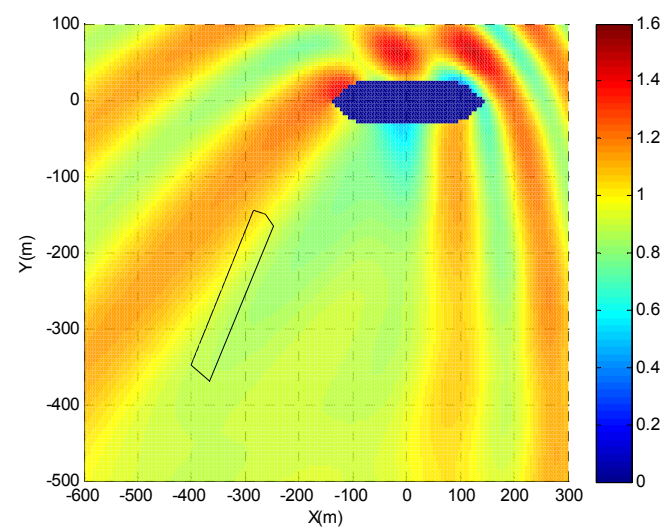

Figura 98 - Mapa de elevação de onda não considerando o navio aliviador para incidência de $240^{\circ}$ e 11 s de período.

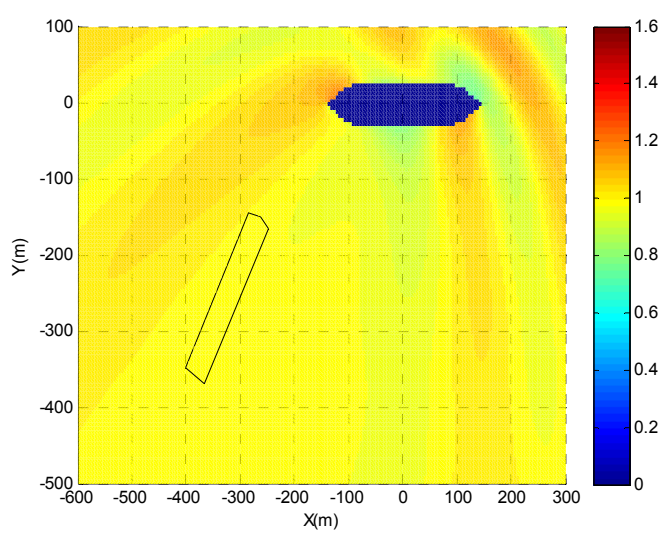

Figura 99 - Mapa de elevação de onda não considerando o navio aliviador para incidência de $240^{\circ}$ e 13 s de período. 


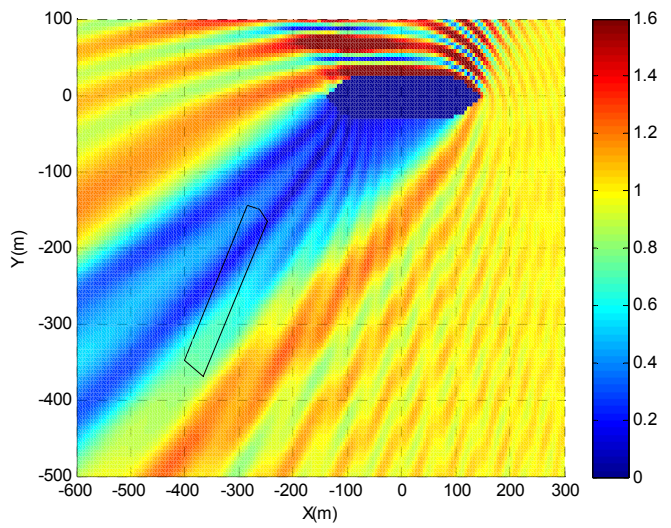

Figura 100 - Mapa de elevação de onda não considerando o navio aliviador para incidência de $210^{\circ}$ e 5 s de período.

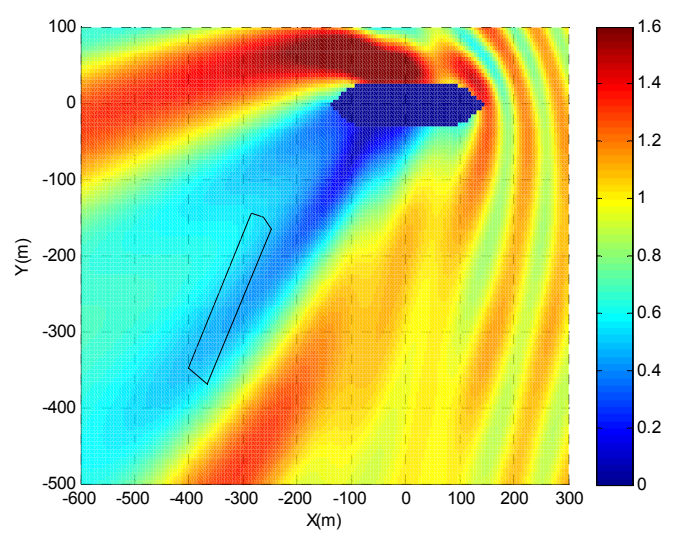

Figura 102 - Mapa de elevação de onda não considerando o navio aliviador para incidência de $210^{\circ}$ e 9 s de período.

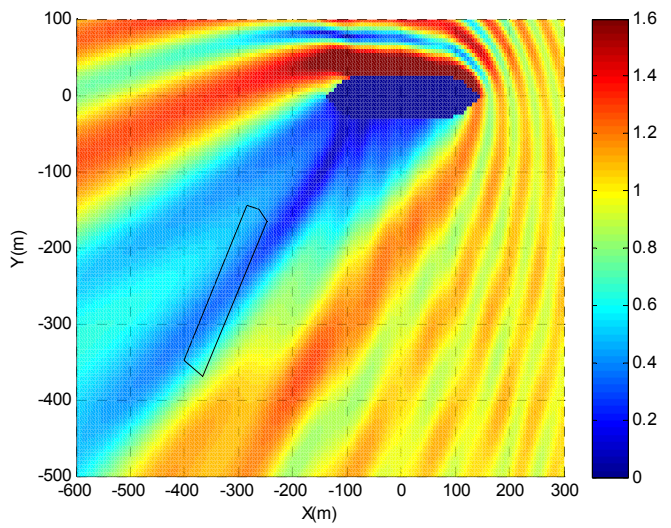

Figura 101 - Mapa de elevação de onda não considerando o navio aliviador para incidência de $210^{\circ}$ e $7 \mathrm{~s}$ de período.

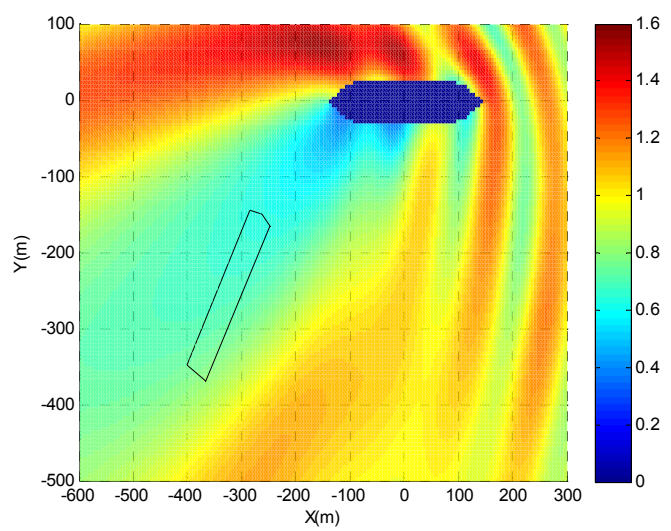

Figura 103 - Mapa de elevação de onda não considerando o navio aliviador para incidência de $210^{\circ}$ e 11 s de período.

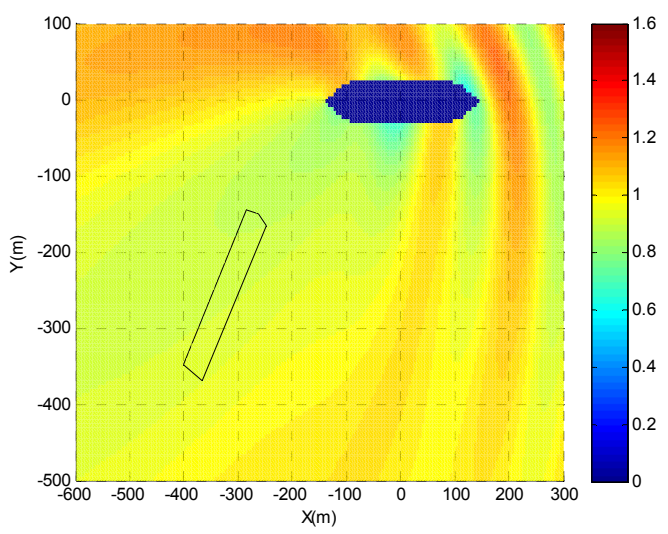

Figura 104 - Mapa de elevação de onda não considerando o navio aliviador para incidência de $210^{\circ}$ e $13 s$ de período. 


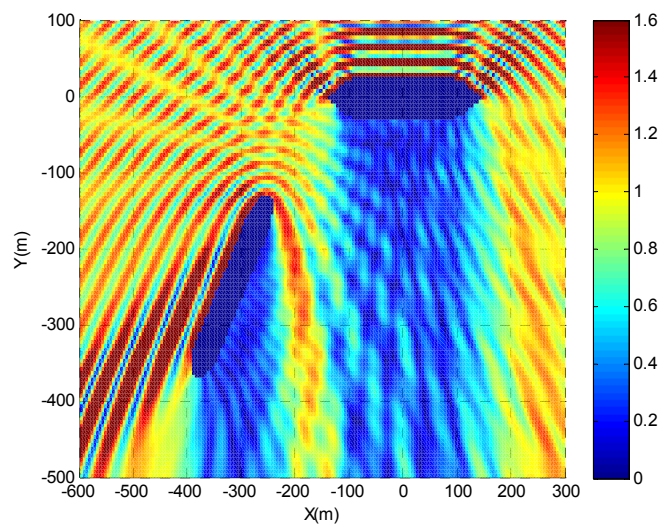

Figura 105 - Mapa de elevação de onda considerando o navio aliviador para incidência de $270^{\circ}$ e 5 s de período.

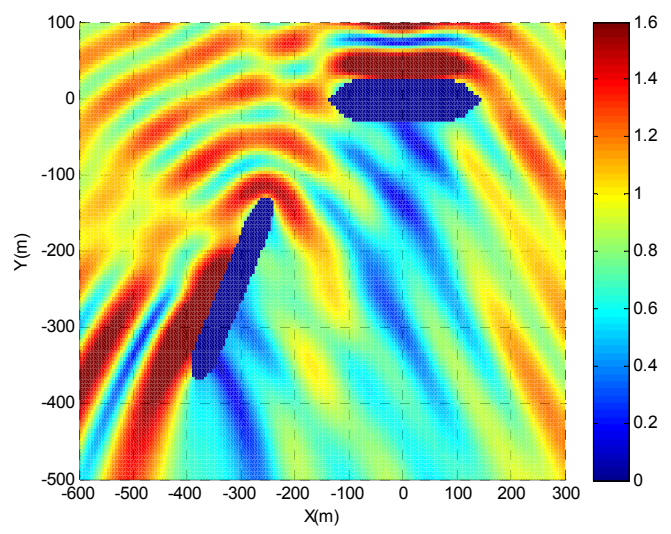

Figura 107 - Mapa de elevação de onda considerando o navio aliviador para incidência de $270^{\circ}$ e 9 s de período.

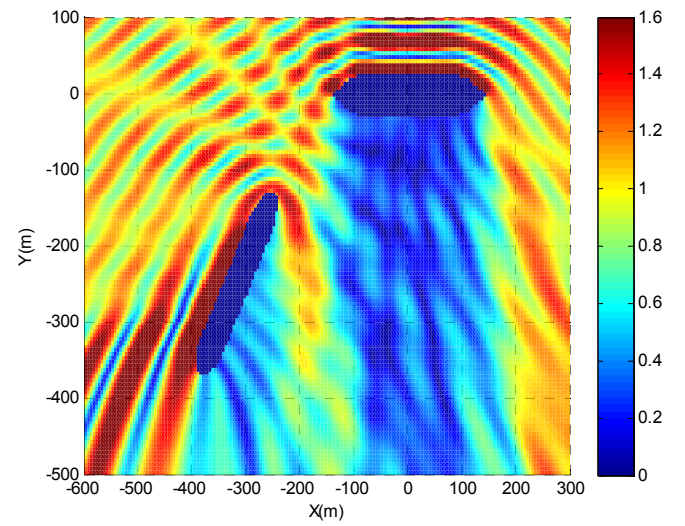

Figura 106 - Mapa de elevação de onda considerando o navio aliviador para incidência de $270^{\circ}$ e $7 \mathrm{~s}$ de período.

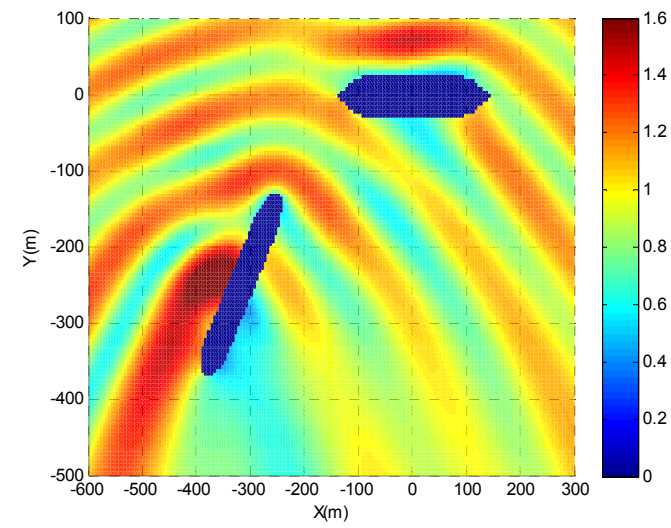

Figura 108 - Mapa de elevação de onda considerando o navio aliviador para incidência de $270^{\circ}$ e 11 s de período.

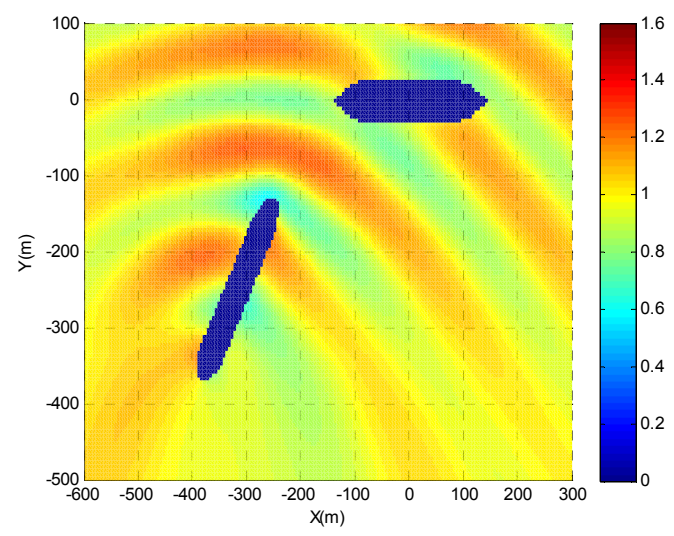

Figura 109 - Mapa de elevação de onda considerando o navio aliviador para incidência de $270^{\circ}$ e $13 s$ de período. 


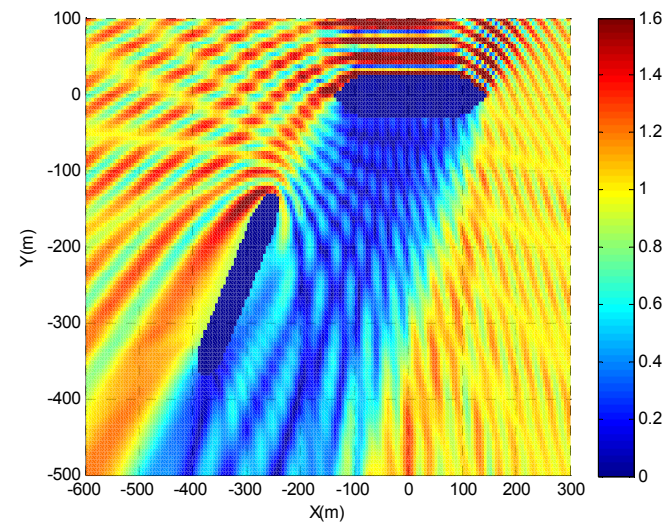

Figura 110 - Mapa de elevação de onda considerando o navio aliviador para incidência de $240^{\circ}$ e 5 s de período.

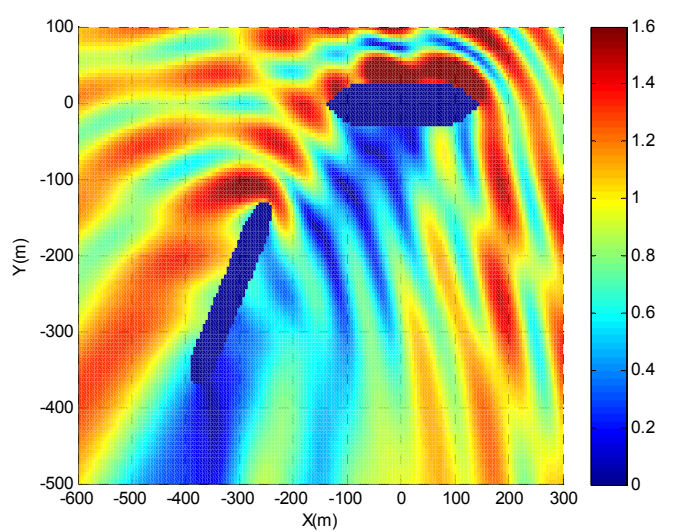

Figura 112 - Mapa de elevação de onda considerando o navio aliviador para incidência de $240^{\circ}$ e 9 s de período.

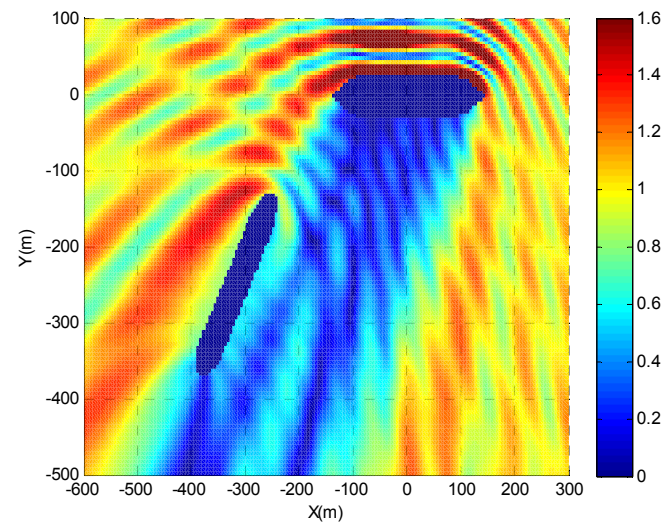

Figura 111 - Mapa de elevação de onda considerando o navio aliviador para incidência de $240^{\circ}$ e $7 \mathrm{~s}$ de período.

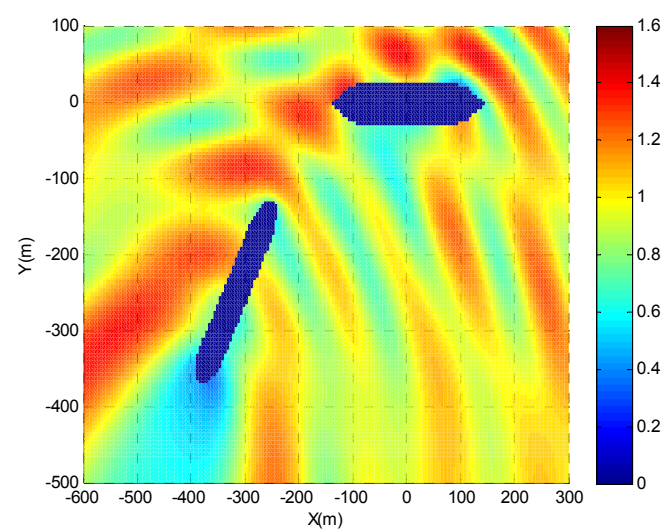

Figura 113 - Mapa de elevação de onda considerando o navio aliviador para incidência de $240^{\circ}$ e 11 s de período.

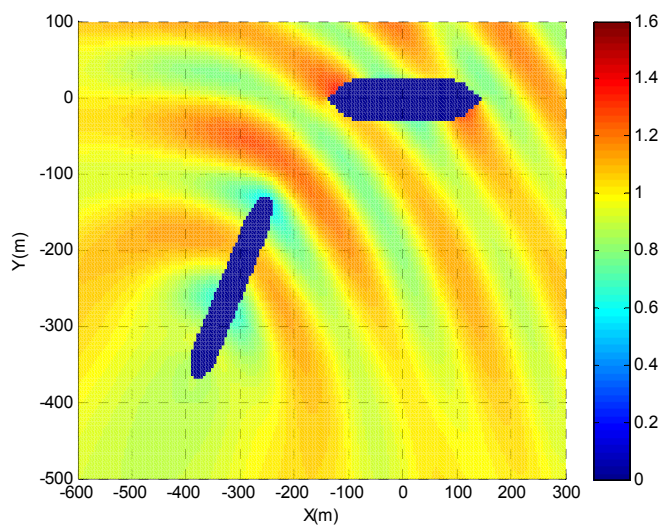

Figura 114 - Mapa de elevação de onda considerando o navio aliviador para incidência de $240^{\circ}$ e $13 s$ de período. 


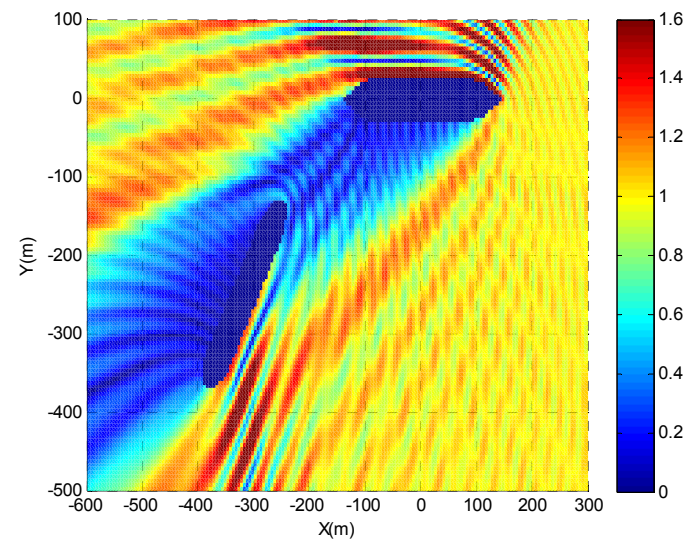

Figura 115 - Mapa de elevação de onda considerando o navio aliviador para incidência de $210^{\circ}$ e 5 s de período.

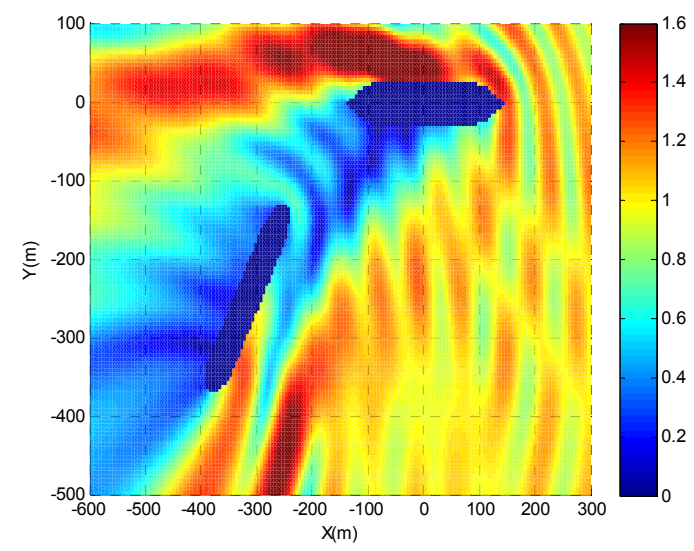

Figura 117 - Mapa de elevação de onda considerando o navio aliviador para incidência de $210^{\circ}$ e 9 s de período.

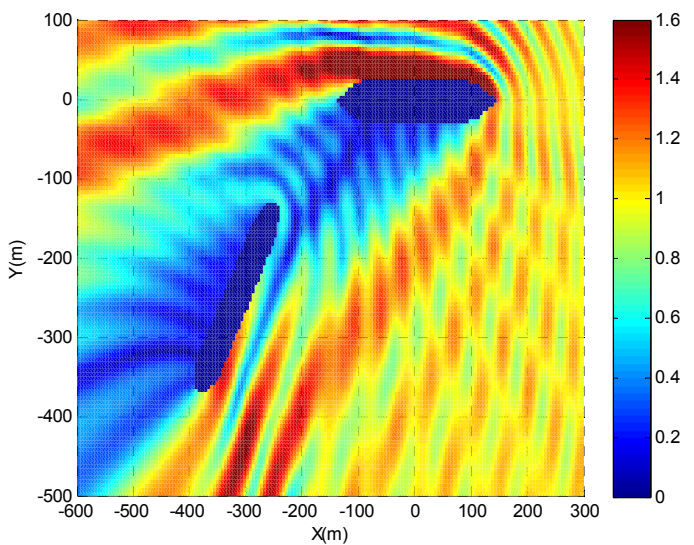

Figura 116 - Mapa de elevação de onda considerando o navio aliviador para incidência de $210^{\circ}$ e $7 \mathrm{~s}$ de período.

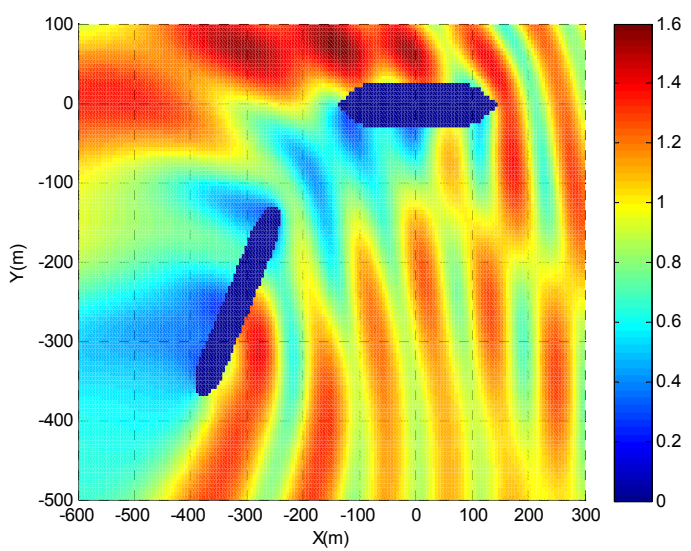

Figura 118 - Mapa de elevação de onda considerando o navio aliviador para incidência de $210^{\circ}$ e 11 s de período.

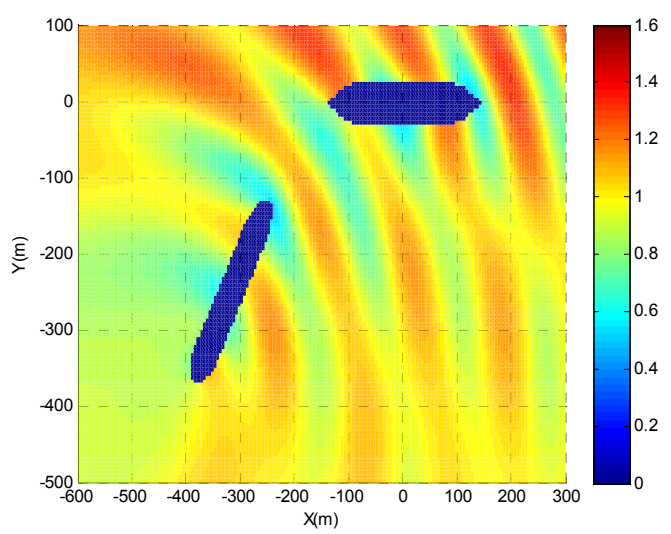

Figura 119 - Mapa de elevação de onda considerando o navio aliviador para incidência de $210^{\circ}$ e 13 s de período. 


\section{APÊNDICE B - COEFICIENTES DE DERIVA DO NAVIO ALIVIADOR}

Neste apêndice serão apresentados os coeficientes de deriva do navio aliviador utilizado neste trabalho, considerando-se todos os casos previamente simulados. Deve-se destacar que nos gráficos a seguir, o ângulo de incidência apresentado é dado em relação ao eixo longitudinal do aliviador, e não do FPSO. A Figura 120 apresenta a correspondência entre os ângulos de incidência relativos ao FPSO (considerado no capítulo 5) e ao aliviador (considerado no presente apêndice).
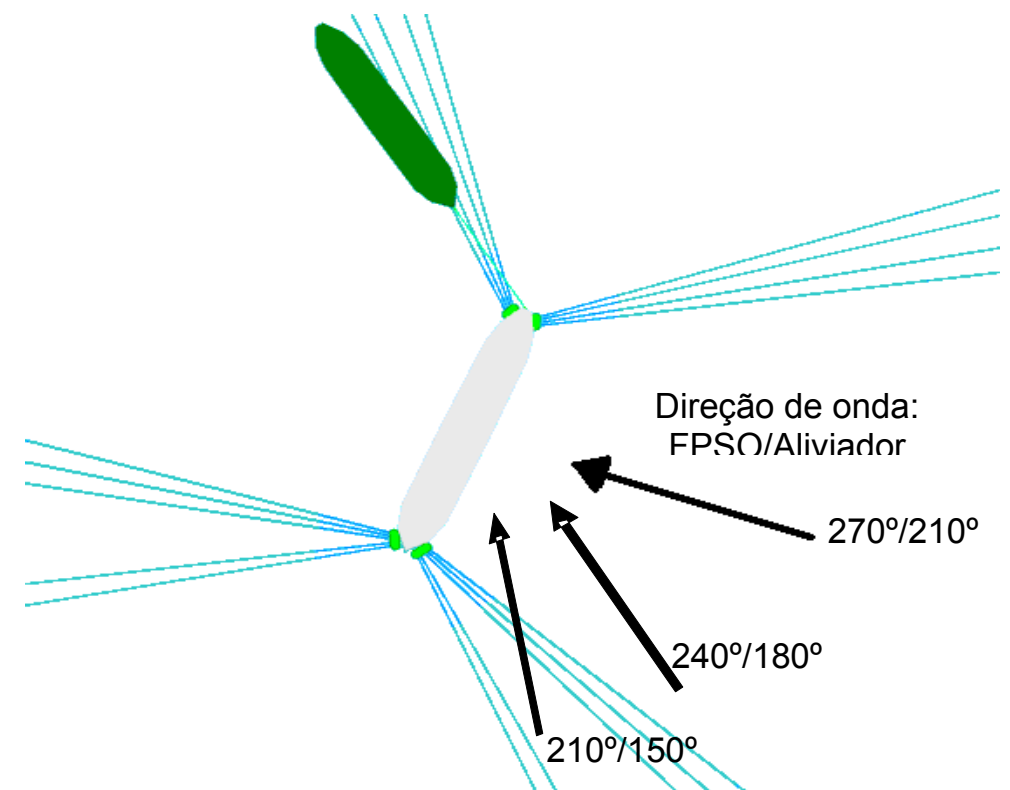

Figura 120 - Direção de propagação de onda em ralação ao FPSO e ao Navio Aliviador. 


\subsection{FPSO carregado e navio aliviador em condição de lastro não considerando a influência do FPSO}

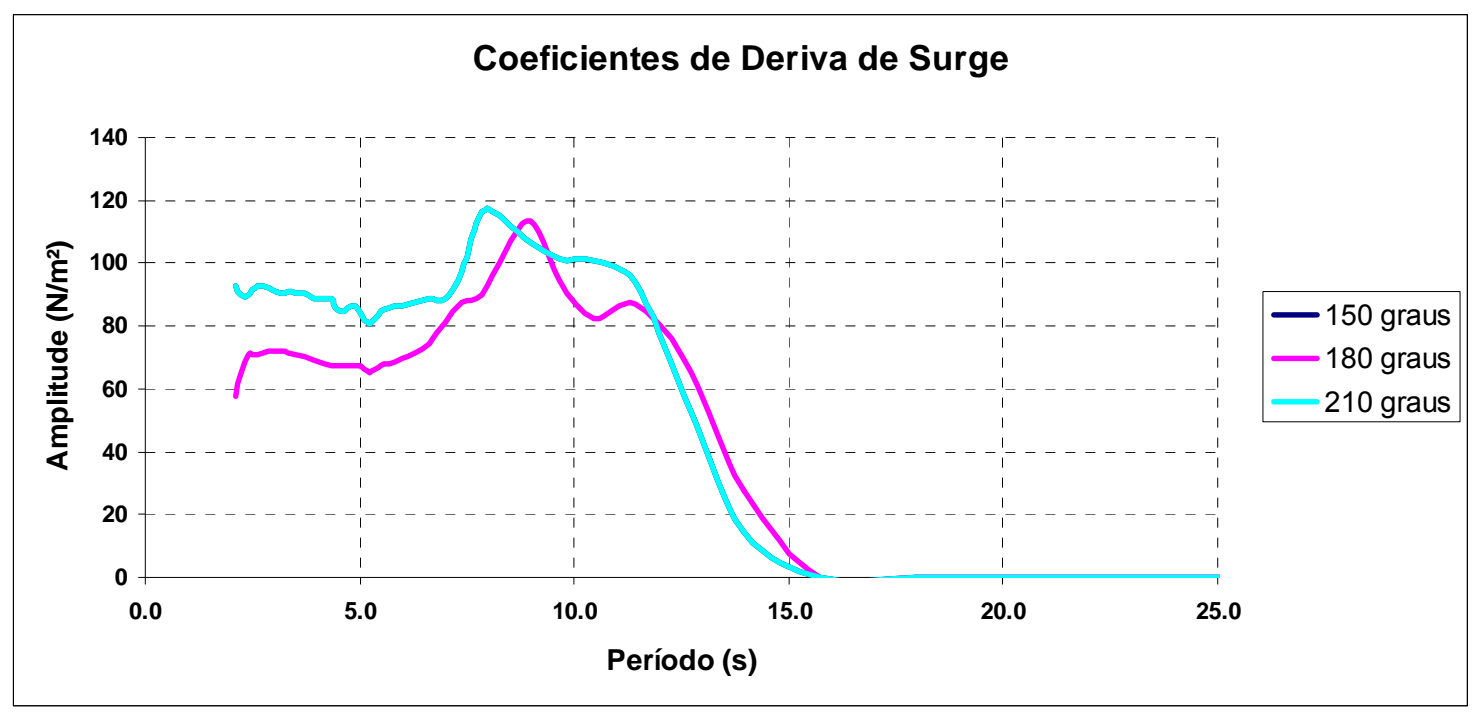

Figura 121 - Coeficientes de deriva de surge do navio aliviador para incidências de $150^{\circ}, 180^{\circ}$ e $210^{\circ}$.

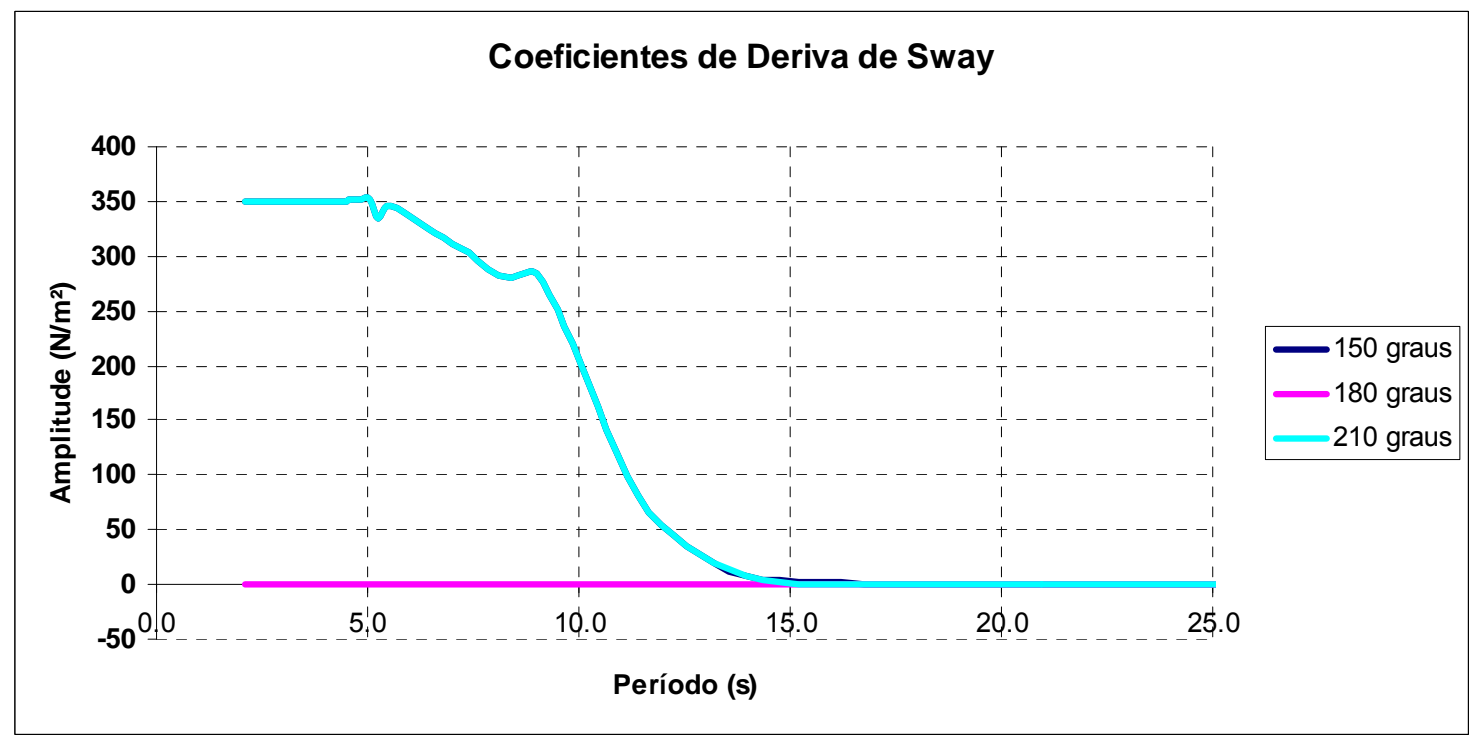

Figura 122 - Coeficientes de deriva de sway do navio aliviador para incidências de $150^{\circ}, 180^{\circ}$ e $210^{\circ}$. 


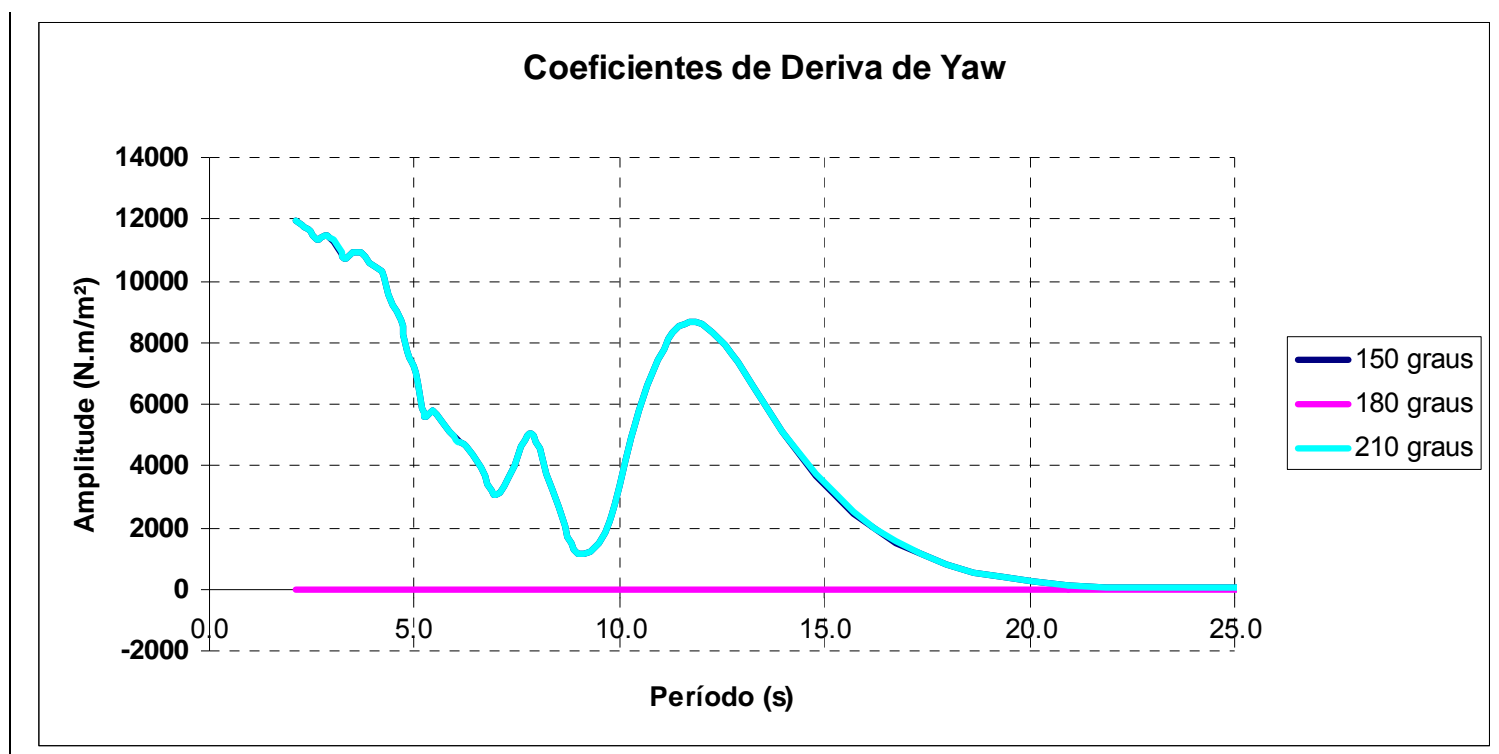

Figura 123 - Coeficientes de deriva de yaw do navio aliviador para incidências de $150^{\circ}, 180^{\circ}$ e $210^{\circ}$.

\subsection{FPSO carregado e navio aliviador em condição de lastro considerando a influência do FPSO para d=160m.}

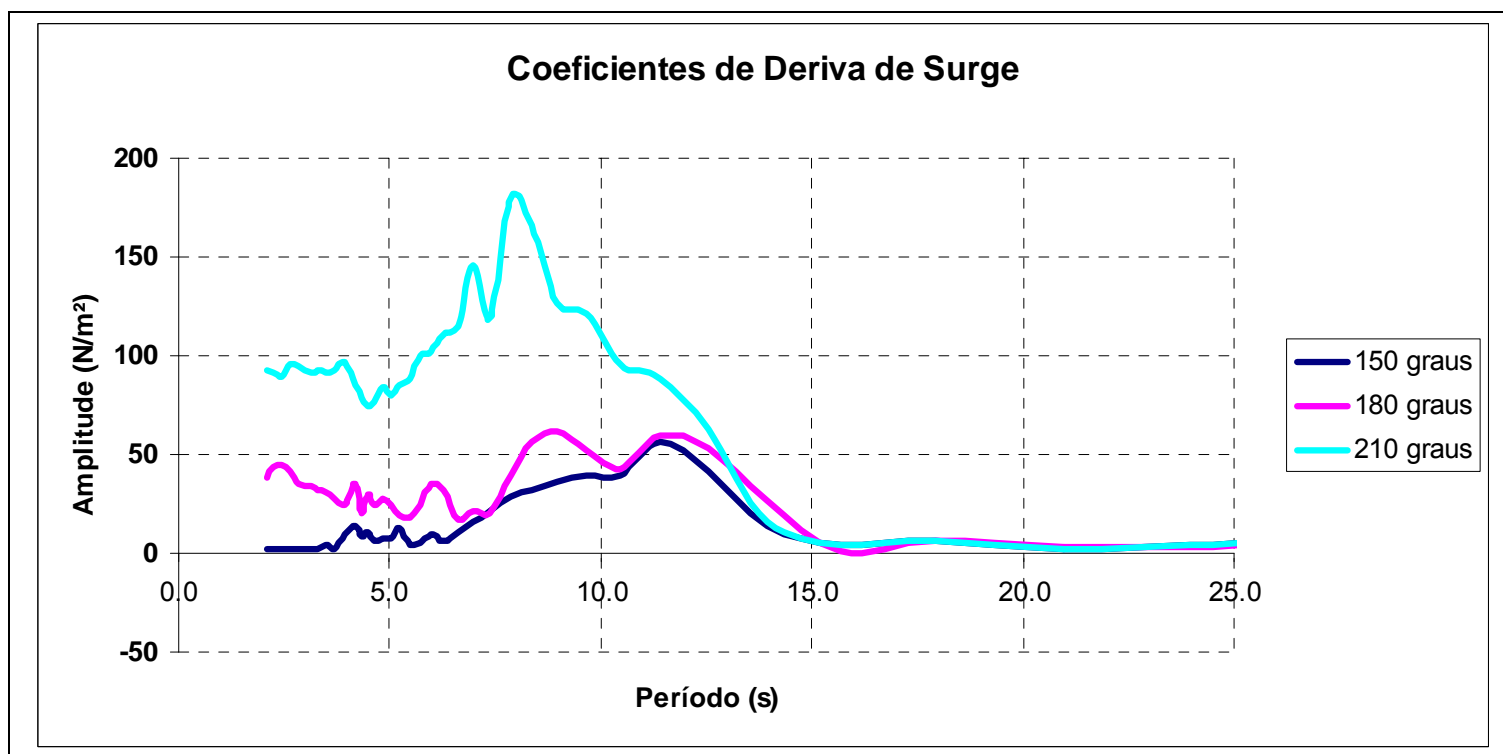

Figura 124 - Coeficientes de deriva de surge do navio aliviador para incidências de $150^{\circ}, 180^{\circ}$ e $210^{\circ}$, considerando a influência do FPSO para d=160m. 


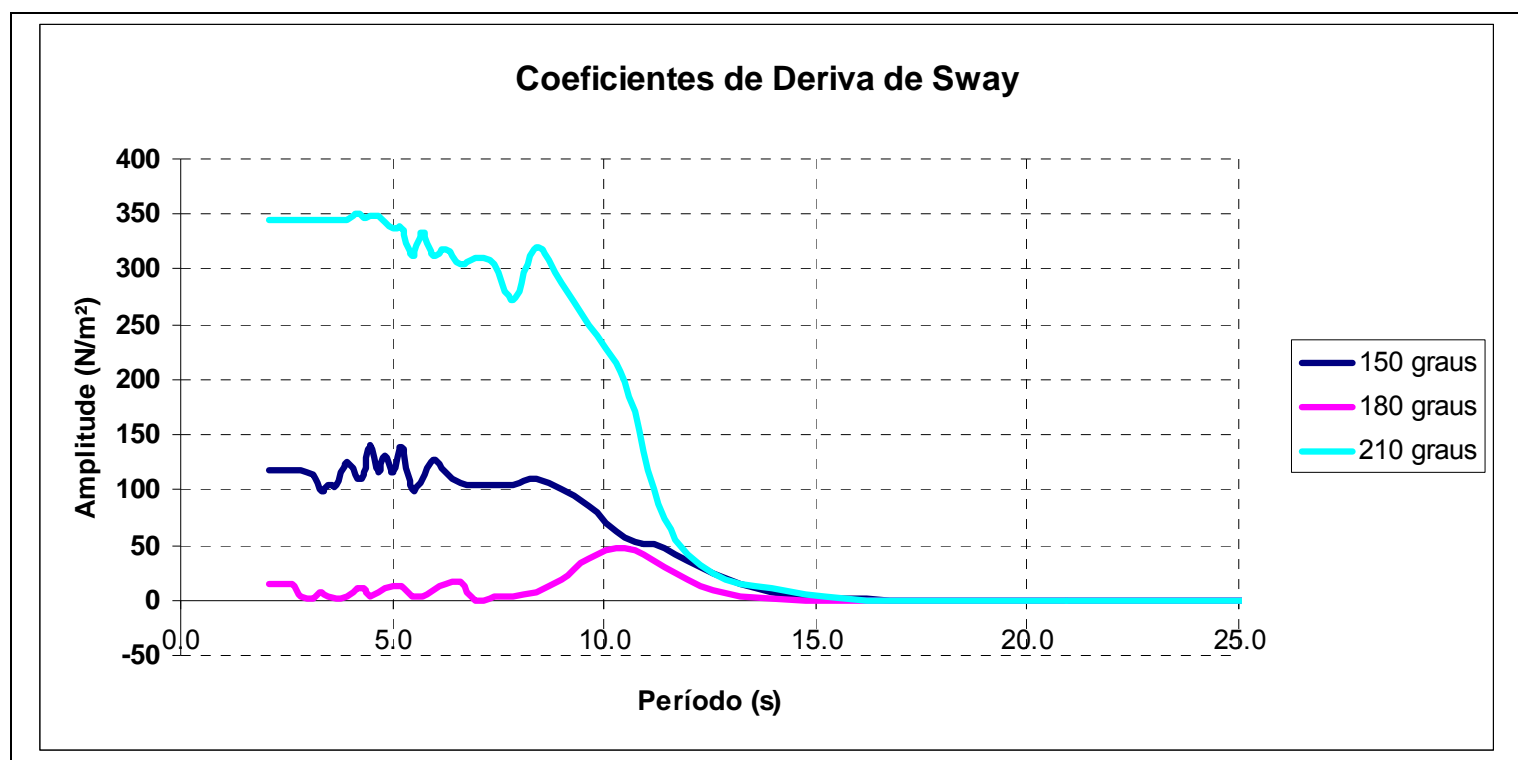

Figura 125 - Coeficientes de deriva de sway do navio aliviador para incidências de $150^{\circ}, 180^{\circ}$ e $210^{\circ}$, considerando a influência do FPSO para d=160m.

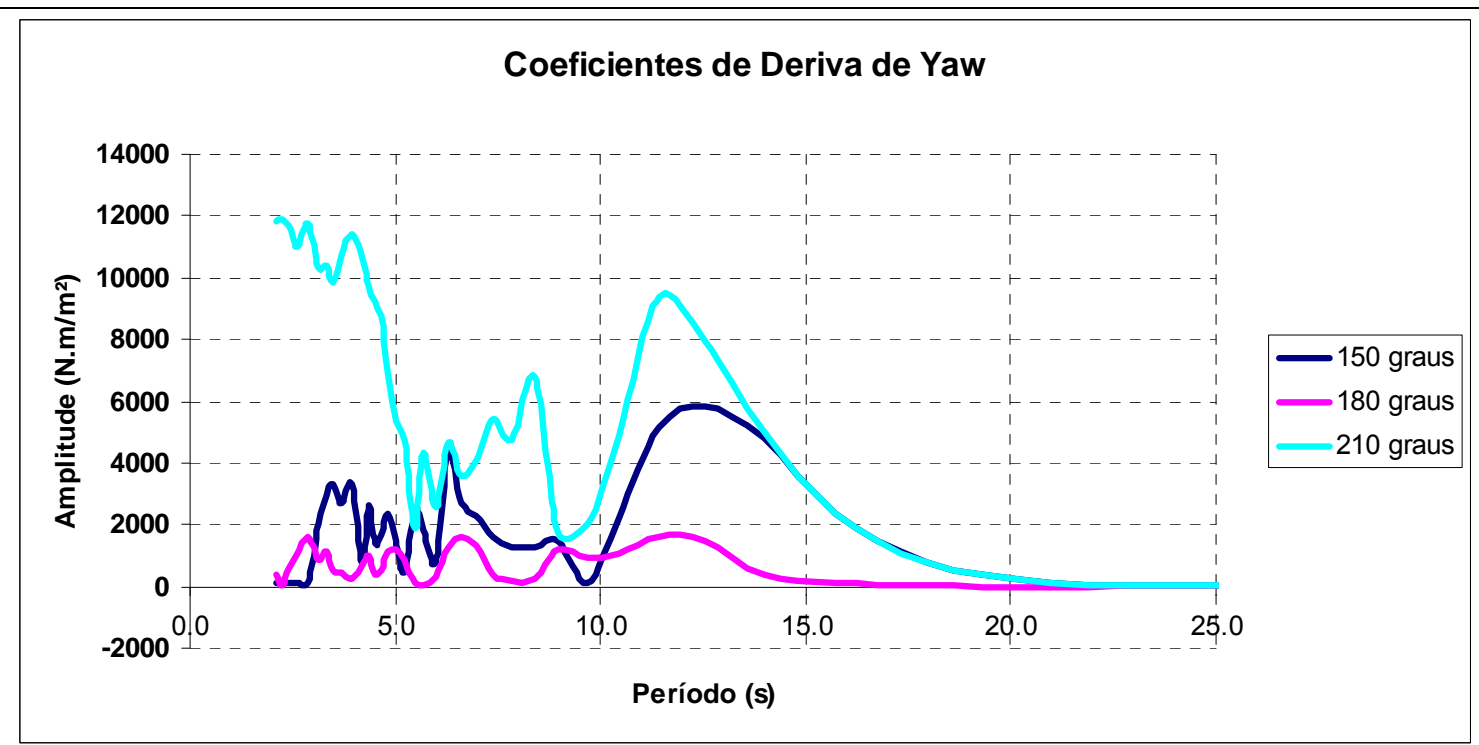

Figura 126 - Coeficientes de deriva de yaw do navio aliviador para incidências de $150^{\circ}, 180^{\circ}$ e $210^{\circ}$, considerando a influência do FPSO para d=160m.

\subsection{FPSO carregado e navio aliviador em condição de lastro considerando a influência do FPSO para $d=80 \mathrm{~m}$.}




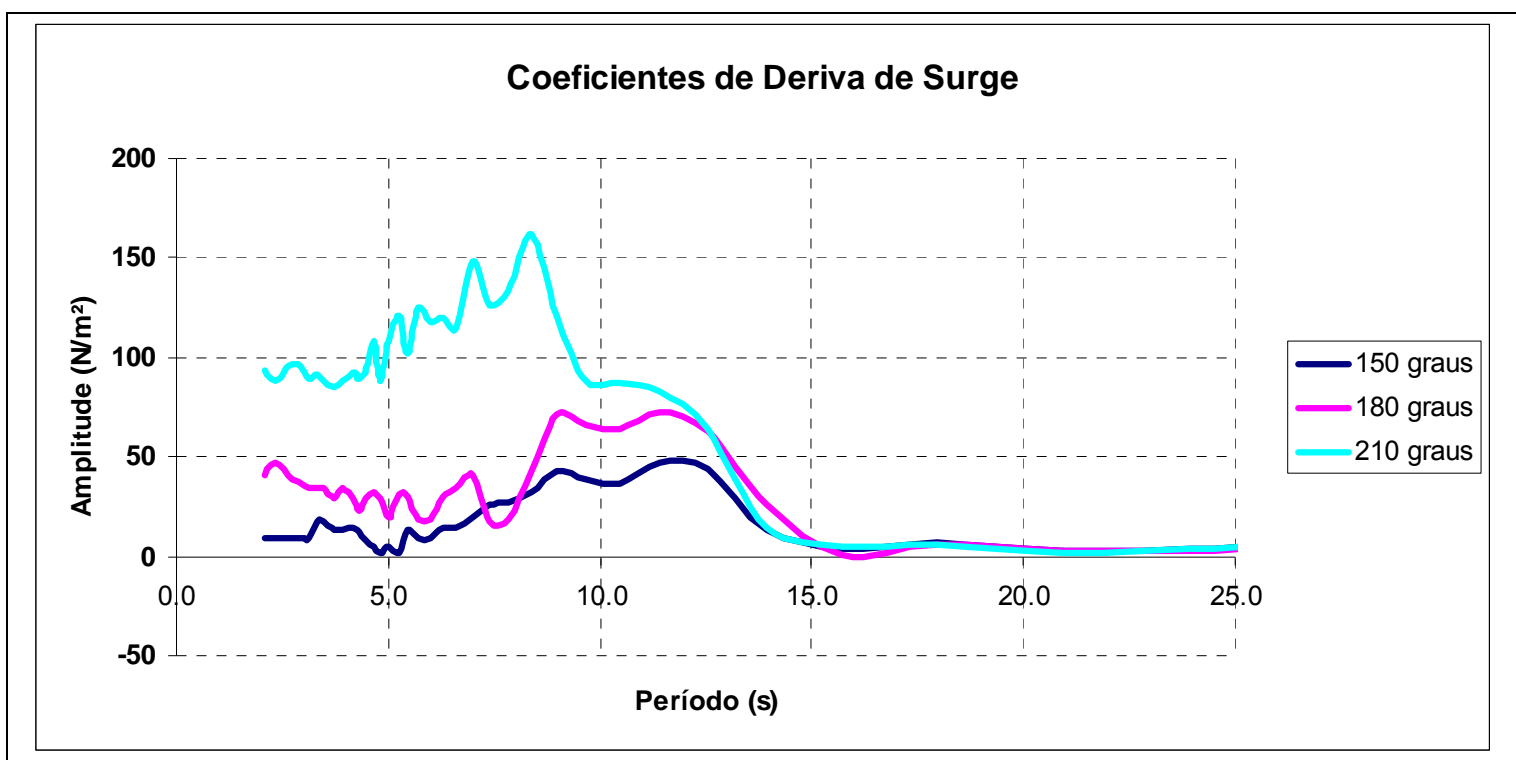

Figura 127 - Coeficientes de deriva de surge do navio aliviador para incidências de $150^{\circ}, 180^{\circ}$ e $210^{\circ}$, considerando a influência do FPSO para $d=80 \mathrm{~m}$.

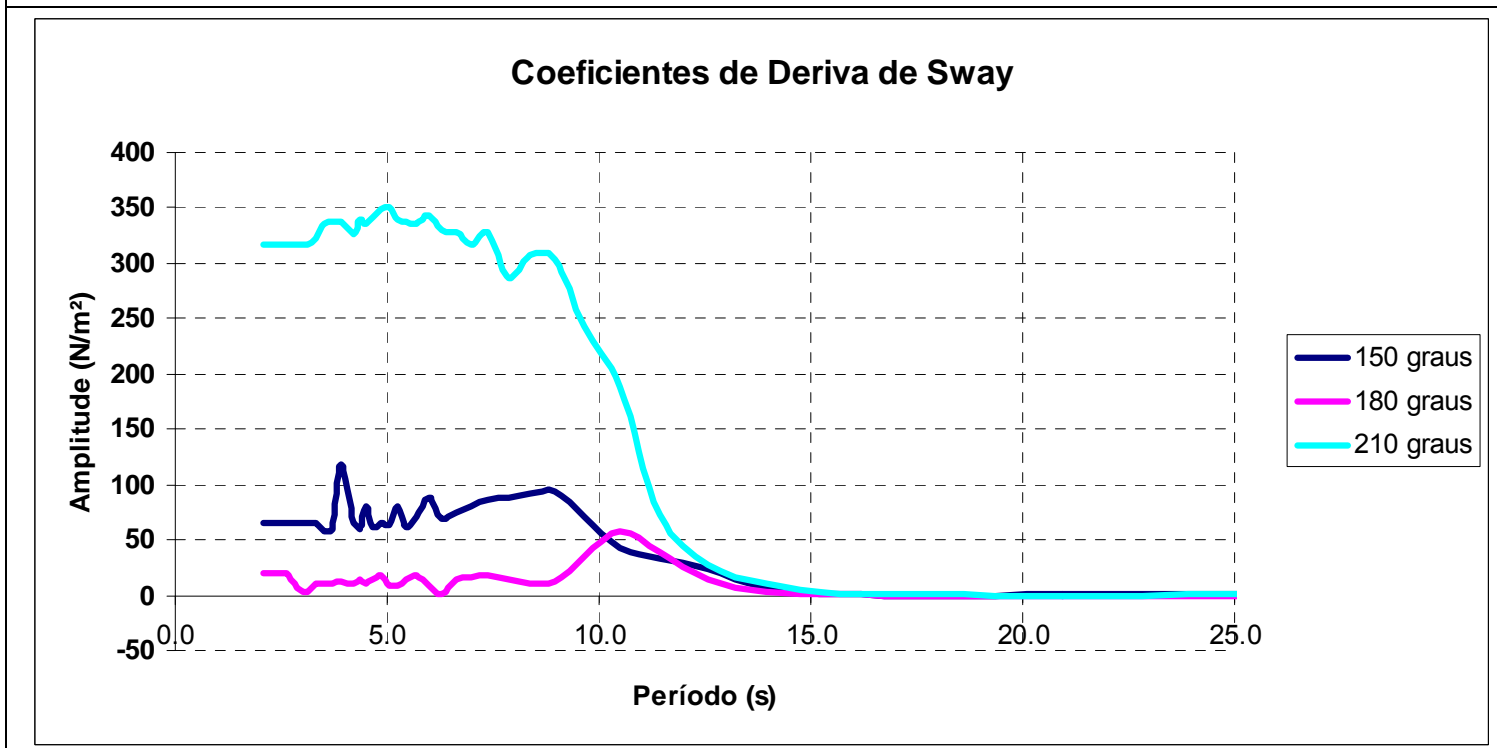

Figura 128 - Coeficientes de deriva de sway do navio aliviador para incidências de $150^{\circ}, 180^{\circ}$ e $210^{\circ}$, considerando a influência do FPSO para d=80m. 


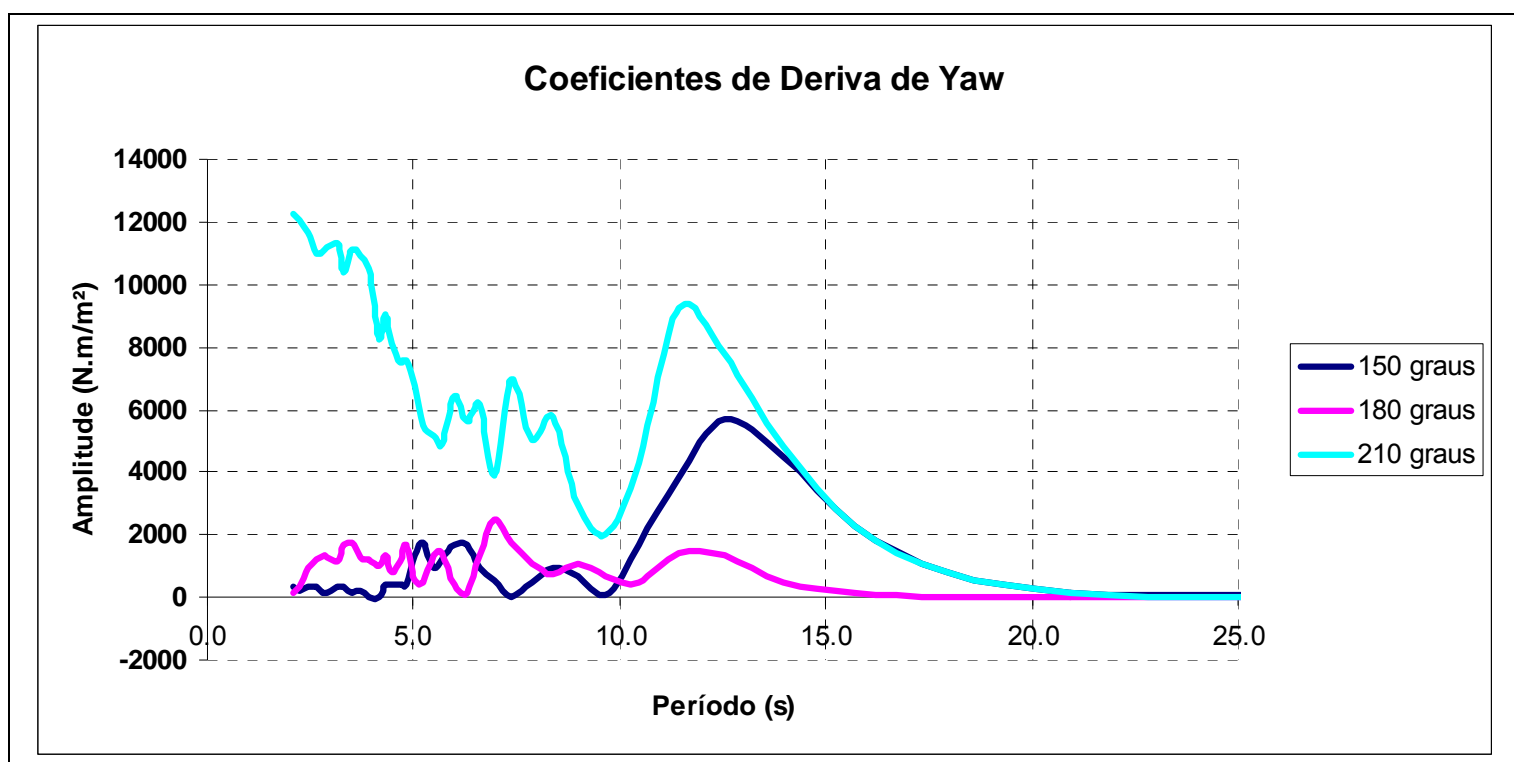

Figura 129 - Coeficientes de deriva de yaw do navio aliviador para incidências de $150^{\circ}, 180^{\circ}$ e $210^{\circ}$, considerando a influência do FPSO para $d=80 \mathrm{~m}$.

\subsection{FPSO em condição de lastro e navio aliviador cheio não considerando a influência do FPSO}

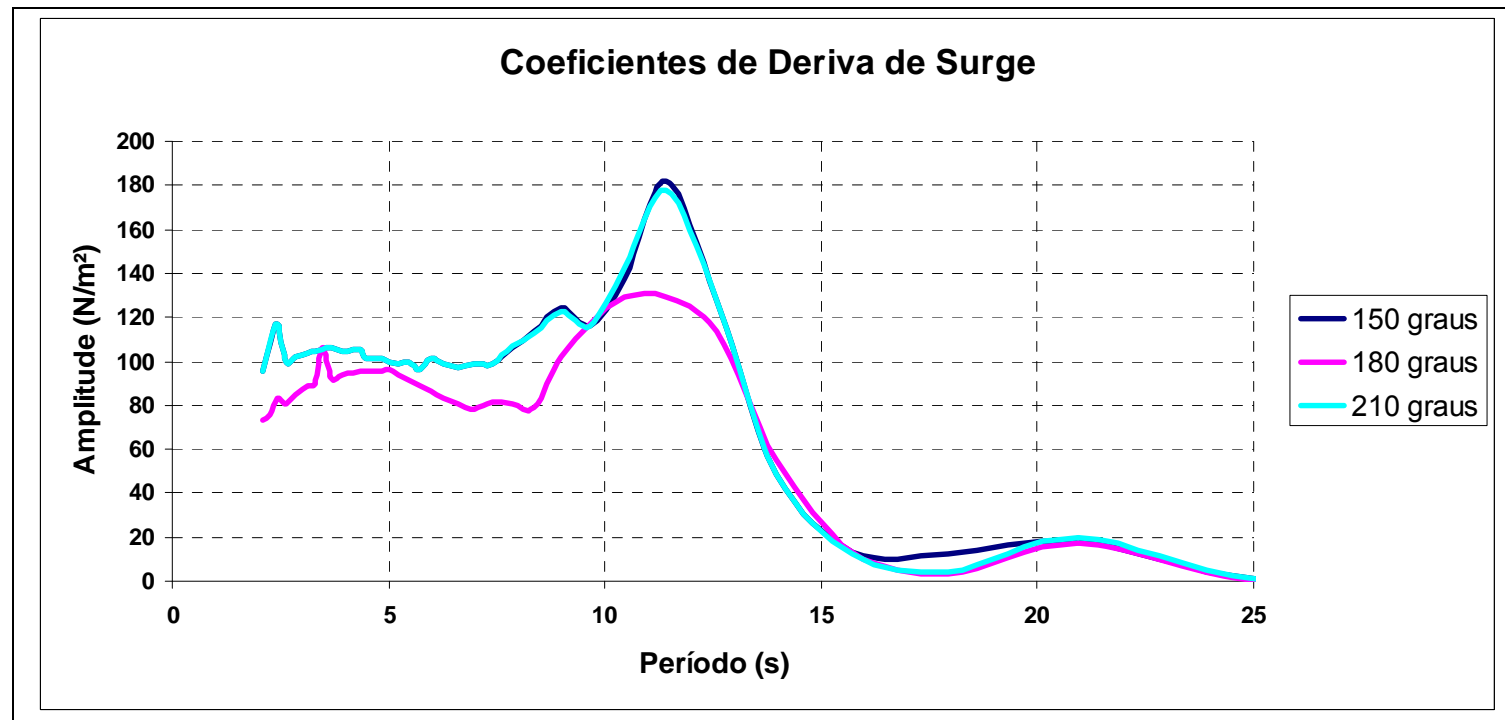

Figura 130 - Coeficientes de deriva de surge do navio aliviador para incidências de $150^{\circ}, 180^{\circ}$ e $210^{\circ}$, considerando a influência do FPSO para d=80m. 


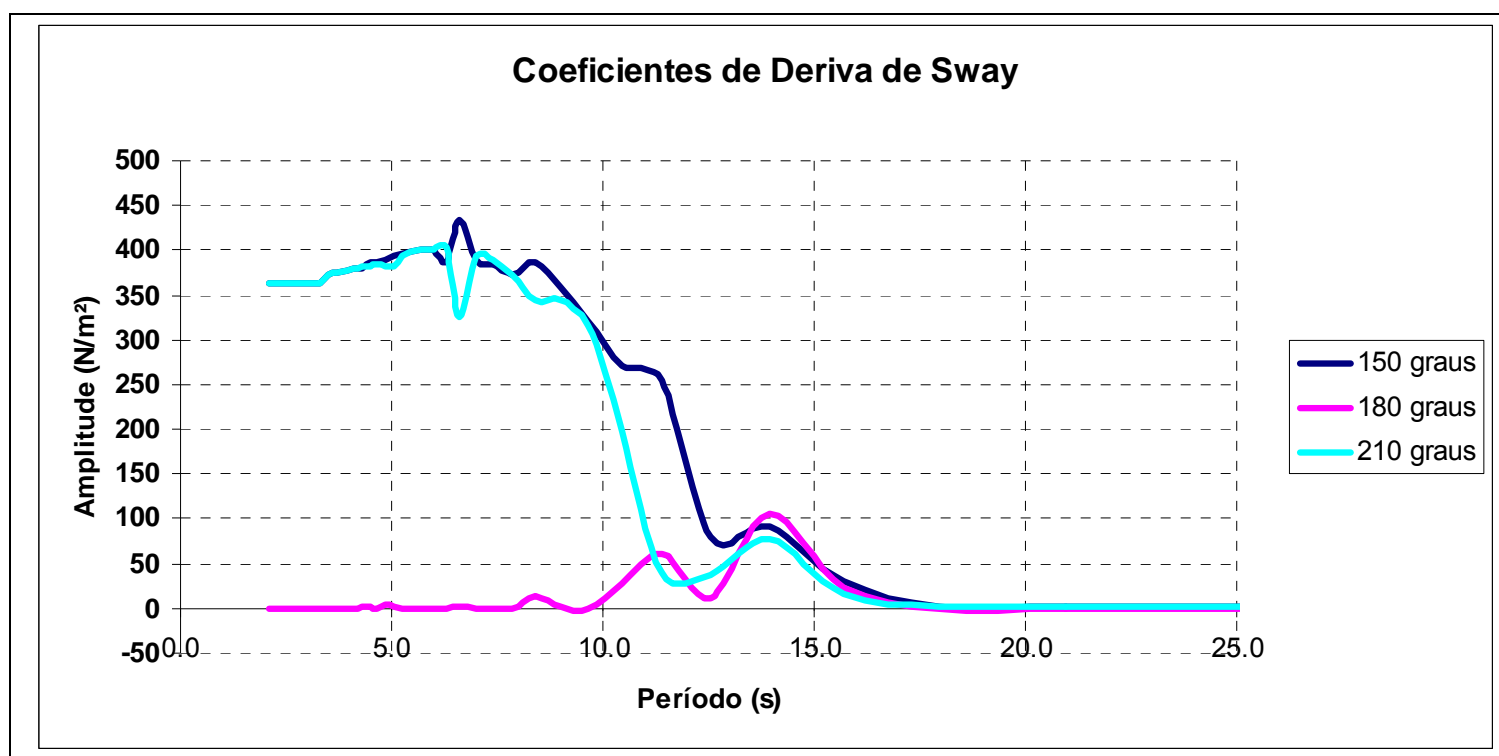

Figura 131 - Coeficientes de deriva de sway do navio aliviador para incidências de $150^{\circ}, 180^{\circ}$ e $210^{\circ}$, considerando a influência do FPSO para $\mathrm{d}=\mathbf{8 0} \mathrm{m}$.

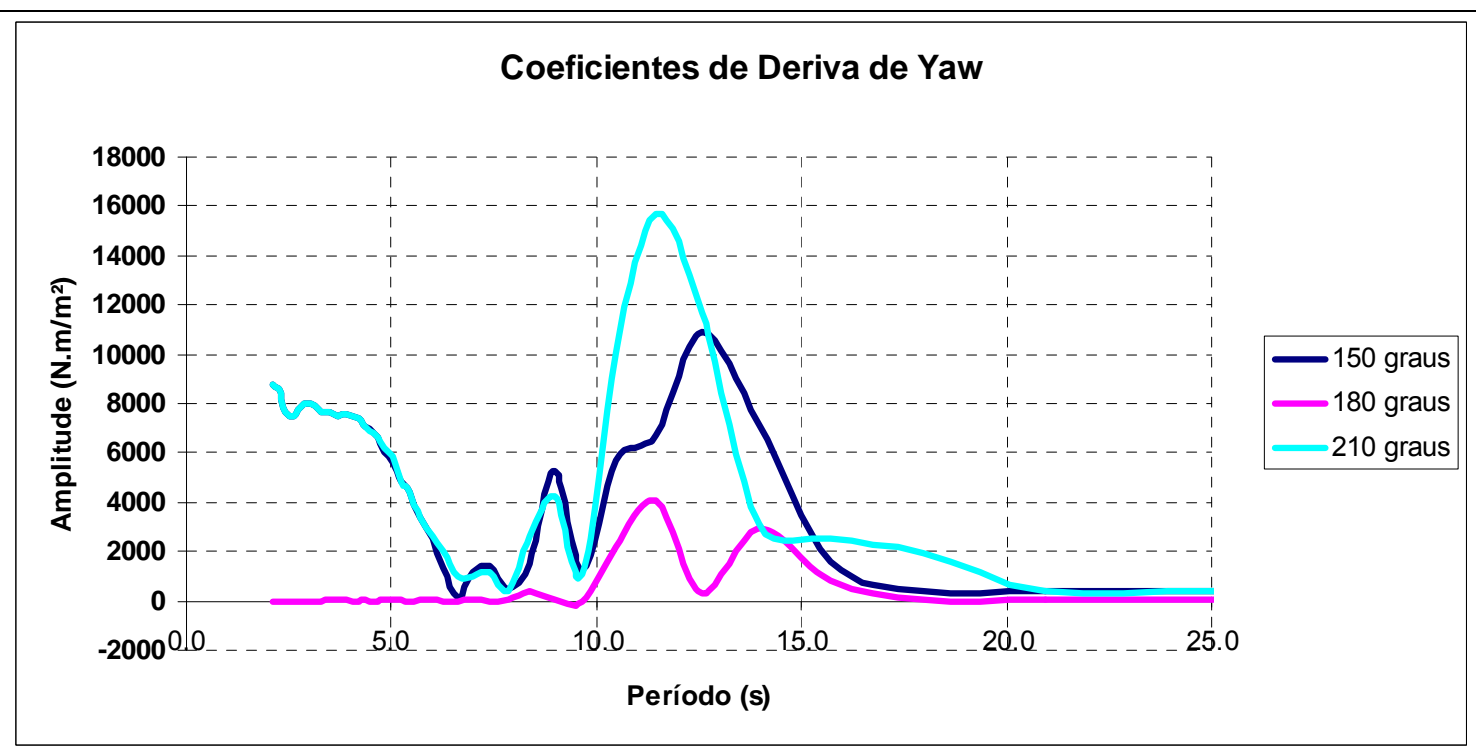

Figura 132 - Coeficientes de deriva de yaw do navio aliviador para incidências de $150^{\circ}, 180^{\circ}$ e $210^{\circ}$, considerando a influência do FPSO para d=80m.

10.5 FPSO em condição de lastro e navio aliviador cheio considerando a influência do FPSO 


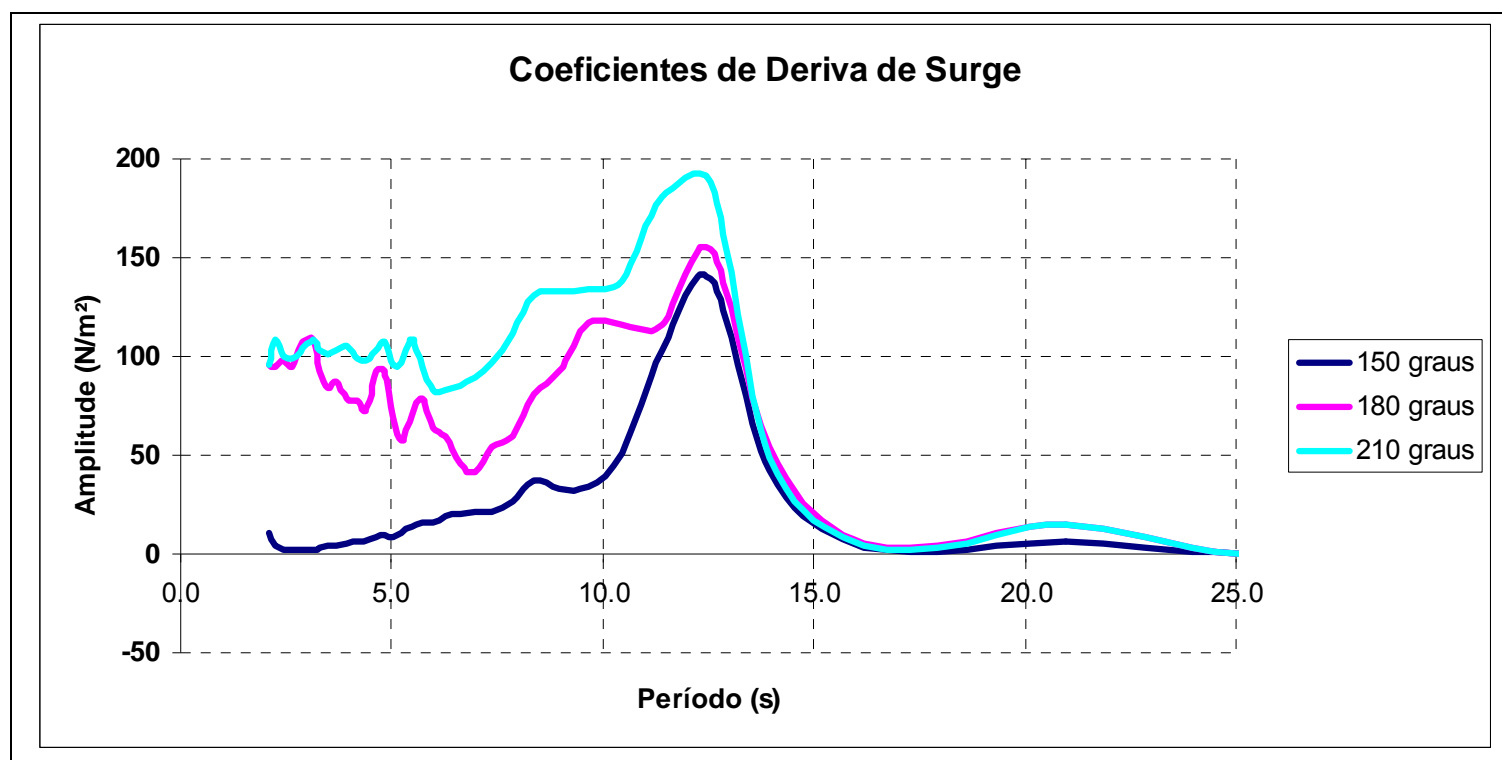

Figura 133 - Coeficientes de deriva de surge do navio aliviador para incidências de $150^{\circ}, 180^{\circ}$ e $210^{\circ}$, considerando a influência do FPSO para $d=80 \mathrm{~m}$.

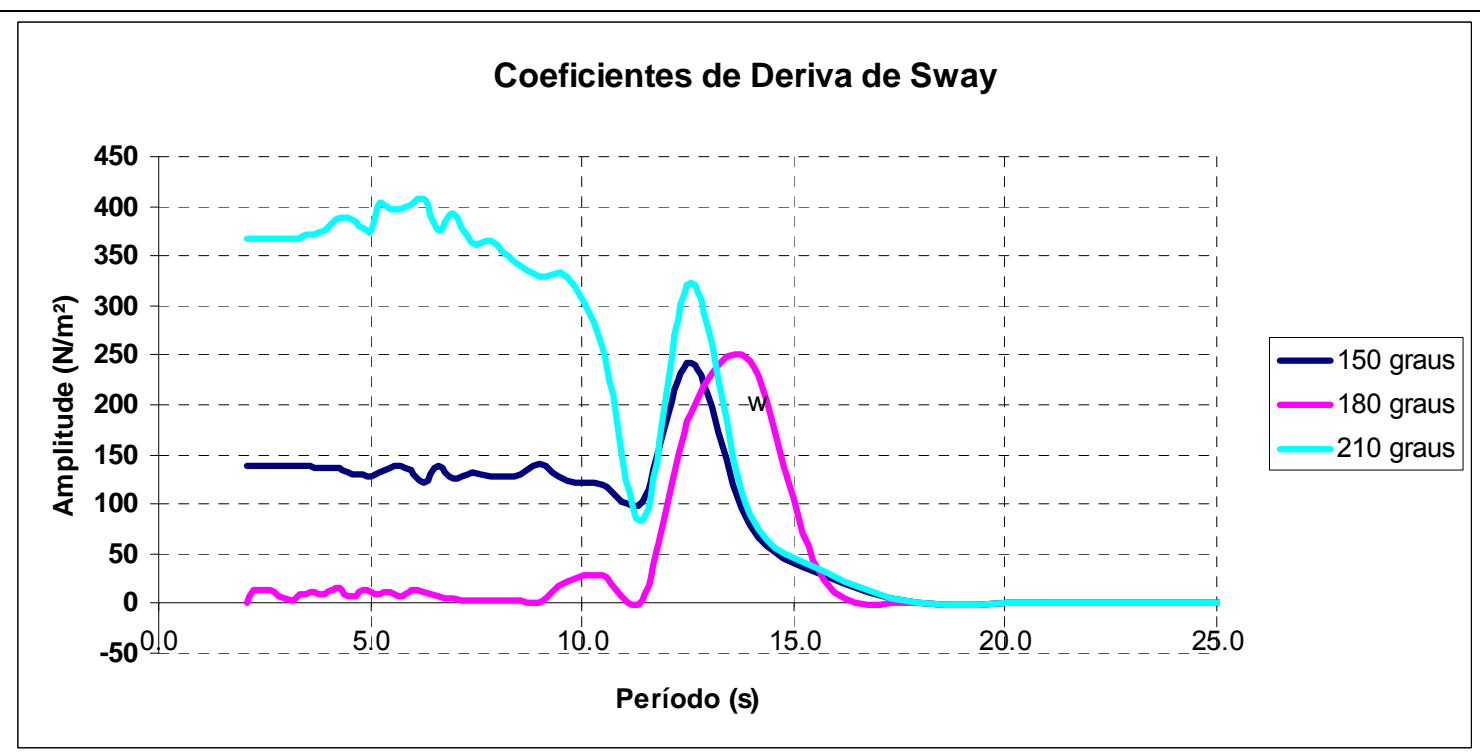

Figura 134 - Coeficientes de deriva de sway do navio aliviador para incidências de $150^{\circ}, 180^{\circ}$ e $210^{\circ}$, considerando a influência do FPSO para d=80m. 


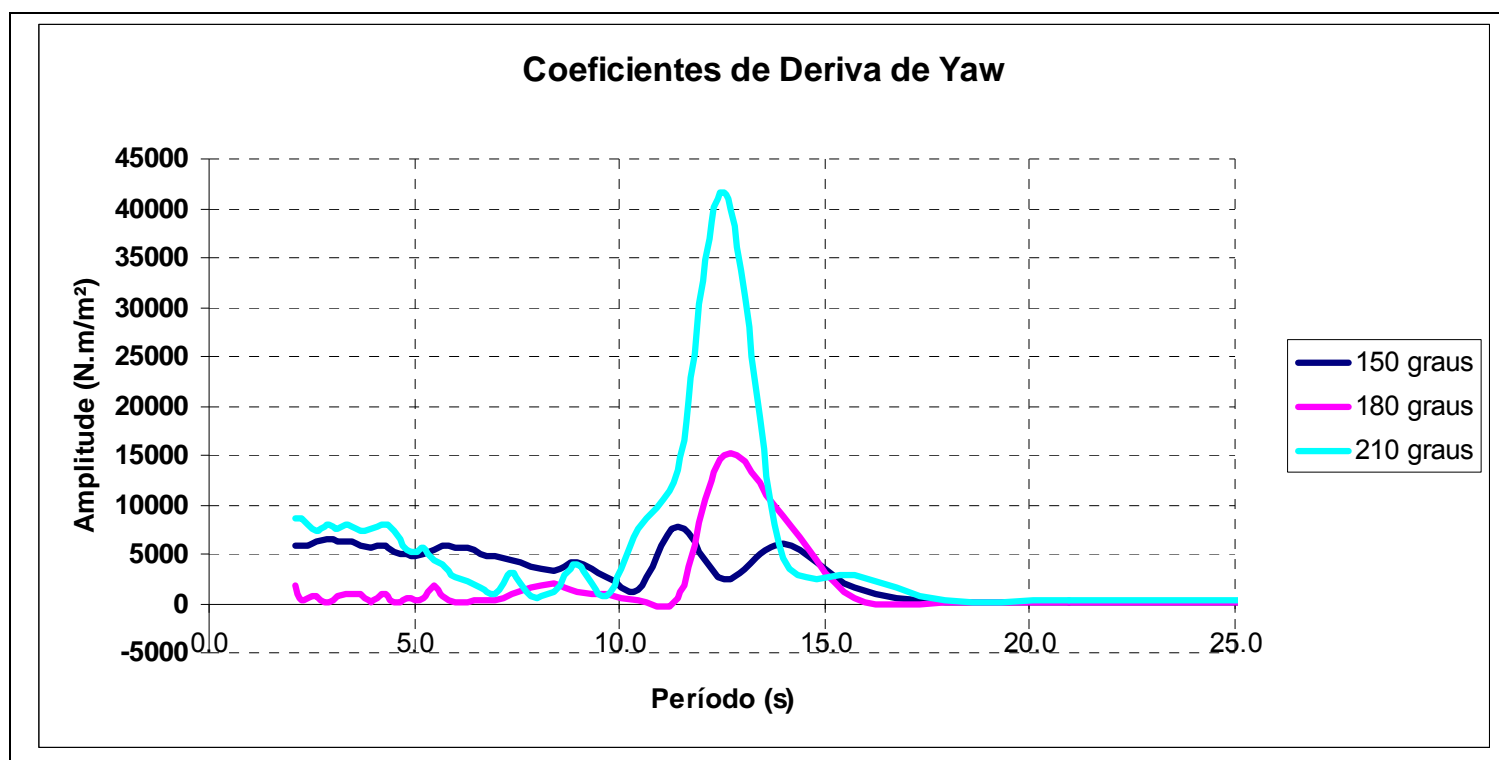

Figura 135 - Coeficientes de deriva de yaw do navio aliviador para incidências de $150^{\circ}, 180^{\circ}$ e $210^{\circ}$, considerando a influência do FPSO para $\mathrm{d}=\mathbf{8 0} \mathrm{m}$. 